\title{
3. LE TERRAIN INDUSTRIEL
}

Will man den europäischen Verlauf der Farbfernsehkontroverse verstehen, ist eine Darstellung des industriellen und industriepolitischen Kontextes unumgänglich. Entsprechend der Funktion, die das Radiogerät bis Anfang der fünfziger Jahre als Leitmedium im massenmedialen Ensemble innehatte, bildete die Radiogeräteproduktion den Schwerpunkt der Rundfunkindustrie. Erst mit der Ablösung des Leitmediums Radio durch das Fernsehen begann der Aufstieg des Fernsehgerätes zum »fordistischen Leitprodukt ${ }^{1}$ und damit zum Indikator der modernen Konsumgesellschaft. Dieser Wandel vom Radio- zum Fernsehzeitalter bescherte der elektronischen Konsumgüterindustrie in der ganzen Welt einen beispiellosen Boom. Dennoch, und dies ist für die folgende Untersuchung von Bedeutung, fand dieser rasante Aufstieg einer Industriebranche in durchaus unterschiedlichen nationalen »Modernisierungsmustern« statt, die sich sowohl auf der Produktions- wie auf der Konsumseite nachweisen lassen.

Diese unterschiedlichen Muster oder Entwicklungspfade sind der Ausdruck eines wirtschafts- und sozialpolitischen Pluralismus, der die nationalen Volkswirtschaften im europäischen Kontext nach 1945 kennzeichnet $^{2}$. Sie reichen von planwirtschaftlichen Modellen zentralistischer Staatsintervention bis zum Neoliberalismus oder kurzfristig angelegter Konjunkturpolitik. Im folgenden gilt es, die Entwicklung der elektrotechnischen Konsumgüterindustrie in diese unterschiedlichen nationalen Kontexte einzubetten, ihre Besonderheiten herauszuarbeiten ohne natürlich den gemeinsamen Nenner, den Weltmarkt, aus dem Auge zu verlieren. Nur diese parallele Betrachtung von

\footnotetext{
I Siehe Volker WITTKE, Wie entstand industrielle Massenproduktion? Die diskontinuierliche Entwicklung der deutschen Elektroindustrie von den Anfängen der "großen Industrie» bis zur Entfaltung des Fordismus (1880-1975), Berlin 1996.

2 Gerold Ambrosius, Wirtschaftsraum Europa: Vom Ende der Nationalökonomien, Frankfurt a.M. 1996, S. 20f. Als Definitionsversuch des schwer faBbaren Begriffs der Modemisierung sei jener von Werner Abelshauser zitiert: »Modernisierung meint die Entwicklung der vergangenen zwei Jahrhunderte als ein Bündel gleichgerichteter Abläufe, die die jeweiligen Gesellschaften von traditionalen in moderne transformierten und die inhaltlich bestimmt sind durch strukturveränderndes Wachstum der materiellen und nicht-materiellen Güter, verstärkte gesellschaftliche Differenzierungsvorgänge und erhöhte Selbststeuerungskapazitäten der Gesellschaft durch Partizipation und Institutionen zur geregelten Konfliktaustragung«. Werner ABELSHAUSER, Westeuropäische Trends und Außenhandelsverflechtungen, in: SCHILDT, SYwOTTEK, Modernisierung im Wiederaufbau, S. 43. Zum Vergleich des deutschen und französischen Weges siehe Thomas BITTNER, Das westeuropäische Wirtschaftswachstum nach dem Zweiten Weltkrieg. Eine Analyse unter besonderer Berücksichtigung der Planification und der sozialen Marktwirtschaft, Münster 2001. Eine allgemeine wenn auch stark soziologisch ausgerichtete Einführung in die Modernisierungstheorien bieten Nina Degele, Christian DRIEs, Modernisierungstheorie: Eine Einführung, München 2005.
} 
nationaler Industriepolitik und industrieller Landschaft erlaubt eine systematische Analyse des komplexen Beziehungsgeflechts zwischen Staat und Unternehmertum. Die Entflechtung der teilweise direkt sichtbaren, manchmal nur indirekt nachweisbaren Beziehungen zwischen Wirtschaft und Politik kann nur unvollständig geleistet werden. $\mathrm{Zu}$ verschlungen sind manche $\mathrm{Be}-$ ziehungen, zu bruchstückhaft das überlieferte oder zugängliche Archivmaterial, um eine lückenlose Rekonstruktion der wirtschaftspolitischen und unternehmensstrategischen Kontexte beanspruchen zu können. 


\subsection{Der europäische Kontext}

Trotz unterschiedlicher theoretischer Erklärungsansätze für die Gründe des Zustandekommens der »Wirtschaftswunder« nach dem Zweiten Weltkrieg sind sich die Wirtschaftshistoriker darin einig, daß die europäische Wirtschaft in der Zeit zwischen 1945 und 1972 eine in der Geschichte der Industrialisierung bislang einmalige Wachstumsphase erlebte ${ }^{3}$. Einmalig nicht nur wegen der Dynamik, die der Eintritt in das Zeitalter des industriellen Massenkonsums entfaltete, sondern auch wegen der Breitenwirkung. Die in dieser Phase beobachtbare individuelle und kollektive, private und öffentliche Wohlstandssteigerung bleibt nicht wie in früheren Prosperitätsschüben auf wenige Regionen oder Länder beschränkt, sondern sie tritt in fast allen westeuropäischen Ländern ein. Es verwundert daher nicht, daß dieses Phänomen in verschiedenen Sprachen begrifflich zu fassen gesucht wurde. Während sich in Deutschland der Terminus des "Wirtschaftswunders ${ }^{4}$ durchsetzte, spricht man in Frankreich von den »trente glorieuses ${ }^{5}$ und in der angelsächsischen Welt vom »Golden Age of Capitalism « ${ }^{6}$.

Das Interessante an diesem Phänomen ist aber weniger die Tatsache der wirtschaftlichen und sozialen Prosperitätsphase Europas, sondern die Beobachtung, daB in den verschiedenen europäischen Ländern durchaus unterschiedliche Wege zur »Rekonstruktion«, zum »Wiederaufbau« oder - wie es Axel Schildt und Arnold Sywottek für den westdeutschen Fall auf den Punkt bringen - zur »Modernisierung im Wiederaufbau« eingeschlagen wurden? Dies wird besonders deutlich, wenn man die Durchsetzung massenindustriell gefertigter Konsumguiter zum Indikator der Modernisierung der Produktionswie der Konsumstrukturen macht. Wie Volker Wittke nachweist, sorgten nationale Kontexte für eine durchaus unterschiedliche Prägung der »Konsumgüter-Revolution «:

${ }^{3}$ Zur Weitläufigkeit des "Wunder «-Begriffs im Bereich der Ökonomie siehe Alain PEYREFITTE, Du "miracle « en économie, Leçons au Collège de France, Paris 1995. Interessanter Weise spricht Peyrefitte in diesem Essay vom britischen (erste industrielle Revolution), französischen (trente glorieuses), asiatischen oder chinesischen Wirtschaftswunder, das "deutsche Wirtschaftswunder« - so tief verankert im Wortschatz und Selbstverständnis der Deutschen - taucht jedoch nicht auf.

4 Philipp HeldmanN, Das "Wirtschaftswunder« in Westdeutschland. Überlegungen zu Periodisierung und Ursachen, in: Archiv für Sozialgeschichte 36 (1996) S. 323-344, sowie Werner ABELSHAUSER, Wirtschaftsgeschichte der Bundesrepublik Deutschland 1945-1980, Frankfurt a.M. 1983.

5 Jean Fourastif, Les Trente Glorieuses, Paris 1979.

6 Sidney Pollard, The Integration of the European Economy since 1815, London 1984.

${ }^{7}$ Eine kritische Diskussion der unterschiedlichen Modemisierungstheorien soziologischer und ökonomischer Natur findet sich bei Werner AbELSHAuser, Die langen fünfziger Jahre. Wirtschaft und Gesellschaft in der Bundesrepublik Deutschland 1949-1966, Düsseldorf 1987. Zur »Modernisierung im Wiederaufbau« siehe Arnold SYwotTEK, Wege in die 50er Jahre, in: SCHILDT, SYWotTEK (Hg.), Modernisierung im Wiederaufbau, S. $13 \mathrm{f}$. 
In allen entwickelten westlichen Industrieländern veränderte sich die Lebensweise in den Dimensionen >Mobilität‘, , Reproduktion ‘ und >Freizeitverhalten<, und in allen diesen gesellschaftlichen Transformationsprozessen spielte derselbe Kanon fordistischer Leitprodukte eine Schlüsselrolle soweit die Gemeinsamkeiten. Allerdings lief die Herausbildung der >modernen Lebensweise keineswegs als international und interkulturell einheitlicher ProzeB ab. Die massenhafte Verbreitung der Leitprodukte fand in den unterschiedlichen Gesellschaften weder in denselben Zeiträumen (^timing،) noch in derselben Reihenfolge (ssequenzing) statt. [...] Mit anderen Worten: Die Konsumgüter-Revolution bewegte sich in Form differenter nationaler Entwicklungsmuster ${ }^{8}$.

Damit bringt Wittke die Forschungsergebnisse der Wirtschaftsgeschichte der letzten zwanzig Jahre auf den Punkt, die sich generell durch eine Abkehr oder zumindest eine Relativierung des festen Kanons von Charakterisierungen auszeichnen, die das Phänomen der "Modernisierung " auf einen allgemeingültigen Nenner zu bringen versuchten ${ }^{9}$. Zwar gelten laut Arnold Sywottek die klassischen Parameter der Modernisierung - Rationalisierung, Differenzierung und Individualisierung - als »modernisierungstypische Tendenzen « auch in der postmodernen Gesellschaft fort, doch komme es nun darauf an, die vielen »feinen Unterschiede " herauszuarbeiten, die bei der näheren Analyse nationaler oder regionaler Modernisierungswege sichtbar würden ${ }^{10}$. Einen »kapitalistischen Königsweg«, so der französische Wirtschaftshistoriker Jean Bouvier, könne es nicht geben. Gerade darin liege aber die Herausforderung für die Historiker: "Notre difficulté centrale d'analyse est la mise en relation d'éléments mesurables et d'autres non quantifiables; de >données (construits par nous) économiques et de comportements de groupes et de milieux; de logiques de systèmes et de mentalités longuement durables, porteuses à la fois de résistance et de mouvement ${ }^{11}$.

Auf jeden Fall sei es notwendig, so Bouvier weiter, simplifizierende Relationen wie die von demografischer Struktur und Wirtschaftswachstum durch komplexere Betrachtungsmuster zu ersetzen, in denen professionelle und geografische Mobilität sowie sozio-ökonomische Faktoren stärkere Beachtung fänden. Obwohl viele Wirtschaftshistoriker den wie auch immer gewonnenen »harten« Zahlen gerne mehr Beachtung schenken, plädieren neuere Ansätze für eine Betonung der »weichen« Wachstumsfaktoren, zu denen auch sozio-psychologische Faktoren wie Mentalitäten (Arbeitsmoral, berufliches Selbstverständnis, Zeitwahrnehmung) oder implizites Wissen

8 WITTKE, Wie entstand industrielle Massenproduktion?, S. 85.

9 Siehe den nützlichen Literaturbericht von Alexander NützENADEL, Abschied vom "Sonderweg«. Neuere Forschungen zur Wirtschafts- und Sozialgeschichte der Bundesrepublik, in: Neue Poitische Literatur (2002) 2 S. 277-299.

10 Sywottek, Wege in die 50er Jahre, S. $13 \mathrm{f}$.

11 Jean Bouvier, Libres propos autour d'une démarche révisionniste, in: Patrick Fridenson, Andre Straus (Hg.), Le Capitalisme français ( $\mathrm{XIX}^{\mathrm{e}}-\mathrm{XX}^{\mathrm{e}}$ siècle). Blocages et dynamismes d'une croissance, Paris 1987, S. 13. 
zählen ${ }^{12}$. "Les facteurs de la croissance constituent bien une combinaison, et non une addition «, so Bouvier ${ }^{13}$.

Bevor diese unterschiedlichen nationalen Entwicklungsmuster am Beispiel der deutschen und französischen Gesellschaft verdeutlicht werden, sollte bei aller Suche nach nationalen »Sonderwegen « aber nicht übersehen werden, daß es nach 1945 generell zu einer Annäherung der wirtschafts- und sozialpolitischen Realitäten in Europa gekommen ist. Ein wichtiger Grund dieser Annäherung waren mit Sicherheit die wirtschaftspolitischen Entwicklungen im Rahmen der europäischen Integration ${ }^{14}$. Die Arbeiten von Hartmut Kaelble zeigen deutlich, daß viele der "Gräben«, die beispielsweise die französische Gesellschaft vor dem Zweiten Weltkrieg von der deutschen Gesellschaft (oder umgekehrt) trennten, im Rahmen der sozialen Integration Westeuropas nach 1945 nach und nach zugeschüttet worden sind ${ }^{15}$. Unbestritten ist auch, daß es besonders die Expansion der Konsumgüterindustrie war, die in Europa $\mathrm{zu}$ einer Harmonisierung der Lebensstile führte ${ }^{16}$. Die zentrale Rolle, welche Radio und Fernsehen als symbolische und mediale Katalysatoren dieses Prozesses spielten, kann kaum überschätzt werden.

Ein weiterer gemeinsamer Nenner im europäischen ModernisierungsprozeB ist der "consumer gap«, der die europäischen Konsumenten von den USAmerikanern trennte. Die Durchsetzung industriell gefertigter Konsumgüter begann in den USA bereits im ersten Jahrzehnt des 20. Jahrhunderts. Die lange Wachstumsphase der amerikanischen Industrie - zwischen 1900 und 1929 hatte sich das Bruttosozialprodukt von 18,3 Mrd. US-Dollar auf 103,1 Mrd. US-Dollar mehr als verfünffacht - machte die Vereinigten Staaten zur ersten Massenkonsumgesellschaft. In der Zwischenkriegszeit konnten sich in den USA mit Ausnahme des Fernsehens alle »fordistischen Leitprodukte« massenhaft verbreiten. Das Leitprodukt des Fordismus war in den USA das Automobil, während es in Europa das Radio war. Interessanter Weise, so Wittke, war es das teuerste Produkt, welches in den USA als erstes breiten Ein-

12 Siehe beispeilsweise Gerold AMBrosıus (Hg.), Moderne Wirtschaftsgeschichte: Eine Einführung für Historiker und Ökonomen, München ${ }^{2}$ 2006, sowie Toni PIERENKEMPER, Wirtschaftsgeschichte: Eine Einführung - oder: wie wir reich wurden, München, Wien 2005.

13 Ibid. S. 20.

14 Einen Überblick bietet Werner BüHRER, Von der Geschichte der westeuropäischen Integration zur Europäischen Geschichte, in: Archiv für Sozialgeschichte 40 (2000) S. 510-523. Siehe auch Jack HAYWARD, Industrial Enterprise and European Integration. From National to International Champions in Western Europe, Oxford 1995.

15 Hartmut KaELble, Die soziale Integration Europas. Annäherungen und Verflechtungen westeuropäischer Gesellschaften seit dem Zweiten Weltkrieg, in: Eckart SCHREMMER (HG.), Wirtschaftliche und soziale Integration in historischer Sicht, VSWG Beihefte 128, Stuttgart 1996, S. 304-344, sowie Ders.: Auf dem Weg zu einer europäischen Gesellschaft. Eine Sozialgeschichte Westeuropas 1880-1980, München 1987.

16 Siehe Kaelble, Kocka, Siegrist (Hg.), Europäische Konsumgeschichte. 
gang in den Massenkonsum fand. Dies zeige, welch zentralen Stellenwert die Mobilität im »American way of life « habe ${ }^{17}$. Für Europa hingegen gelte die Faustregel: Je teurer das Produkt, desto größer der »time lag« gegenüber den USA! Erstaunlich ist auch, daß die Ausbreitungsdynamik der oben aufgeführten Konsumgüter auch durch die Weltwirtschaftskrise kaum gebremst wurde. Der fast dreißigjährige »Vorsprung" der amerikanischen Konsumgesellschaft auf Europa macht die Faszination und die Anziehungskraft des amerikanischen Lebensstils für viele Europäer verständlich, zumal die USA ihre Vorreiterrolle als Protagonisten fordistischer Leitprodukte nach dem Zweiten Weltkrieg wiederholten.

Die wirtschaftliche Potenz der USA nach 1945 führte Mitte der sechziger Jahre in verschiedenen europäischen Ländern zu der öffentlichkeitswirksamen Diskussion um den »technological gap«, der Europa anscheinend von den Vereinigten Staaten trennte. Inwiefern diese in Frankreich oder Deutschland recht unterschiedlich geführte Diskussion Ausdruck der unterschiedlichen Modernisierungskonzepte war, wird im Laufe der Arbeit zu klären $\operatorname{sein}^{18}$. Fest steht, daß die Reaktionen auf das massive Eindringen des amerikanischen Konsumverhaltens in den europäischen Ländern durchaus unterschiedlich ausfielen. Für die einen war die »Amerikanisierung" der Gesellschaft traumhaft, für die anderen war sie ein Alptraum ${ }^{19}$.

Aus wirtschafts- und technologiepolitischer als auch aus kulturhistorischer Perspektive lassen sich in Frankreich und der Bundesrepublik Deutschland deutlich voneinander abweichende Muster in der Auseinandersetzung mit der »amerikanischen Herausforderung « beobachten ${ }^{20}$. Während die Diskussion

17 WITTKe, Wie entstand industrielle Massenproduktion?, S. 86.

18 Einen guten Überblick über die europäische Diskussion des „technological gap« in den 60er Jahren liefert der Aufsatz von Hubert Zimmermann, Western Europe and the American Challenge: Conflict and Cooperation in Technology and Monetary Policy, 1965-1973, in: Journal of European Integration History $6(2000) 2$ S. 85-110.

19 Als allgemeinen Überblick zu diesem Thema siehe: Philipp GASSERT, Amerikanismus, Antiamerikanismus, Amerikanisierung, S. 531-561. Zu Europa allgemein siehe Rob KroEs, If You've Seen One, You've Seen Them All. Europeans and American Mass Culture, Urbana 1996; Richard Pells, Not Like Us. How Europeans Have Loved, Hated, and Transformed American Culture since World War II, New York 1997. Zu Frankreich siehe Philippe Roger, Rêves et cauchemars américains: Les Etats-Unis au miroir de l'opinion publique française (1945-1953), Paris 1996; David Strauss, Menace in the West: The Rise of French Anti-Americanism in Modem Times, Westport 1978; Richard F. Kulsel, Seducing the French. The Dilemma of Americanization, Berkeley 1993. Zu Deutschland siehe Doering-ManteufFel, Wie westlich sind die Deutschen?; Bernd GREINER, »Test the West «: über die "Amerikanisierung « der Bundesrepublik Deutschland, in: Mittelweg 36 (1997/98) 5, S. 4-40; Konrad JARAusch, Amerikanisierung und Sowjetisierung in Deutschland 1950-1970, Frankfurt a.M., New York 1997; Axel ScHILDT, Ankunft im Westen. Ein Essay zur Erfolgsgeschichte der Bundesrepublik, Frankfurt a. M. 1999; POIGER, Jazz, Rock, and Rebels.

${ }^{20}$ Eine scharfsinnige Analyse der technological-gap-Diskussion im Kontext des Kalten Krieges lieferte der Schweizer Peter Sager bereits 1971 mit dem Buch »Die technologische Lücke zwi- 
um den »défi américain« in Frankreich primär in den Kontext der französischen »politique de la grandeur« einzubetten ist, also als ein Ausdruck der Suche nach nationaler Identität nach $1945 \mathrm{zu}$ verstehen ist, markiert die "Lücken-Diskussion " in der Bundesrepublik erst den zarten Beginn eines wiedererwachenden wissenschaftlich-technischen Selbstbewußtseins, in dem die USA jedoch immer die Rolle des potentiellen Partners, nie die des Feindes gespielt haben. ${ }^{21}$

Ein wesentlicher Grund für diese unterschiedlichen nationalen Deutungen der europäischen Lage im wissenschaftlich-technischen Bereich ist in der militärischen Ausgangslage der Staaten zu sehen. Erst die Überlegenheit der USA und der Sowjetunion im Bereich der Nukleartechnik hatte das Bewußtsein eines wissenschaftlich-technischen Rückstandes in Europa geschaffen. Die restriktive Wissens- oder Techniktransferpolitik der USA in diesem Bereich $^{22}$ sowie Bemühungen um eine europäische Zusammenarbeit im Rahmen der Euratom-Verhandlungen ${ }^{23}$ hoben die Bereiche Wissenschaft und Technik auf die Ebene der Außen- und Wirtschaftspolitik und damit in das Feld der öffentlichen Wahrnehmung. Der Höhepunkt der technological-gapDiskussion (Oktober-Dezember 1966) fallt genau in die Zeit des Scheiterns der Bemühungen um einen einheitlichen europäischen Standard beim Farbfernsehen (Juni 1966). Dies darf wohl als deutliches Zeichen für die ambivalente Technologiepolitik einzelner europäischer Staaten im Kontext der europäischen Integrationsbemühungen verstanden werden ${ }^{24}$.

schen Ost und West«, Bern 1971. Zur Position der Bundesrepublik Deutschland in dieser Debatte siehe Johannes BÄHR, Die »amerikanische Herausforderung «. Anfänge der Technologiepolitik in der Bundesrepublik Deutschland, in: Archiv für Sozialgeschichte 35 (1995) S. 115-130. Hervorzuheben ist in diesem Kontext die Arbeit des amerikanischen Politologen Robert Gilpin, der bereits 1968, als die Diskussion ihren Höhepunkt kaum überschritten hatte, die französische Auseinandersetzung mit dem »défi américain« einer systematischen Kritik unterzog. Robert GILPIN, France in the Age of Scientific State, Princeton, New Jersey 1968.

21 BäHR, Die »amerikanische Herausforderung «. Joachim Radkau stellt fest, daß eine auf zukunftsorientierte Branchen ausgerichtete Technologiepolitik in der Bundesrepublik Deutschland bis zur Gründung des Atomministeriums unter Strauß eigentlich nicht vorhanden gewesen sei. Selbst nach der Gründung dieses Ministeriums sei eine Politik, die dem Namen »Technologiepolitik « gerecht werde, nur zögernd nachweisbar. Joachim RADKAU, "Wirtschaftswunder « ohne technologische Innovation? Technische Modernität in den 50er Jahren, in: SchiLdr, SYwotTEX (Hg.), Modernisierung im Wiederaufbau, S. 129-154.

22 Siehe hierzu Zmmermann, Western Europe and the American Challenge.

${ }^{23}$ Henry R. NAU, National Politics and International Technology. Nuclear Reactor Development in Western Europe, Baltimore 1974.

24 Im September 1964 wurde in der französischen Zeitschrift "Le progrès scientifique« ein Aufsatz mit dem Titel »Recherche scientifique et indépendance« veröffentlicht, in dem vor dem Ungleichgewicht zwischen Frankreich und den USA im Bereich von Wissenschaft und Technik gewarnt wurde. Diese Veröffentlichung kann als Beginn der "technological gap«-Debatte und der »défi américain«-These angesehen werden. Im Anschluß an diesen Artikel haben sich zahlreiche Politiker zu diesem Thema geäußert, wie beispielsweise Gaston Deffere in Frankreich oder Franz 
Die »amerikanische Herausforderung « war für die Europäer gleichzeitig eine »europäische Herausforderung«: Das Zugeständnis amerikanischer Überlegenheit wurde überlagert von der sich nur zögerlich durchsetzenden Einsicht, daß man dieser Überlegenheit nur in einer europäischen Gemeinschaftsanstrengung wirklich entgegenwirken konnte. Das Eingeständnis nationaler Begrenztheit der wissenschaftlich-technischen Ressourcen in der angebrochenen Ära von »big science« fiel den vergangenen Größen auf diesem Feld jedoch nicht leicht ${ }^{25}$.

Nachdem mit der generellen wirtschaftlichen Dynamik, der daraus resultierenden sozialen Integration der europäischen Gesellschaften, dem Aufbau supranationaler Institutionen, dem »consumer gap« zwischen den USA und Europa und dem Mitte der sechziger Jahre einsetzenden Bewußtsein eines »technological gap « einige gemeinsame Nenner genannt worden sind, die als Hintergrund sowohl des französischen als auch des bundesdeutschen Modernisierungsprozesses angesehen werden können, sollen im folgenden die elementaren und feinen Unterschiede herausgearbeitet werden, die den französischen Weg von demjenigen der Bundesrepublik unterscheiden. Am Beispiel der elektronischen Konsumgüterindustrie sollen diese Differenzen beispielhaft verdeutlicht werden. Erst vor diesem Hintergrund werden die unterschiedlichen wirtschaftlichen und politischen Strategien verständlich, die den Verlauf der Farbfernsehkontroverse in seiner sheißen Phaser wesentlich bestimmt haben.

Josef StrauB in der Bundesrepublik. Der italienische Außenminister Amintore Fanfani plädierte am 7. Oktober 1966 für einen technologischen Marshall-Plan, der englische Premier Wilson schlug am 15. November gar die Bildung einer "European Technological Community « vor - natürlich unter Einschluß der Briten! Siehe hierzu GILPIN, France in the Age of Scientific State, S. $3 \mathbf{f}$.

${ }^{25}$ Peter Galison, Bruce Hevly (Hg.), Big Science: The Growth of Large-Scale Research, Stanford 1992. 


\subsection{Die Bundesrepublik zwischen »Wirtschaftswunder« und »konservativer Modernisierung"}

In der Interpretation der wirtschaftlichen Entwicklung der Bundesrepublik Deutschland lassen sich drei Phasen unterscheiden, die jeweils an dominierende Deutungsmuster und Untersuchungsperspektiven in der Wirtschaftsgeschichte gebunden waren. Mit Philipp Heldmann könnte man die erste Phase als jene bezeichnen, in der die »Strukturbruchthese « dominierte, nach der der wirtschaftliche Aufschwung der frühen Bundesrepublik hauptsächlich das Resultat eines erzwungenen radikalen wirtschaftlichen wie gesellschaftlichem Neuaufbaus war $^{26}$. Die wirtschaftliche Überwindung der "Stunde Null « war laut dieser These zu einem großen Teil der US-amerikanischen Wiederaufbauhilfe im Rahmen des Marshall-Plans zu verdanken. Wie Werner Abelshauser in mehreren Studien nachzuweisen versucht hat, fiel sowohl die erwartete als auch die tatsächlich eingetretene Wirkung der US-amerikanischen Finanzhilfen weitaus geringer aus, als führende Wirtschaftspolitiker erhofft und frühe historische Einschätzungen angenommen hatten ${ }^{27}$. Abelshauser setzte der "Strukturbruchthese « seine auf langfristige Entwicklungstendenzen gestützte »Rekonstruktionsthese « entgegen, nach der es in den »langen fünfziger Jahren « zu einer »nachholenden Modernisierung « gekommen $\operatorname{sei}^{28}$. Das Wirtschaftswunder der Bundesrepublik war nach Abelshauser das Resultat einer größtenteils auf bestehenden Produktionsstrukturen aufbauenden Phase nachholenden Konsums.

Abelshausers Thesen wurden aber von Volkswirten und Wirtschaftshistorikern wie Rainer Klump, Christoph Buchheim und Knut Borchardt kritisiert, die Abelshauser unter anderem methodische Unzulänglichkeiten in der Interpretation des quantitativ ermittelten Zahlenmaterials vorwarfen ${ }^{29}$. Die Debatte um die Deutung des außergewöhnlichen Wirtschaftswachstums in der Phase des "golden age« dauert bis heute an. Wie Thomas Bittner in seiner Studie zum westeuropäischen Wirtschaftswachstum nach dem Zweiten Weltkrieg gezeigt hat, vermag bislang kein Ansatz - weder in theoretischer noch in em-

\footnotetext{
26 Heldmann, Das "Wirtschaftswunder « in Deutschland, S. 323.

27 ABELSHAUSER, Wirtschaftsgeschichte der Bundesrepublik Deutschland.

${ }^{28}$ Ders, Die langen fünfziger Jahre. Wirtschaft und Gesellschaft der Bundesrepublik Deutschland, 1949-1966, Düsseldorf 1987.

29 Siehe Rainer KLUMP, Wirtschaftsgeschichte der Bundesrepublik Deutschland. Zur Kritik neuerer Interpretationen aus ordnungspolitischer Sicht, Wiesbaden 1985; Christoph BUCHHEIM, Die Wiedereingliederung Westdeutschlands in die Weltwirtschaft 1945-1958, München 1990; Knut BorchardT, Trend, Zyklus, Strukturbrüche, Zufälle: Was bestimmt die deutsche Wirtschaftsgeschichte des 20. Jahrhunderts?, in: DERs., Wachstum, Krisen, Handlungsspielräume der Wirtschaftspolitik, Göttingen 1982. Eine knappe Zusammenfassung der unterschiedlichen Interpretationen liefert Rolf WALTER, Wirtschaftsgeschichte. Vom Merkantilismus bis zur Gegenwart, Köln u. a. 1995, S. 194-236.
} 
pirischer Sicht - das hohe Einkommenswachstum zwischen 1950 und 1970 tatsächlich zu erklären ${ }^{30}$ !

Für Gerold Ambrosius weist das bundesdeutsche Wirtschaftswunder die Züge einer »konservativen Modernisierung « auf. Die Führungsbranchen der industriellen Modernisierung der Bundesrepublik seien im wesentlichen die gleichen wie die der $» z w e i t e n$ industriellen Revolution« Ende des 19./Anfang des 20. Jahrhunderts gewesen: Chemieindustrie, Maschinen- und Fahrzeugbau sowie die Elektroindustrie. Lediglich das Tempo des industriellen Strukturwandels (Abbau des primären, Stärkung des sekundären Sektors) sei stark angestiegen. Insgesamt zeichne sich der bundesdeutsche Rekonstruktionsprozeß jedoch durch eine hohe strukturelle Invarianz aus. Als Ursache für diese strukturelle Inflexibilität sieht Ambrosius, „daß der Nachholbedarf der Deutschen die strukturellen Produktionsverluste der traditionellen Verbrauchsgüterindustrie abmilderte und damit die Positionsgewinne der expansiven Branchen bremste $\ll^{31}$.

Übereinstimmung herrscht bei den meisten Wirtschaftshistorikern und historisch argumentierenden Volkswirten darüber, daß das »deutsche Wirtschaftswunder « nicht das Resultat einer radikalen neo-liberalen Wirtschaftspolitik war, wie sie immer wieder vom »Vater des Wirtschaftswunders«, Bundeswirtschaftsminister Ludwig Erhard, propagiert wurde. Der deutsche Wiederaufbau weist deutliche ordnungspolitische Elemente auf, die Werner Abelshauser veranlassen, vom Modell einer »korporativen Marktwirtschaft« zu sprechen ${ }^{32}$. Das normative Leitbild der sozialen Marktwirtschaft, so Wolfgang Neumann und Henrik Uterwedde, habe nie mit der wirtschaftlichen und wirtschaftspolitischen Realität der Bundesrepublik übereingestimmt: »Unbestritten aber hat es eine erhebliche politische Wirkung entfaltet, die vor allem auf die überaus erfolgreiche Bewältigung der Wiederaufbauprobleme zurückzuführen ist und die wirtschaftspolitische Diskussion in der Bundesrepublik bis heute prägt $\ll^{33}$.

${ }^{30}$ BitTnER, Das westeuropäische Wirtschaftswachstum nach dem Zweiten Weltkrieg.

31 Gerold AMBrosius, Wirtschaftlicher Strukturwandel und Technikentwicklung, in: ScHILDT, SrwotTeX (Hg.), Modernisierung im Wiederaufbau, S. 111.

32 Abelshauser, Wirtschaftsgeschichte der Bundesrepublik Deutschland, S. 76f. "Strukturpolitische Interventionen, wie sie sich unter anderem im Investitionshilfegesetz niederschlugen«, so der Volkswirt Karl Georg Zinn, »beweisen, daß der deutsche Wiederaufbau keineswegs ohne Planung und Lenkung seitens des Staates gelaufen ist. Eine Entwicklung, die völlig den freien Marktkräften überlassen worden wäre, hätte wahrscheinlich weder den raschen Strukturwandel noch das starke Wachstum von Produktion und Beschäftigung in den 50er Jahren gewährleisten können«. Karl Georg ZiNN, Soziale Marktwirtschaft. Idee, Entwicklung und Politik der bundesdeutschen Wirtschaftsordnung, Mannheim 1992, S. 76.

${ }^{33}$ Wolfgang NeumanN, Henrik UTERWEDDE, Industriepolitik. Ein deutsch-französischer Vergleich, Leverkusen 1986, S. 42. 
Daß sich die »Strukturbruchthese« auch aus akteurzentrierter Perspektive nicht halten läßt, zeigen neuere Studien im Bereich der Unternehmensgeschichte und Elite-Bildung ${ }^{34}$. So weist Hervé Joly in seiner soziologischen Untersuchung der Vorstandsmitglieder der 26 größten Industriekonzerne des Dritten Reiches nach, daß der Zusammenbruch 1945 zwar zu einer »außerordentlich großen Störung in den etablierten Positionen der Wirtschaft « geführt habe, daß die meisten Industriellen nach dem Ende der Entnazifizierung jedoch wieder auf ihre ursprünglichen Positionen zurückgekehrt seien ${ }^{35}$. Wenn es, so Christof Biggeleben in seiner Rezension des von Dieter Ziegler herausgegebenen Sammelbandes »Großbürger und Unternehmer. Die deutsche Wirtschaftselite im 20. Jahrhundert", nach 1918, 1933 und 1945 überhaupt zu einem Teilaustausch von Personen kam, dann »wiesen die Nachfolger in der Regel dieselben sozialen Merkmale (soziale Herkunft, Bildungsniveau etc.) auf wie ihre Vorgänger ${ }^{36}$. Die personellen Kontinuitäten wirtschaftlicher Eliten nach 1945 tragen demnach ebenfalls zur Falsifikation der "Strukturbruchthese« bei.

Wie kommt es, so muß man sich nach den wirtschaftshistorischen Forschungsergebnissen fragen, daß die Vorstellung eines bundesdeutschen Wirtschaftswunders dennoch eine solche ideengeschichtliche Wirkungsmacht entfalten konnte? Um diese Frage zu beantworten, bedarf es des >Seitenwechsels der historischen Betrachtung: Nicht die Produktionsstrukturen stehen dabei im Vordergrund des Interesses, sondern die Konsumstrukturen. Will man das Phänomen des »Wirtschaftswunders« begreifen, muß man sich verstärkt dem zweiten Substantiv des Kompositums zuwenden. Es waren die Konsumenten, welche "Wundersames" in der Veränderung ihres alltäglichen Kaufumfeldes zu erkennen glaubten, als - ausgelöst durch Währungsreform und Korea-Boom - die lange ersehnten Konsumgüter die Warenhäuser füllten. Es ist das Merkmal der dritten Phase wirtschaftshistorischer Studien, sich verstärkt den psychologischen Faktoren der »Konsumgüter-Revolution« in der Bundesrepublik zugewendet zu haben. Überzeugend ist der Ansatz von Volkswirt Karl Georg Zinn, der das Phänomen des »Wirtschaftswunders « durch die Historisierung der Wahrnehmung zu erklären versucht:

\footnotetext{
34 Siehe Paul Erker, Toni Pierenkemper (Hg.), Deutsche Unternehmer zwischen Kriegswirtschaft und Wiederaufbau. Studien zur Erfahrungsbildung von Industrie-Eliten, München 1999, sowie Herve Joly, Patrons d'Allemagne: sociologie d'une élite industrielle 1933-1989, Paris 1996. Beispielhaft demonstriert wird dieser neue Ansatz in der Dissertation von Bemhard LoRENTZ, Industrieelite und Wirtschaftspolitik 1928-1950. Heinrich Dräger und das Drägerwerk, Paderbom 2001.

35 Hervé JoLY, Großunternehmer in Deutschland: Soziologie einer industriellen Elite (1933-1989), Leipzig 1998.

${ }^{36}$ Christof Biggeleben, Rezension des Buches von Dieter Ziegler (Hg.), Großbürger und Unternehmer. Die deutsche Wirtschaftselite im 20. Jahrhundert, Göttingen 2000, in: www.h-sozu-kult.de/rezensionen.htm
} 
Für die Generation, die die zerstörten deutschen Städte wiederaufbaute, die Verkehrswege erneuerte und die gleichzeitig noch einen Anstieg ihres Konsumniveaus erlebte, konnte das alles swie ein Wunder، erscheinen, auch wenn es der eigenen Arbeit zu verdanken war. Integration der Heimatvertriebenen, Beschäftigungswachstum bis zum Erreichen der Vollbeschäftigung 1960 (Arbeitslosenquote $0,6 \%$ ), das bereits erwähnte Wohnungsbauvolumen von über 350000 fertiggestellten Einheiten pro Jahr (Jahresdurchschnitt von 1949-1967), wovon knapp die Hälfte auf den staatlich geförderten Wohnungsbau verfiel, eine Verdreifachung des realen privaten Konsums zwischen 1950 und 1967 bei einem Anstieg der durchschnittlichen Wochenverdienste des Industriearbeiters um 242\% zwischen 1950 und 1967 bildeten die materiellen Faktoren der Wahrnehmung eines, Wirtschaftswunders ${ }^{37}$.

Robert Frank geht in seiner Deutung des deutschen Wirtschaftswunders aus mentalitätshistorischer Perspektive noch einen Schritt weiter, wenn er es als die bundesdeutsche Antwort auf die Krise nationaler Identität deutet. Die »Flucht« in den materiellen Wiederaufbau Deutschlands habe sich als erfolgreiche Strategie zur Überwindung des »Stunde-Null-Syndroms« erwiesen ${ }^{38}$. Auch Joachim Radkau deutet die Konzentration auf den Wiederaufbau in ähnlicher Weise als eine Art Vergangenheitsbewältigung, die unter anderem vom »Kult der Technik « heilen sollte ${ }^{39}$. Radkau überträgt in diesem Sinne Werner Sombarts These der Industrialisierung Deutschlands im 19. Jahrhundert auf die Nachkriegszeit: Es sei in erster Linie Anpassungsfähigkeit gewesen, durch welche die Deutschen die Stellung am Weltmarkt erobert hätten ${ }^{40}$. Damit spricht Radkau ein Thema an, daß besonders für den Vergleich der deutsch-französischen Modernisierungswege nach 1945 bedeutend ist: Die Frage, ob es eine gezielte Politik der Modemisierung gegeben hat oder nicht? Wie Radkau sind auch Uterwedde und Neumann sowie Peters der Meinung, daß eine Industrie- oder Strukturpolitik im Konzept der "sozialen Marktwirtschaft« keinen Platz hatte ${ }^{41}$. Daß dies in Frankreich gänzlich anders aussah, wird im Laufe der Darstellung deutlich werden.

\section{ZiNN, Soziale Marktwirtschaft, S. 76f.}

38 Robert FraNK, Mentalitäten, Vorstellungen und internationale Beziehungen, in: Wilfried LoTH, Jürgen Osterhammel (Hg.), Intemationale Geschichte. Themen, Ergebnisse, Aussichten, München 2000, S. 179.

39 Damit wehrt sich Radkau gegen die weitverbreitete Interpretation des Nationalsozialismus als »antimodernistische« Strömung. Der Kult der Technik sei in der DDR viel charakteristischer als in der Bundesrepublik gewesen. Erst mit der Kemenergie und dem Sputnik-Schock habe eine neue Begeisterung für Technik in der BRD eingesetzt. Joachim RADKAU, Nationalsozialismus und Modernisierung, in: Hans-Ulrich WEHLER (Hg.), Scheidewege der deutschen Geschichte. Von der Reformation bis zur Wende 1617-1989, München 1995, S. 183-197.

40 »Weil wir keinen Staat hatten, der uns mit Stolz zu erfüllen vermocht hätte [...] lemten wir Demut und Bescheidenheit, waren ohne Mühe bereit, die eigene Art den Bedürfnissen anderer anzupassen«, so Werner Sombart in seiner Studie "Die deutsche Volkswirtschaft im 19. Jahrhundert«. Zitiert nach RADKAU, »Wirtschaftswunder « ohne technologische Innovation?, S. 135.

41 NeumanN, Uterwedde, Industriepolitik, S. 42; »Das wirtschaftspolitische Leitbild der Bundesregierungen bis etwa Mitte der fünfziger Jahre war ausschließlich ordnungspolitisch bestimmt.« Erst Ende der sechziger Jahre sei es zur Einfuigung strukturpolitischer Elemente in die 
Axel Schildt und Arnold Sywottek haben die für die bundesdeutsche Geschichte der fünfziger Jahre charakteristische ambivalente Situation von Wiederaufbau und Modernisierung treffend als »konservative Modernisierung " oder $»$ Modernisierung im Wiederaufbau« beschrieben ${ }^{42}$. Obwohl die Rekonstruktion der Wirtschaft auf den klassischen industriellen Sektoren fußte, kam es seit Beginn der 50er Jahre zu einer enormen Steigerung des privaten Konsums, die in den Anfangsjahren der Bundesrepublik unter anderem durch eine staatlich festgelegte Preispolitik gefördert wurde. Entgegen des Leitbildes der Erhardschen Konsumpolitik (»so viel Freiheit wie möglich, so wenig Regulierung wie nötig «), war die Konsumfreiheit zu Beginn der fünfziger Jahre stark eingeschränkt. Harm Schröter behauptet gar:

Wenn alle Sektoren zusammengenommen werden, in denen Behörden direkt und indirekt die Preise ganz oder teilweise gestalten, so muß festgestellt werden, daß der Konsument zu Beginn der 50er Jahre fast ausschließlich auf regulierte Preise traf. Je direkter die entsprechenden Waren und Dienstleistungen zu den unmittelbaren Lebensnotwendigkeiten gehörten, desto stärker und länger blieben die entsprechenden Preise und Qualitäten vorgeschrieben ${ }^{43}$.

Die Festlegung bestimmter Preise für öffentliche Verkehrsmittel (Bundesbahn, öffentlicher Nahverkehr), den Nachrichtensektor (Telefon, Post, Rundfunk), öffentliche Ver- und Entsorgungsbetriebe (Gas, Wasser, Elektrizität, Müll) sowie zahlreicher Nahrungsmittel (z.B. »Konsumbrot«) erzeugte aber beim Verbraucher nicht den Eindruck, daß die Regulierung zu seinen Ungunsten stattfände. Was oftmals als verbraucherfreundlich galt, so Harm Schröter, entpuppt sich bei näherem Hinsehen als »krasser Fall von ausgenutzter Produzentensouveränität«. Besonders deutlich sei dies im Falle der Energieversorger zu beobachten, die zum Teil »exorbitante Monopolprofite« erwirtschaftet hätten ${ }^{44}$.

Trotzdem, und hier soll wieder die Wahrnehmungsperspektive des "kleinen Mannes« eingenommen werden, erlebten viele Bundesbürger die fünfziger und vor allem die sechziger Jahre als eine Phase rasant ansteigenden Konsums und damit der Verbesserung ihres Lebensstils. Typisch für die Entwicklung des privaten Konsums war dabei, daß der Anteil der Ausgaben für Nahrungs- und Genußmittel sowie Kleidung ständig gesunken ist, während jener für Wohnungsmiete, langlebige Konsumgüter (Radio- und Fernsehgerä-

wirtschaftspolitische Konzeption der Bundesregierung gekommen, da die reine Nachholphase beendet war. Hans-Rudolf PETERS, Grundlagen der Mesoökonomie und Strukturpolitik, Bern, Stuttgart 1981, S. $394 \mathrm{f}$.

42 Schild, Srwottek (Hg.), Modernisierung im Wiederaufbau.

${ }^{43}$ Harm G. SCHRöTER, Konsumpolitik und »soziale Marktwirtschaft«. Die Koexistenz liberalisierter und regulierter Verbrauchsgütermärkte in der Bundesrepublik der 1950er Jahre, in: Hartmut Berghoff (Hg.), Konsumpolitik. Die Regulierung des privaten Verbrauchs im 20. Jahrhundert, Göttingen 1999, S. 116.

44 Ibid. S. $115 f$. 
te, Waschmaschine, Kühlschrank) ständig gestiegen ist. Auch die Ausgaben für Verkehr (v.a. Autos) und Nachrichtenübermittlung (v.a. Telefon) haben sich in der Zeitspanne von 1950 bis 1970 fast verdreifacht.

Auch aus technikhistorischer Perspektive, so Joachim Radkau, weisen die fünfziger und sechziger Jahre mit der Durchsetzung der »fordistischen Leitprodukte « Automobil, Fernsehgerät, Waschmaschine und Kühlschrank während der Konsumgüter-Revolution "markante Epochenmerkmale« auf. Damit widerspricht Radkau der verbreiteten Auffassung, daß die Aufbauzeit der Bundesrepublik aus technikhistorischer Sicht »ein strukturloser weißer Fleck « gewesen sei und verweist auf die Unzulänglichkeiten des herkömmlichen technikhistorischen Zugriffs:

Es zeigt beispielhaft die Grenzen einer allzu stark auf Basisinnovationen, auf technische Pionierleistungen, auf spektakuläre Superlative und auf ein enges Spektrum >neuer Technologien`konzentrierten Betrachtungsweise, und es zeigt die Folgen der Vernachlässigung trivialer und konventioneller Technik, der Technik-Anwendung, der Herausbildung eines breiten technischen Durchschnittsniveaus, der Veralltäglichung technischer Produkte, der Integration neuer Technologien in organisatorische Strukturen und Arbeitsgewohnheiten und der Anpassung technischer Innovation an Marktbedingungen und Konsumentenpräferenzen. [...] Aus der westdeutschen wie aus der japanischen Erfolgsgeschichte der Nachkriegszeit kann man lernen, daB es nicht auf die aufsehenerregenden technischen GroBprojekte, nicht auf Erdsatelliten und Riesenkraftwerke ankommt, und daß es oft nicht einmal nützlich ist, bei teuren Spitzentechniken unbedingt der Erste zu sein, sondern daß Arbeitsmoral, ein nüchtern-pragmatischer Umgang mit Technik und die kreative Anpassung der Produktion an den Bedarf viel wichtiger sind ${ }^{45}$.

So nachvollziehbar dieses Plädoyer Radkaus für eine generelle Erweiterung der technikhistorischen Betrachtungsweise in Richtung alltags- und mentalitätshistorischer Fragestellungen ist, zeigt das Beispiel der PAL-SECAMKontroverse, daß die symbolische Bedeutung, welche die stechnischen Pionierleistungen « im Modernisierungsproze $B$ gespielt haben, nicht unterschätzt werden darf. Weniger aus immanent technikwissenschaftlicher Perspektive, sondern aus mentalitätshistorischer Perspektive: Gerade das französische Beispiel zeigt, daß »technologischen Meisterleistungen« (Stichwort »champion national«) eine zentrale Stellung im französischen Modernitätsdiskurs zukam. Aus diskursanalytischer Sicht lohnt die Beschäftigung mit diesen Superlativen daher allemal, wie neuere Arbeiten deutlich unter Beweis gestellt haben ${ }^{46}$.

45 RADKAU, Wirtschaftswunder ohne technologische Innovation?, in: ScHILDT, SYwotTEK (Hg.), Modernisierung im Wiederaufbau, S. 130.

46 Siehe hierzu Kapitel 3.2.2.1. Technologische Großprojekte und »champions nationaux«. 


\subsubsection{Die elektrotechnische Industrie als »Leitsektor» der Konsumgüterrevolution}

Folgt man der These von Volker Wittke, nahmen die elektrotechnischen Konsumgüter eine Leitfunktion in der Konsumgüterrevolution ein. Auch wenn die Durchsetzung dieser Konsumgüter, wie gesehen, mit fast dreißigjährigem Rückstand auf die USA erfolgte - erst 1955 erreichte das Pro-KopfEinkommen in der Bundesrepublik das Niveau, welches in den USA zu Anfang der 1930 er Jahre herrschte - so stieg der private Verbrauch langfristiger Konsumgüter in der Bundesrepublik zwischen 1954 und 1964 um das 2,5 fache. Im selben Zeitraum wuchsen jedoch Nachfrage und Absatz im Bereich elektrotechnischer Konsumgüter um das 8,5 fache $^{47}$ ! Damit nehmen elektrotechnische Konsumgüter innerhalb der verschiedenen »Wellen« des Konsums eine zentrale Rolle ein, zumal die Herstellung dieser Konsumgüter eine hohe Produktions- und Arbeitsteilung forderten ${ }^{48}$. Die Durchsetzung des fordistischen Modells der Massenproduktion und das Aufkommen des Massenkonsums gingen im Bereich der elektrotechnischen Konsumgüter jedoch keineswegs Hand in Hand. Die eigentlichen Vorreiter der Konsumgüterproduktion in der Elektroindustrie waren Branchenneulinge:

Bei Radios und bei Hausgeräten stellten die Startphasen massenhafter Verbreitung der neuen Produkte jeweils Zeiträume dar, in denen zahlreiche Neueinsteiger mit ausgesprochen vielfältigen Produktideen und Konzeptionen in den noch wenig konkurrierenden Märkten auftauchten. Ob Radio, Kühlschrank oder Waschmaschine: vor allem Newcomer waren es, die der aufkeimenden Nachfrage mit den verschiedensten Formen technischer Umsetzung der Funktionsprinzipien Nahrung boten ${ }^{49}$.

In diesem Punkt unterscheidet sich die erste von der zweiten Konsumgüterrevolution: Während es in der Durchsetzungsphase der Starkstromtechnik als Voraussetzung der generellen Elektrifizierung wenige Unternehmen waren, die als »global player in der Lage waren, die hohen Investitionsleistungen aufzubringen, bildeten sich in der zweiten Phase jeweils einheimische Konsumgüter-Industrien aus:

Aus der Perspektive der Branchenentwicklung betrachtet war demnach der jeweilige Ablauf der Konsumgüter-Revolution in den einzelnen Ländern ausschlaggebend dafür, wann und in welchem Umfang sich der Schwerpunkt der Elektroindustrie von der Investitions- auf die Konsumgüterproduktion verlagerte. Und weil von der Konsumgüterproduktion in diesem Zeitraum die

47 WIrTKE, Wie entstand industrielle Massenproduktion?, S. 92.

48 Gerold Ambrosius macht zahlreiche solcher $» N a c h f r a g e w e l l e n «$ aus: EBwelle, Bekleidungswelle, Wohnungs- und Einrichtungswelle, Autowelle und schließlich die Reisewelle folgten einander in kurzen Abständen. Sie alle sind ein Zeichen dafür, daB der private Verbrauch der mit Abstand dominierende Nachfrageblock war. Gerold AMBRosius, Wirtschaftlicher Strukturwandel und Technikentwicklung, in: SchILDT, SYwotrek ( $\mathrm{Hg}$.), Modernisierung im Wiederaufbau, S. 113.

49 WITTKE, Wie entstand industrielle Massenproduktion?, S. 109. 
größte Wachstumsdynamik ausging, entwickelten sich die Elektroindustrien dort besonders expansiv, wo dieser Strukturwandel früh einsetzte. Kurz gesagt: die nationalen Entwicklungsmuster der Konsumgüter-Revolution schlugen sich in national variierenden Industrialisierungsverläufen nieder ${ }^{50}$.

Sicherlich bildete das Radiogeschäft die Grundlage für den Wiederaufbau der elektronischen Konsumgüterproduktion. Neben den alten Branchenriesen Siemens, AEG, Philips sowie dem neuen Star Grundig waren es Firmen wie Telefunken, Saba, Loewe-Opta, Nordmende, Kuba-Imperial, Braun, Graetz, Schaub-Lorentz, Blaupunkt, Akkord-Radio Metz oder Tonfunk, die der deutschen Rundfunkindustrie zu einem extrem dynamischen Wachstum verhal$\mathrm{fe}^{51}$. Besaßen die beiden Branchenriesen Siemens und AEG auf dem Höhepunkt der Starkstrom-Ära vor dem Ersten Weltkrieg einen Anteil an der Gesamtproduktion der deutschen Elektroindustrie von 65\%, sackte dieser Anteil im Zuge der Konsumgüterrevolution auf rund 31\% im Jahre $1960^{52}$. Diese Verschiebung ist nicht nur ein Indiz für die enorme Steigerung des Konsumgütersektors in der gesamten elektrotechnischen Industrie, sondern auch ein Hinweis dafür, daß eine der Stärken der Universalhersteller - die hohe vertikale Integration und der breite »scope - für das erfolgreiche Agieren auf dem Konsumgütermarkt zum Nachteil werden konnte.

Im Vergleich zu den Universalherstellern handelte es sich bei den kleineren und mittleren Rundfunkgerätefirmen um »Spezialisten«, die sich untereinander durch abweichende Fabrikationsprogramme unterschieden ${ }^{53}$. Die meisten Firmen konzentrierten sich auf die Endmontage sowie auf das Design der Geräte, waren aber beim Kauf der zentralen Bausteine des Empfängers (vor allem Elektronenröhren und später Transistoren) wieder auf die 'Großen angewiesen. In diesem Sinne profitierten sowohl die alten Monopolisten im Röhrengeschäft (Telefunken, Siemens, Valvo, Philips) als auch die kleineren Spezialhersteller vom Boom in der Konsumgüterrevolution. Allerdings setzte sich bei den Universalherstellern die Erkenntnis, sich aus dem Konsumgütergeschäft besser zurückzuziehen und sich auf die klassischen Geschäftsfelder zu konzentrieren, nur sehr langsam durch. Trotz des Versuchs, die Spagatsituation zwischen Anlagen- und Verkaufsgeschäft durch die Gründung spezialisierter Tochtergesellschaften zu lösen, sind sowohl Siemens als auch AEG an dieser Aufgabe gescheitert ${ }^{54}$. Wittke ist der Meinung,

\section{Ibid. S. 96.}

511955 gab es 36 westdeutsche Firmen, die Radiogeräte herstellten, Fernsehempfänger wurden von 21 Firmen produziert. 1954 näherte sich die Zahl der Radiogeräteproduktion in der Bundesrepublik der 3-Millionen-Grenze. Konkret bedeutet dies, daB 1955 rund 75\% der westdeutschen Haushalte mit einem Radiogerät ausgestattet waren. Siehe FICKERS, »Der Transistor«, S. 30 f.

52 WITTKE, Wie entstand industrielle Massenproduktion?, S. 117f.

53 FICKERS, »Der Transistor «, S. 30f.

54 Siemens hatte 1957 die "Siemens-Electrogeräte GmbH« gegründet. Für die Hausgeräteproduktion wurde 1966 zusammen mit Bosch die $» B o s c h-S i e m e n s-H a u s g e r a ̈ t e ~ G m b H$ « gegründet. 
daß die AEG nicht zuletzt daran zugrunde gegangen ist, daß man sich zwischen Großunternehmen »alten« und »neuen« Typs nicht habe entscheiden können ${ }^{55}$.

Die mittelständischen Rundfunkunternehmen konnten in den fünfziger und sechziger Jahren dagegen ihre Position auf dem nationalen wie internationalen Markt immer weiter ausbauen. Dabei kamen den deutschen Herstellern drei Faktoren zugute: Zum ersten die bereits seit Ende der zwanziger Jahre existierenden Produktionsstrukturen und Fertigungserfahrungen, die im Sinne der Rekonstruktionsthese zu einem schnellen Wiederaufbau der Rundfunkindustrie führten. Zum zweiten der hohe Grad an Vertrautheit mit dem Medium Rundfunk, das bereits in den dreißiger Jahren zum neuen Leitmedium im massenmedialen Ensemble aufstieg und von den Nationalsozialisten konsequent propagiert worden war. Zum dritten die durch politische Ausgrenzung erzwungene frühe Umstellung des Senderbetriebs auf den UKW-Rundfunk.

Vor allem dieser dritte Faktor wurde für die deutsche Rundfunkindustrie zum entscheidenden Marktvorteil, als sich die Technik des UKW-Rundfunks Ende der fünfziger Jahre international durchsetzte. Waren die Deutschen durch die diskriminierende Verteilung der Mittelwellenfrequenzen auf der Kopenhagener Wellenkonferenz des Jahres 1948 gezwungen worden, nach einer technischen Alternative zum Mittelwellenrundfunk zu suchen, stellte dies für die anderen europäischen Staaten unmittelbar keine Notwendigkeit dar, da ein flächendeckender Rundfunkbetrieb auf den ihnen zur Verfügung stehenden Mittel- und Langwellen möglich $\mathrm{war}^{56}$. Dieser Nachteil für Deutschland, der im politisierten Technikerjargon des Kalten Krieges als "Wellendemontage « bezeichnet wurde, sollte sich aus wirtschaftstheoretischer Perspektive als »first-mover«-Vorteil herausstellen. Mit einigen Jahren Vorsprung im Bereich der Fertigungstechnik und im Marketing gelang es der deutschen Rundfunkindustrie, binnen kurzem eine marktführende Position im europäischen Ausland zu erlangen. Innerhalb von vier Jahren von 1951 bis

Siehe hierzu Bernhard PletrNer, Abenteuer Elektrotechnik. Siemens und die Entwicklung der Elektrotechnik seit 1945, München 1994, sowie Wilfried FeldenKIRCHEN, Siemens 1918-1945, München 1995.

55 WrTTKe, Wie entstand industrielle Massenproduktion?, S. 121. Diese Sicht wird indirekt auch vom ehemaligen Vorstandsvorsitzenden von Telefunken, Dr. Felix Herriger, bestätigt, der sich in einem Interview mit dem Autor in ähnlicher Weise äußerte. Wittke argumentiert, daß sich die AEG nach der Fusion mit Telefunken gerade in jenem Augenblick zum "global player« der Konsumgüterproduktion emporschwingen wollte, als die zweite Konsumgüterrevolution in ihre Endphase trat (Ende der sechziger/Anfang siebziger Jahre). Erreichen wollte man diese Stellung vor allem durch die Übernahme mittlerer Spezialunternehmen. Zwischen 1965 und 1973 wurden insgesamt acht Hausgerätehersteller von AEG-Telefunken übernommen, so unter anderem die Linde AG, Neff, Zanker, BBC und Küppersbusch.

56 FICKERS, »Der Transistor «, S. $9 \mathrm{f}$. 
1954 vervierfachte sich die Empfängerausfuhr auf jährlich 867000 Radiogeräte.

Die "Welle der Freude«, so wurde der UKW-Rundfunk in der Bundesrepublik wegen der erheblich besseren Tonqualität genannt, schwappte unerwartet schnell in die anderen europäischen Länder über, so daß das Rundfunkexportgeschäft bereits 1955 als »bedeutender stabilisierender Faktor der gesamten Radiowirtschaft « bezeichnet werden konnte. In einem Artikel der Fachzeitschrift »Funkschau« des Jahres 1955 heißt es hierzu: »Die deutsche Rundfunkindustrie kann daher wohl für sich in Anspruch nehmen, in Europa die Wegbereiterin der guten Tonwiedergabe gewesen zu sein. Namhafte deutsche Firmen [...] haben dazu beigetragen, den Gedanken des sguten Tons ‘ in Europa volkstümlich und darüber hinaus Deutschland zum größten Rundfunkgeräte-Exporteur der Welt zu machen $\kappa^{57}$. Das »symbolische Kapital«, das sich Rundfunkgeräte »Made in Germany « in dieser Zeit erarbeitet haben, ist teilweise bis heute spürbar ${ }^{58}$.

Obschon man Mitte der fünfziger Jahre auch in der Bundesrepublik Deutschland noch weit von einem ersten Sättigungsgrad im Bereich der Radioempfänger entfernt war, kündigte sich mit dem Fernsehgeschäft ein weiterer Boom in der Rundfunkindustrie an. Obwohl noch in den Kinderschuhen, stieg die Fernsehgeräteproduktion innerhalb eines Jahres um $200 \%$ von 52583 Empfängern im Jahr 1953 auf $147583 \mathrm{im}$ Jahr $1954^{59}$. Noch deutli-

57 Fischer, SCHMITZ, Betrachtungen über den Rundfunkgeräte-Export, in: Funkschau 8 (1955) S. 157.

58 Dies wurde auf einer Tagung zum Thema »Radio in Afrika« deutlich. Dort berichteten zahlreiche Seminarteilnehmer aus afrikanischen Ländern, daß heute noch jeder, der etwas auf sich halte, ein "Grundig «- oder ein »Telefunken «-Gerät besitzen müsse! Daß das Innenleben dieser Geräte heute in asiatischen Ländern gefertigt und zusammengebaut wird, interessiert in diesem Zusammenhang nicht. Es ist der Name, der zählt - mein Grundig muB es sein«. Siehe hierzu Andreas Fickers, Transistorradio in Afrika: Geschichte, Politik und Technik, in: DGB-Bildungswerk (Hg.), Radio. Kommunikation in Afrika, Düsseldorf 2002, S. 36-41, sowie Richard FARDON, Graham Furniss (Hg.), African Broadcast Cultures. Radio in Transition, Oxford u. a. 2000. Der Export der »Welle der Freude «-Empfänger wurde für viele ausländische Radiohersteller zur "Welle der Pleite«. Am Beispiel der Schweiz lässt sich zeigen, wie massiv die westdeutsche Rundfunkindustrie in ausländische Märkte einbrach. Allein im Jahre 1956 mußten acht Schweizer Radiofirmen Konkurs anmelden. In der Neuen Zürcher Zeitung vom 5. Juni 1956 hieß es: "Ursache dieses großen >Sterbens〈 ist vor allem die aggressive und anscheinend übermächtige Konkurrenz Westdeutschlands. Die deutsche Radioindustrie hat sich vor einigen Jahren anheischig gemacht, auf dem schweizerischen Radiomarkt wuchtig einzubrechen, und sie hatte dabei einen derartigen Erfolg, daB von einem eigentlichen Umbruch gesprochen werden muss. [...] Die westdeutsche Radioindustrie hat zahlreiche Märkte im Sturm genommen, und die Bundesrepublik hat sich in dieser Branche zum ersten Weltexporteur aufgeschwungen. Eine lange Reihe nationaler Produzenten ist dem vehementen Vorstoß erlegen und auf der Strecke geblieben «. N.N., Ein Wirtschaftswunder hat zwei Seiten!, in: Radio und Fernsehen 22 (1956) S. 669.

59 FICKERS, »Der Transistor«, S. 30. 
cher wird der rasante Produktionsanstieg, wenn man sich die Zahlen bei Grundig anschaut:

Tabelle 3: Produktions-, Beschäftigungs- und Umsatzzahlen bei Grundig, aus: Egon FEIN, Sieben Tage im Leben des Max Grundig, München 1983.

\begin{tabular}{lcrrrrrrr}
\hline & 1953 & 1954 & 1955 & 1956 & 1957 & 1958 & 1959 & \multicolumn{1}{c}{1960} \\
\hline $\begin{array}{l}\text { Radios } \\
\text { inkl. }\end{array}$ & 489.508 & & & 638.331 & 489.508 & 704.160 & & 850.808 \\
Musikschränke & & & & & & & & \\
Fernseher & 7.399 & 19.677 & 35.520 & 80.470 & 125.937 & 222.450 & 241.254 & 256.214 \\
Beschäftigte & 6.000 & 8.369 & 8.597 & & & 16.470 & 15.384 & 16.495 \\
Umsatz & & 128 & 150 & & & 360 & 399 & 426 \\
(Mio. DM) & & & & & & & & \\
\hline
\end{tabular}

Der Geschäftsführer der Deutschen Philips GmbH, Kurt Hertenstein, beurteilte die günstige Lage der deutschen Rundfunkindustrie auch nach dem hohen technischen Leistungsstand bei gleichzeitig günstigem Preisniveau:

Die Rundfunk- und Fernsehindustrie ist die einzige Branche innerhalb der Konsumgüterindustrie, die heute noch ihre Erzeugnisse unter dem Preisniveau von 1938 anbietet, so daß man beim Kauf eines Rundfunkgerätes im Vergleich zu anderen Konsumgütern den höchsten Gegenwert erhält. Das ist ein Positivum, mit dem wohl kaum ein anderer Wirtschaftszweig in Deutschland aufwarten kann ${ }^{60}$.

Die sechziger Jahre weisen für die gesamte Elektroindustrie in der Bundesrepublik eine exzeptionelle Wachstumsdynamik auf, mit einer jährlichen $\mathbf{Z u}$ nahme der Produktion von durchschnittlich 18,5\%. Diese Wachstumsrate ging, wie auch das Beispiel Grundig zeigt, mit einer starken Beschäftigungszunahme einher. Von 1950 bis 1960 stieg die Anzahl der in der westdeutschen Elektroindustrie beschäftigten Menschen von rund 300000 auf 800000 an. 1970 waren 1,1 Millionen Arbeitnehmer in der Elektroindustrie beschäftigt. Damit waren 1960 rund 10,1\% aller in der Industrie tätigen Arbeitnehmer in der Elektroindustrie beschäftigt, und der Anteil an der industriellen Gesamtproduktion bzw. dem industriellen Gesamtumsatz lag bei $7,6 \%{ }^{61}$.

Ohne weiter auf wirtschaftshistorische Rahmendaten eingehen zu wollen, sollten diese Zahlen verdeutlichen, in welch dynamischem Sektor sich Anfang der 1960er Jahre derjenige Industriezweig befand, für den das Farbfernsehen eine weitere Etappe der wirtschaftlichen Expansion eröffnete. Aus diesem Grunde ist es wichtig, sich die zentralen Akteure und Institutionen, die

60 Kurt Hertenstein, Ein neues Rundfunk- und Fernsehjahr, in: Funk-Technik 13 (1955) S. 351 .

61 Zahlen aus WITTKE, Wie entstand industrielle Massenproduktion?, S. 132. 
in der Bundesrepublik mit der strukturellen und technischen Durchsetzung des Farbfernsehens betraut waren, im folgenden Kapitel näher anzusehen.

\subsubsection{Die »drei Säulen« der PAL-Durchsetzung in der Bundesrepublik Deutschland}

DaB die Farbfernsehvorbereitungen im Bundesgebiet letztlich einen so kontinuierlichen und reibungslosen Verlauf nehmen - das steht im angenehmen Widerspruch zu der Entwicklung in einigen anderen europäischen Ländern - ist der guten Zusammenarbeit der drei `Säulen< des Fernsehens zu danken: Rundfunkanstalten (für Studiotechnik, Sender des Ersten Programms und Programmvorbereitungen), Deutsche Bundespost (für Übertragungstechnik) und Rundfunk-Geräteindustrie ${ }^{62}$.

Dieses Zitat des Funkschau-Chefredakteurs Karl Tetzner kann als Wegweiser der nun folgenden Darstellung der Institutionen und Akteure dienen, die an der Einführung des Farbfernsehens in der Bundesrepublik beteiligt waren. Wie am Beispiel der französischen 819-Zeilendiskussion gesehen, konnten unterschiedliche Vorstellungen und Strategien der an der Normdiskussion beteiligten Akteure (Rundfunkindustrie, Informationsministerium, Staatliche Rundfunkanstalt) dazu führen, daß die von allen Beteiligten geteilte Intention, nämlich die Förderung eines zukunftsweisenden industriellen Sektors, eher verhindert denn gefördert wurde. Die daraus resultierende europäische Isolation war nicht zuletzt das Resultat einer Kommunikationsverweigerung bzw. des bewußten Ausschlusses einer »Säule« im nationalen Diskurs - im französischen Fall des Ausschlusses des Verbandes der Elektroindustrie (FNIE).

Die Einführung des Farbfernsehens in der Bundesrepublik dagegen kann als gelungenes Beispiel des Aufbaus eines Informations- und Kommunikationsnetzwerkes gesehen werden. Zwar könnte man in diesem Netzwerk lediglich die logische organisatorische Folge der föderalen Struktur des Rundfunks in der Bundesrepublik sehen, doch geht die funktionale Organisation des Netzwerkes über diese bloße Notwendigkeit hinaus. Wie zu zeigen sein wird, können die unterschiedlichen Funktionseinheiten dieses Netzwerkes auch als das Resultat eines gezielten Spezialisierungsprozesses verstanden werden, in dem jede der »drei Säulen « strategisch agierte, um ihre jeweiligen Kompetenzen und Zuständigkeiten zu wahren oder auszubauen.

Am Falle Walter Bruchs als Repräsentant der Säule "Rundfunkindustrie» wird demonstriert, wie wichtig die Besetzung zentraler Knotenpunkte des Netzwerkes für die Durchsetzung eigener Strategien und - im Falle der Rundfunkindustrie - Verkaufsziele war. Nicht zuletzt bot die ständige Präsenz in Ausschüssen und Gremien einigen zentralen Akteuren die Möglich- 
keit zur Profilierung und zur Anhäufung »symbolischen Kapitals«. Daß die »Ökonomie der Aufmerksamkeit ${ }^{63}$ auch monetäre Vorzüge mit sich brachte, darf sicherlich als zusätzliche Motivation für "unermüdliches Engagement« gedeutet werden.

\subsubsection{Die technische Ausgangslage des westdeutschen Fernsehens}

Noch während der Phase konkurrierender Vorstellungen der alliierten Besatzungsmächte über die zukünftige Gestaltung des Rundfunks in den drei Westzonen beschloß der Verwaltungsrat des Nordwestdeutschen Rundfunks (NWDR) mit Zustimmung der britischen Militärregierung im Jahre 1948, Vorbereitungen für den Wiederaufbau eines regelmäßigen Fernsehbetriebs zu treffen. Der NWDR mit Sitz in Hamburg bot personell und materiell die besten Bedingungen für den Wiederaufbau des Fernsehrundfunks und die Senderreichweite umfaßte zudem etwa die Hälfte der Bevölkerung in den drei Westzonen $^{64}$. Am 27. November 1950 startete der NWDR ein Fernsehversuchsprogramm, bis zur offiziellen Eröffnung des regelmäßigen Programmbetriebs sollte es aber noch zwei Jahre dauern. In seiner Eröffnungsansprache am ersten Weihnachtstag 1952 faßte Fernsehintendant Werner Pleister seine Erwartungen an das neue Medium in folgende Worte:

Wir versprechen Ihnen, uns zu bemühen, das neue, geheimnisvolle Fenster zu ihrer Wohnung, das Fenster in die Welt, Ihren Fernsehempfänger, mit dem zu erfüllen, was Sie interessiert, Sie erfreut und Ihr Leben schöner macht. Man hat das Fernsehen eine neue Form menschlicher Verständigung genannt. In der Tat: es kann dazu führen, daß die Menschen einander besser verstehen. Man hat auch die Befürchtung geäußert, das Fernsehen könne dem Menschen schaden, da es im Zuge der Technisierung der Schöpfung sein Leben weiter mechanisiert. Es kommt auf uns an, ob dieses technische Mittel schadet oder nützt. ${ }^{65}$

Auch wenn der weitere technische Ausbau des Fernsehrundfunks zu keinem Zeitpunkt ernsthaft in Frage gestellt wurde, macht dieses Zitat deutlich, wie ernst man den »öffentlich-rechtlichen« Auftrag des Fernsehrundfunks nahm.

63 Siehe den anregenden Essay des Wiener Professors für Architektur Georg Franck, Ökonomie der Aufmerksamkeit: Ein Entwurf, München u. a. 1998.

64 Zur Aufbauphase des NWDR-Fernsehens siehe HickeTHIER, Geschichte des deutschen Fernsehens, S. $66 \mathrm{f}$. Zur technikhistorischen Dimension siehe die unveröffentlichte Magisterarbeit an der Universität Hamburg von Klaas KLAASSEN, Die Wiedereinführung des Fernsehens beim Nordwestdeutschen Rundfunk 1948-1955. Zur Beziehung von Fernsehtechnik und Programmgestaltung, Hamburg 1997. Ein ausführlicher institutionen- und programmgeschichtliche Überblick wurde zum sechzigjährigen Jubiläum des NWDR im Jahre 2005 veröffentlicht. Siehe Peter von RüDEN, Hans Ulrich WAGNER,(Hg.), Die Geschichte des Nordwestdeutschen Rundfunks. Hamburg 2005

65 HickETHIER, Geschichte des deutschen Fernsehens, S. 76. Zum Fernsehen als neuen Tabernakel im Heim siehe John HarTley, The Uses of Television, London 1999, sowie Christina BarTZ, Spiegel und Zauberspiegel. Zur Beobachtung und Konstruktion des Fernsehens in der frühen Bundesrepublik, in: Irmela Schneider, Peter M. SPangenberg (Hg.), Medienkultur der 50er Jahre. Diskursgeschichte der Medien nach 1945, Bd. 1, S. 155-176. 
Die kulturkritische Dimension des Zitats spiegelt jene Ambivalenz wieder, die man dem neuen Medium aus intellektuellen Kreisen entgegen brachte. Ähnlich wie Pleister äußerte sich auch der Generaldirektor des NWDR, Adolf Grimme. In bewußter Distanzierung von der am eigenen Leib erlebten Instrumentalisierung des Mediums Rundfunk unter den Nationalsozialisten erinnerte er 1953 an die Aufgaben, die nun auch dem Bild-Rundfunk zukämen. Das Fernsehen habe nur dann eine tiefere Bedeutung, so Grimme, »wenn der Mensch auf dem Umweg über das Sehen wieder zu sich selbst kommt«. An anderer Stelle heißt es: "Was früher der Kamin war, wie einst die Petroleumlampe den Familienkreis vereinte, das muß im deutschen Haus der Rundfunk werden: der Mittelpunkt der inneren Sammlung « ${ }^{66}$.

Paßte der erste Teil des Satzes auch problemlos in die "VolksempfängerRhetorik « der Nationalsozialisten, schließt der Schlußteil an die "volkspädagogische Mission des Rundfunks an, wie sie u. a. vom "Vater des deutschen Rundfunks« in den zwanziger Jahren, Staatssekretär Hans Bredow, immer wieder verlautbart worden war $^{67}$. War der Radioempfänger Anfang der 1950er Jahre längst zum festen Bestandteil des häuslichen Inventars und der massenmedialen Umwelt geworden, sorgte der Fernsehrundfunk als bildmäßige Erweiterung der Nachrichtenüberlieferung für eine erneute Beschleunigung der Informationsübermittlung ${ }^{68}$. Alle, sowohl Kritiker wie Befürworter des Fernsehens, waren sich der Macht des Bildes bewußt.

Über die kulturhistorischen Folgen, welche diese neue Form massenmedialer Partizipation sowohl für den Einzelnen als auch für die Masse darstellte, wurde je nach politischem oder intellektuellem Lager heftig spekuliert. Die "Verschränkung von Öffentlichkeit und Privatheit«, die das »televisuelle Dabeisein ${ }^{69}$ schaffte, die scheinbare Auflösung von Nähe und Ferne, die durch die Live-Übertragung stattfand und den Zuschauer zum anonymen Teil »historischer Augenblicke« werden lieB - all dies macht die teilweise heftige

66 HickETHIER, Geschichte des deutschen Fernsehens, S. 66.

${ }^{67} \mathrm{Zu}$ Bredow siehe Hans Bausch, Der Rundfunk im Kräftespiel der Weimarer Republik, 1923-1933, Tlibingen 1956, sowie LeRG, Rundfunkpolitik in der Weimarer Republik, und Hans BREDOW, Im Banne der Ätherwellen, Stuttgart 1956. Einen interessanten Vergleich der Mediendiskurse während der Einführungsphase des Radios und des Fernsehens in Deutschland bietet die Dissertation von Clas Damann, Stimme aus dem Äther - Fenster zur Welt. Die Anfänge von Radio und Fernsehen in Deutschland. Köln 2005.

68 Zum Thema maudiovisuelle Revolution « siehe den anregende Essay von Siegfried ZIELINSKI, Audiovisionen. Kino und Fernsehen als Zwischenspiele der Geschichte, Reinbek bei Hamburg 1989.

69 Die wahrnehmungstheoretischen Aspekte der »Herausforderung Fernsehen « werden in dem Aufsatz von Monika Bernold beispielhaft thematisiert. Dort heiBt es: "Die Idee der Moderne, daB ein Ereignis erst nach dem Ablauf einer gewissen Zeit 'Geschichte` wird, daß die Zeit des Ereignisses und die seiner Repräsentation voneinander zu unterscheiden sind, wurde durch die Technologie des Fernsehens tendenziell in Frage gestelltк. BerNold, Fernsehen ist gestern, S. 12. 
Diskussion um Sinn und Zweck des Fernsehens verständlich ${ }^{70}$. Der Medienwissenschaftler Knut Hickethier beschreibt dies aus der Perspektive des Fernsehzuschauers wie folgt:

Man konnte ungehemmt auf das Angebot reagieren, mußte nicht bestimmten Kleidungs- und Verhaltensnormen gehorchen, konnte - so das populäre Bild vom fernsehsehenden Zuschauer unrasiert, in Pantoffeln und im Hemd, mit einer Flasche Bier in der Hand, dem Präsidenten ins Auge sehen, sich eine Oper anschauen oder einer Sportveranstaltung folgen. Die Zuschauer (und vor allem die Zuschauerinnen) konnten audiovisuell teilhaben am Weltgeschehen - und zugleich ganz privat $\operatorname{sein}^{71}$.

Die von Hickethier beschriebene Verschränkung von Privatheit und Öffentlichkeit zählt zweifellos zu den Phänomenen, die bei einer alltags- und mentalitätshistorischen Analyse des Fernsehens in den Mittelpunkt der Betrachtung gehörten, doch scheint seine "populäre» Beschreibung des Fernsehzuschauers eher eine unzulässige Übertragung heutiger Zustände in die Vergangenheit. Vieles deutet darauf hin, daß das $» F e r n S e h e n \ll$ in den fünfziger und sechziger Jahren in relativ starre räumliche wie gesellschaftliche Strukturen eingebettet war, in denen geschlechtsspezifische und kulturelle Muster zum Ausdruck kamen ${ }^{72}$. Die Historisierung dieser Debatte wäre aber die Aufgabe einer rezeptionsgeschichtlichen Analyse des Mediums und seiner programmlichen Inhalte, die an dieser Stelle nicht geleistet werden will ${ }^{73}$.

Wie bereits erwähnt, gestaltete sich der rasche technische Ausbau des Fernsehrundfunks in der jungen Bundesrepublik weitgehend ungestört von

70 Siehe hierzu die Pionierarbeit des amerikanischen Literaturwissenschaftlers und "Vordenkers" der britischen Cultural Studies, Raymond Williams, der das Konzept der »mobilen Privatisierung " entwickelte. Williams interpretiert Mobilität und Privatisierung als die beiden zentralen Faktoren der Modernisierung im 20. Jahrhundert. Diese beiden Pole stellen ein »Gravitationsfeld« her, innerhalb dessen die Entwicklung des Fernsehens in seiner Verknüpfung mit gesellschaftlichen Einflüssen dargestellt werden kann. Williams war der erste, der das Paradox der zunehmenden Mobilisierung (also Enthäuslichung) bei gleichzeitig zunehmender Privatisierung (Häuslichkeit) als Phänomen der postmodernen Gesellschaft analysiert hat. Siehe Raymond WrLLIAms, Television. Technology and Cultural Form, New York 1975; Ders., Mobile Privatisierung, in: Das Argument (März/April 1984) S. 260-263.

71 HickeThIER, Geschichte des deutschen Fernsehens, S. 61.

72 Vergleich etwa SCHILDT, Der Beginn des Fernsehzeitalters: Ein neues Massenmedium setzt sich durch, in: SchILdT, SYwotTeK (Hg.), Modernisierung im Wiederaufbau, S. 477-492.

${ }^{73}$ Gerade in der Frühzeit des Fernsehens (fünfziger Jahre) war das Fernsehschauen sehr häufig eine inszenierte und hochgradig ritualisierte Gemeinschaftsaktivität. Während der Besuch von Nachbarn und/oder Bekannten und Freunden die häufigste Form des kollektiven Fernseherlebnisses dargestellt haben dürfte, gab es auch regelrechte Fernsehclubs, in denen sich die Mitglieder regelmäBig zum gemeinsamen Fernsehen trafen. Siehe hierzu beispielsweise Marie-Françoise LÉvy, La création des télé-clubs. L'expérience de l'Aisne, in: Dies., La télévision dans la République. Les années 50, Paris 1999, S. 107-132. Die profundeste deutschsprachige rezeptionsgeschichtliche Analyse aus kulturhistorischer Perspektive bietet der Österreicher Thomas Steinmaurer in seinem Buch Tele-Visionen. 
der kulturkritischen Diskussion um die gesellschaftlichen Aufgaben des neuen Mediums. Mit der Wiedererlangung der Souveränität im Jahre 1955 ging auch die Rundfunkhoheit auf die Bundesrepublik beziehungsweise die einzelnen Bundesländer über. Am 31. März 1955 trat der Staatsvertrag in Kraft, der die Auflösung des NWDR und die Schaffung des Westdeutschen (WDR) und des Norddeutschen (NDR) Rundfunks festlegte. Trotz der Zusammenfassung der öffentlich-rechtlichen Landesrundfunkanstalten unter das Dach der Arbeitsgemeinschaft der Rundfunkanstalten Deutschlands (ARD), die 1950 mit dem Zweck gegründet worden war, ein gemeinsames Handeln bei Verhandlungen mit Dritten (z. B. bei Urheberrechtsfragen) oder der Repräsentanz nach außen (z.B. in der EBU) zu ermöglichen, kam es in der Folge zu einer für die Fernsehentwicklung förderlichen Konkurrenz zwischen den verschiedenen Landesrundfunkanstalten. Federführend in der technischen Entwicklung des Fernsehens blieben aber weiterhin der NDR und der WDR, während sich ersterer eher auf die Senderentwicklung, der zweite eher auf die Studiotechnik konzentrierte ${ }^{74}$. Parallel zum Aufbau fernsehtechnischer Produktionsanlagen in den verschiedenen Landesrundfunkanstalten sorgte die Deutsche Bundespost für die Realisierung eines Fernseh-Übertragungsnetzes.

Auf der Stockholmer Wellenkonferenz des Jahres 1952 waren der Bundesrepublik zur Ausstrahlung des Ersten Fernsehprogramms zehn Kanäle in den Bändern I und III zugesprochen worden. Diese reichten jedoch nur zu einer 85\%-Versorgung des Landes aus. Schon 1953 wurden dem NWDR von der CCIR auf Anfrage und zu Versuchszwecken fünf Kanäle in Band IV zugesprochen. Da sich die Wellen der Sender in den Bänder I und III im Ultrakurzwellenbereich annähernd so ausbreiten wie Licht, ist die Reichweite der Sender mit einer Leistung von $100 \mathrm{~kW}$ auf einen Radius von ca. 70 bis 100 km vom Sender beschränkt. Bei hohem Aufwand für die Empfangsantennen lassen sich maximale Reichweiten von 120 bis $180 \mathrm{~km}$ erzielen. Da die Versorgungsweite also ungefähr gleich der Sichtweite ist, war es besonders wichtig, geeignete Standorte für die jeweiligen Sender und Relaisstationen ausfindig zu machen. Im Stockholmer Wellenplan wurden zwar Sendeleistung und Frequenzen der Sender festgelegt, die Höhe der Masten blieb jedoch undefiniert.

Doch die Auswahl von Sendemaststandorten wurde neben technischen Gesichtspunkten auch von politischen Überlegungen beeinflußt. Dies wird besonders deutlich, wenn man sich die geopolitischen Realitäten Deutschlands Anfang der fünfziger Jahre vergegenwärtigt. Es fällt auf, daß die Installation von Sendemasten sowohl auf seiten der drei Westzonen als auch auf seiten der Sowjetzone immer in der Nähe der Zonengrenze realisiert wurde. In ei-

74 Siehe Interview des Autors mit dem Leiter des Farbfernseh-Versuchsstudios beim WDR, Dr. Franz-Josef In der Smitten. 


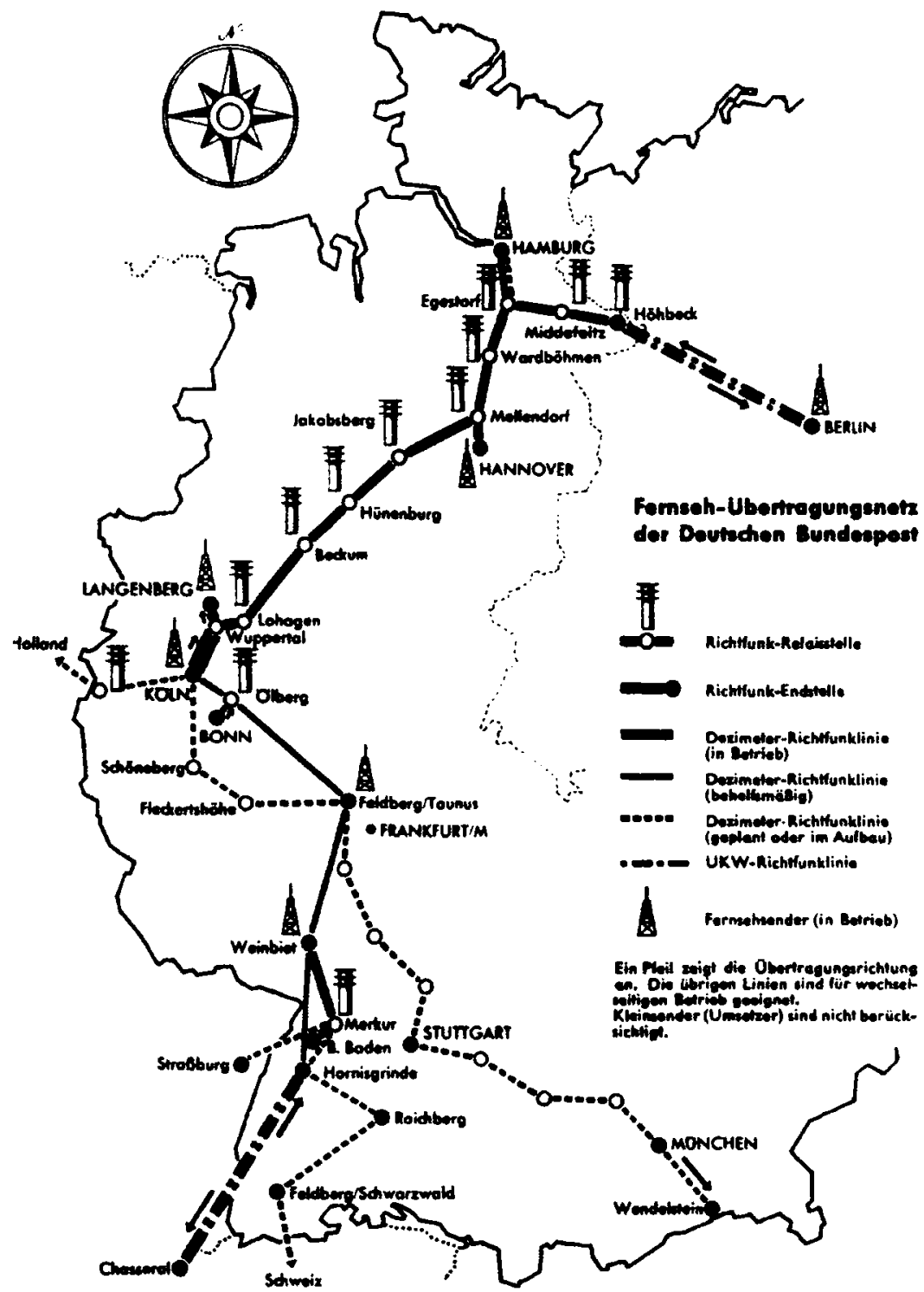

Abb. 11: Fernsehübertragungsnetz der DBP, aus: HICKETHIER, Geschichte des deutschen Fernsehens, $S .78$.

nem Memorandum mit dem Titel »Zur gegenwärtigen technischen Situation des deutschen Rundfunks« vom November 1960 stellte der Technische Direktor des NDR, Dr. Hans Rindfleisch, fest: 
Der Versorgungsbereich eines Senders reicht also noch sehr weit über den Horizont hinaus. An einer Reihe wichtiger Standorte wurden daher extrem hohe Masten errichtet, so z.B. ein 300 m-Mast in Hamburg und ein $250 \mathrm{~m}$-Mast bei Torfhaus (Harz) in unmittelbarer Nähe der Zonengrenze. Diese für einen Bergsender ungewöhnliche Masthöhe wurde gewählt, um über den Brokken hinweg weit in das Gebiet der sowjetischen Zone wirken zu können. [...] Die Forderung nach einer möglichst weit in die SBZ reichende Wirkung war von Anfang an einer der maßgebenden Gesichtspunkte für die Planung der Fernsehsender in der Bundesrepublik ${ }^{75}$.

Insgesamt waren acht Sender in der Bundesrepublik in den Wellenbändern I, III, IV und V darauf ausgerichtet, ihre Senderreichweite so weit wie möglich in die DDR auszudehnen ${ }^{76}$. Die DDR verfolgte dieselbe Politik. Von ihr aus strahlten die vier Band III-Sender Katzenstein, Inselsberg, Brocken und Schwerin sowie der Band IV-Sender in Dequede in Richtung Bundesrepublik. Hinzu kam der Sender Berlin-Ost, der selbstverständlich auch Westberlin abdeckte. Rindfleisch schätzte, daß etwa 60 bis $70 \%$ der Bevölkerung in der Sowjetzone das Erste Fernsehprogramm empfangen könnten, während in der Bundesrepublik etwa 30 bis 35\% »im Wirkungsbereich der sowjetzonalen Fernsehsender « lebten ${ }^{77}$. Da mit zunehmender Wellenlänge auch deren Reichweite sinkt, kam Rindfleisch zu dem Urteil, daß für die zukünftigen Sender in den Bändern IV und V (Dezimeterwellen-Bereich) - also auch für den zukünftigen Sendebereich des Farbfernsehens - selbst bei größerer Senderleistung (500 bis $1000 \mathrm{~kW}$ ) keine weitere Ausdehnung des Empfangsbereichs in der Sowjetzone zu erwarten sei:

Kein weiteres Fernsehsendernetz wird daher so weit in die Sowjetzone hineinreichen können wie das bereits bestehende Sendernetz für das Erste Fernsehprogramm in den Bändern I und III. Vergleicht man die bisher bekanntgewordenen Planungen der Bundespost mit denen der Rundfunkanstalten für je ein weiteres Sendernetz in Band IV/N, so ist festzustellen, daB das Sendernetz der ARD, die sich schon vor Jahren die besten Standorte auswählen konnte, eindeutig überlegen ist $^{78}$.

75 Hans RundFLeISCH: "Zur gegenwärtigen technischen Situation des deutschen Rundfunks«, Hamburg, 26. November 1960, in: Historisches Archiv des WDR, Signatur 05534, 10 maschinegeschriebene Seiten, hier S. 5 f. und S. 8.

76 Es handelte sich um die Senderstandorte Ochsenknopf (BR), Kreuzberg (BR), Hoher Meissner (HR), Harz West (NDR) und Hamburg (NDR). In den Bändern IV und V kamen Bungsberg (NDR) und Dannenberg (NDR) hinzu. Natürlich muß hier auch der Sender des SFB hinzu gerechnet werden, der naturgemäß den besten Wirkungsbereich hatte.

77 RINDFLEISCH, "Zur gegenwärtigen technischen Situation des deutschen Rundfunks«, Hamburg, 26. November 1960, in: Historisches Archiv des WDR, Signatur 05534, 10 maschinegeschriebene Seiten, hier S. 9.

${ }^{78}$ Ibid. S. 10. Sicherlich spielt Rindfleisch in seinem letzten Satz auf die Planungen zur Gründung des Zweiten Deutschen Fernsehens (ZDF) an, nachdem Bundesinnenminister Gerhard Schröder am 3. Juni 1959 ein Bundesrundfunkgesetz angekündigt hatte, das den Aufbau eines zweiten Fernsehprogramms auf bundesstaatlicher Ebene regeln sollte. Bis zur Unterzeichnung des Staatsvertrags zur Gründung des ZDF durch die Ministerpräsidenten der bundesdeutschen Länder sollten aber noch zwei Jahre vergehen (6.6.1961). 
Bis Ende 1958 war der Ausbau des westdeutschen Sendernetzes weitgehend abgeschlossen. 1960 existierten in der Bundesrepublik 31 Fernsehsender und über 200 Umsetzer (automatisch arbeitende Kleinsender), davon arbeiteten 13 Sender bereits in den Bändern IV und V, um die aus dem Stockholmer Wellenplan übriggebliebenen Versorgungslücken zu schließen. Nachdem auf der IX. Vollversammlung der CCIR in Los Angeles 1959 die Weichen für die Harmonisierung der Zeilennorm für den Fernsehrundfunk in den Bändern IV und V gestellt worden waren (625 Zeilen), machte man sich auch in der Bundesrepublik daran, einen neuen Frequenzplan für den Fernsehbetrieb auszuarbeiten. Die Übertragung der Entscheidungen von Los Angeles auf die BRD ergab, daß die 40 Kanäle, die nunmehr in den Bändern IV und V zur Verfügung standen, ausreichten, um die vollständige Versorgung der BRD mit zwei weiteren Fernsehprogrammen sowie der Schließung der Versorgungslücken des Ersten Programms sicherzustellen.

Waren damit die Weichen für den weiteren Ausbau des Fernsehrundfunks in der Bundesrepublik aus frequenzplanerischer Sicht gestellt, rückte nun auch für die Landesrundfunkanstalten ein bislang marginales Thema in den Vordergrund: das Thema Farbfernsehen. Zwar besaß der Ausbau des s/w-Programms im Rahmen des Gründung des ZDF sowie der »Dritten Programme « weiterhin oberste Priorität, doch sorgten die internationale Diskussion um die zukünftige europäische Farbfernsehnorm sowie die praktische Einführung des Farbfernsehens in den USA und Japan zunehmend für Aufmerksamkeit. In einem Brief vom 19. Juni 1961 an den Intendanten des WDR, Klaus von Bismarck, brachte der Staatssekretär im Nordrhein-Westfälischen Ministerium für Wirtschaft und Verkehr, Prof. Leo Brandt, seine Überlegungen diesbezüglich wie folgt zum Ausdruck:

Die Notwendigkeit, das Schwarz-Weiß-Fernsehen mit seinem 1., 2. und 3. Programm in Deutschland auszubauen, würde vielleicht nahelegen, die Arbeit auf diesem Gebiet [des Farbfernsehens, A.d.V.] terminlich nicht so sehr zu forcieren. Andererseits sind die Nachrichten aus den USA, England, UdSSR und Ostdeutschland doch so eindeutig, daß man mit einer baldigen breiten Einführung des Farbfernsehens in diesen Ländern rechnen muB, und deshalb der Wunsch begründet erscheint, daB auch in Deutschland eine Initiative in nicht zu ferner Zukunft ergriffen wird $^{79}$.

Konkret schlug Brandt vor, den WDR, der in seinen Augen seinen technischen Fortschritt auf dem Fernseh-Gebiet an[strebe] und [sich] zu einer gewissen Pionierrolle verpflichtet [fühle]«, mit vergleichenden Untersuchungen auf dem Gebiet der Farbfernsehtechnik zu betrauen. Statt lediglich die amerikanische Technik zu kopieren bestünde gerade in der Möglichkeit einer vergleichenden Beurteilung der bislang in der Diskussion befindlichen Systeme

79 Brief von Staatssekretär Leo Brandt an den Intendanten des WDR, Klaus von Bismarck, Düsseldorf, 19. Juni 1961, in: Historisches Archiv des WDR, Signatur 526, 4 maschinegeschriebene Seiten, hier S. $3 f$. 
(NTSC, SECAM und FAM) die Chance, einen eigenen Beitrag zur qualitativen Verbesserung des Farbfernsehen zu leisten: »Ich bin sicher«, so Brandt weiter, »daß Einrichtungen, die in deutschen Laboratorien entstehen, entsprechend der Tatsache der höheren Bildqualität des Schwarz-Weiß-Fernsehens auch weit bessere Übertragungen beim Farbfernsehen ergeben werden; sicherlich besser als dasjenige, was heute in den USA akzeptiert wird ${ }^{80}$.

Brandts Vertrauen in die Überlegenheit deutscher Technik wurde von Fernsehexperten wie Fritz Schröter oder Richard Theile differenzierter beurteilt, da sie sich des Verlustes früherer "Größe« der deutschen Fernsehtechnik bewußt waren. Dagegen teilten sie Brandts Einschätzung, daß man in der Bundesrepublik nun dringend an die technisch-wissenschaftliche Erprobung des Farbfernsehens gehen müsse, wolle man nicht ganz ins fernsehtechnische Abseits fallen. »Obwohl seit Jahren in unserem Institut für Rundfunktechnik (IRT) in München, in Laboratorien der Bundespost, der Industrie und in Hochschulen an den Problemen des Farbfernsehens gearbeitet wird«, so Prof. Theile in einem Erfahrungsbericht, "sind wir dem Ausland gegenüber im Rückstand ${ }^{81}$. Um diesen Rückstand aufzuholen sei es dringend notwendig, $\mathrm{da} B$ in der Bundesrepublik so bald wie möglich mit Farbfernsehversuchssendungen innerhalb der Testbild-Sendezeit begonnen werde. Zwar seien die Sender und Richtfunkstrecken der Deutschen Bundespost bereits prinzipiell "farbfernsehtauglich «, jedoch könnten wichtige Erfahrungen im Bereich der Meß- und Justierarbeiten erst in der Praxis gewonnen werden. Außerdem, so Theile weiter, seien Versuchssendungen dringend notwendig, weil erst hierdurch die Mitarbeit der Industrie ermöglicht werde: »FarbfernsehempfängerEntwicklung braucht Sendungen ${ }^{82}$ ! Im Namen der Technischen Direktoren der ARD bat Theile darum dringend um einen entsprechenden Beschluß seitens der Intendanten sowie des Bundespostministeriums.

Brandts Initiative, die u. a. die Gründung einer Arbeitskommission »Farbfernsehen« vorsah, sowie die Äußerungen des IRT-Chefs Theile trafen bei den Direktoren des WDR auf offene Ohren. Der Aufbau eines FarbfernsehVersuchs-studios beim WDR schien ihnen der richtige Weg zu sein, um die Vielzahl der anfallenden programmtechnischen Probleme rechtzeitig studieren zu können. In einem Schreiben an den Intendanten des WDR, Klaus von Bismarck, wies die Technische Direktion des WDR jedoch darauf hin, daß in der Funkbetriebskommission bereits seit längerem ein Unterausschuß »Farbfernsehen« existiere. Die Funkbetriebskommission der Bundesrepublik, beauftragt mit der Regelung nachrichtentechnischer Fragen wie beispielsweise

80 Ibid. S. 2.

81 Memorandum von Prof. Richard Theile, betr. „Farbfernseh-Versuchssendungen«, München, 19. Januar 1962, in: Historisches Archiv des WDR, Protokolle der Technischen Direktion 1961-1964, Signatur 526, 3 maschinegeschriebene Seiten, hier S. 1.

82 Ibid. S. 2. 
der Zuweisung von Sendefrequenzen, unterhielt als ständigen Ausschuß einen »Fernsehausschuß«, dem Vertreter der ARD, des IRT, der Bundespost, der Rundfunkindustrie sowie des ZVEI angehörten. Der bereits erwähnte Unterausschuß »Farbfernsehen « wurde von Prof. Kirschstein (TU Braunschweig) geleitet. Ihm gehörte neben Walter Bruch (Telefunken) als Vertreter der Rundfunkindustrie auch Prof. Richard Theile (IRT) an. Auch der Zentralverband der Deutschen Elektroindustrie (ZVEI) hatte in seiner Technischen Kommission einen Unterausschuß »Farbfernsehen « gebildet, dessen Vorsitz Walter Bruch hatte. Da diese beiden Ausschüsse bereits existierten und die Diskussion der technischen Probleme des Farbfernsehens so in kompetenten Händen waren, schien die Gründung eines weiteren Ausschusses aus der Perspektive der Technischen Direktion des WDR vorerst nicht notwendig ${ }^{83}$.

Schienen die Überlegungen der Technischen Direktion aus Gründen der Arbeitsökonomie vernünftig, kam es Anfang Juli 1962 dennoch zur Gründung eines weiteren Farbfernsehausschusses, der unter dem Terminus »Dreierausschuß $\ll$ in die Geschichte einging. Dieser $» D r e i e r a u s s c h u ß \ll$, bestehend aus Prof. Theile als dem Vertreter der ARD, Walter Bruch als Vertreter der Industrie und Oberpostrat Dr. Johannes Müller vom Fernsehtechnischen Zentralamt (FTZ) als Vertreter der Bundespost, hatte die Aufgabe, die nunmehr anstehenden Farbfernsehversuchssendungen zwischen Bundespost, Landesrundfunkanstalten und Rundfunkindustrie zu koordinieren.

Dieses »Triumvirat ohne Kompetenzen, aber mit beträchtlichem Einfluß ${ }^{84}$, so die Worte des Funkschau-Chefredakteurs Karl Tetzner, wurde in der Folgezeit zur organisatorischen Achse der Farbfernsehplanungen in der Bundesrepublik. Auch wenn ihre jeweiligen Kompetenzen auf bundesrepublikanische Institutionen beschränkt waren, reichte ihr Einfluß, wie zu zeigen sein wird, weit über den nationalen Rahmen hinaus.

Nach der Gründung des Dreierausschusses, die während einer Besprechung am 3. Juli 1962 im Bundespostministerium beschlossen worden war, wurde folgendes Pressecommuniqué veröffentlicht, das die Öffentlichkeit über die anstehenden Farbfernsehversuchssendungen informieren sollte:

Auf dem Gebiet des Farbfernsehens wird in der BRD, wie auch in anderen Ländern, seit Jahren intensiv gearbeitet. Die bisherigen Laborarbeiten müssen nun durch versuchsweise Ausstrahlung

83 „Nach der Klärung aller technischen und programmlichen Probleme wird es in zwei bis drei Jahren wahrscheinlich zweckmäßig sein, einen technisch-politischen Ausschuß zwischen den Partnern Bundespost/Rundfunk/Industrie auf höchster Ebene zu gründen, um den Zeitpunkt der offiziellen Einführung des Farbfernsehens vom rundfunkpolitischen und wirtschaftlichen Standpunkt aus zu beraten «. Brief von Schulz, Technische Direktion des WDR, an den Intendanten Klaus von Bismarck, Köln, 2. Februar 1962, in: Historisches Archiv des WDR, Protokolle der Technischen Direktion 1961-1964, Signatur 526, 3 maschinegeschrieben Seiten, hier S. 3.

84 TetZnER, Die Farbe im Fernsehen, S. 117. 


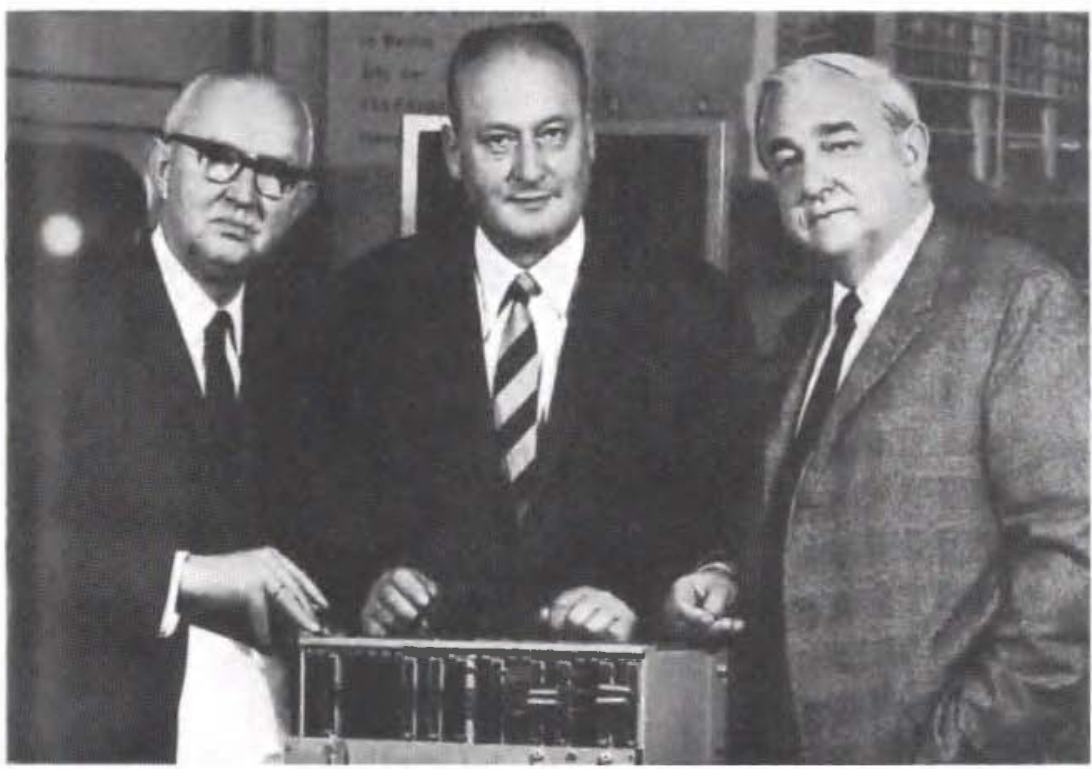

Abb. 12: Der Dreierausschuß (das „Triumvirat «) der deutschen Farbfernsehtechnik, v.l.n.r.: Johannes Müller (Deutsche Bundespost), Walter Bruch (Telefunken), Richard Theile (Institut für Rundfunktechnik, ARD), aus: Archiv des Deutschen Museums, Nachlaß Walter Bruch, Signatur NL 101, Nr. 123.

von farbigen Testbildern erweitert werden und ergänzt werden. Ziel ist die Erreichung einer gemeinsamen europäischen Norm. Die Versuchssendungen sind nicht für die Öffentlichkeit bestimmt. Zur Vorbereitung dieser Versuche und weiterer gemeinsamer Arbeiten sind Experten der Deutschen Bundespost, der ARD und der Rundfunkindustrie am 3. Juli 1962 im Bundespostministerium zu einer Besprechung zusammengekommen. Ein Zeitpunkt für die Aufnahmè eines farbigen Fernsehprogramms kann heute noch nicht festgelegt werden. Auch bei Einsatz aller Mittel der beteiligten Stellen, Rundfunkanstalten, Bundespost und Industrie, wird es noch einige Jahre dauern, bis wir ein Farb-Fernsehprogramm haben werden ${ }^{85}$.

Wie ist diese Beschleunigung der Aktivitäten in der Bundesrepublik zu erklären? Ausschlaggebend für diesen Aktionismus war eine Zwischentagung der XI. Studienkommission (Fernsehen) des CCIR, die vom 13. bis 29. Juni 1962 in Bad Kreuznach stattgefunden hatte ${ }^{86}$. Auf dieser Tagung konnten unter anderem dank der Unterstützung von Telefunken überzeugende Vorführungen des französischen SECAM-Verfahrens realisiert werden, die in der Folge dazu fuihren sollten, das SECAM-System als echte europäische Alternative

85 "Ereignisniederschrift über die Besprechung über die Aufnahme von Farbfernsehversuchssendungen am 3. Juli 1962 im BPM «, in: Historisches Archiv des WDR, Protokolle der Technischen Direktion 1961-1964, Signnatur 526, 3 mảschinegesschriebène Seiten, S. 3.

${ }^{86}$ Hans Rindfleisch, Zwischentagung des CCIR in Bad Kreuznach in der Zeit vom 13. bis 29. Juni 1962, in: Rundfunktechnische Mitteilungen 6 (1962) S. 219. 
zum amerikanischen NTSC-System im Rahmen der CCIR-Studien anzuerkennen und somit die endgültige Entscheidung über einen Farbfernsehstandard weiter aufzuschieben ${ }^{87}$. Da Walter Bruch, wie in Kap. 2.5. geschildert, zu dieser Zeit bereits ernsthaft an der Entwicklung einer eigenen Farbfernsehübertragungsvariante beschäftigt war, verwundert es nicht, daß Bruchs Vorgesetzter, Telefunken-Vorstandsmitglied Prof. Werner Nestel, sich bereits kurz nach Ablauf der Tagung in Bad Kreuznach an den Verwaltungsratsvorsitzenden des WDR, den Nordrhein-Westfälischen Innenminister Josef Dufhues wandte. In diesem Brief sprach Nestel die Bitte aus, »in Deutschland nicht nur einfach das amerikanische Farbfernsehsystem zur Einführung zu bringen, sondern ein sorgfältiges Versuchsprogramm aufzustellen, in dem die über das amerikanische System hinausgehenden Verbesserungsvorschläge geprüft werden und ihre praktische Verwendbarkeit ermittelt wird ${ }^{88}$.

Die Tagung in Bad Kreuznach habe gezeigt, so Nestel, daß man in Europa durchaus bereit sei, nach Alternativen zum amerikanischen NTSC-System zu suchen. Ein wenig pathetisch forderte Nestel:

Hieraus ergibt sich nun eine Aufgabe, der für die Zukunft des Farbfernsehens verantwortlichen Stellen in Deutschland, sich an der Klärung dieser Fragen aktiv zu beteiligen, um an die Tradition der Pionierrolle Deutschlands aus früherer Zeit wieder anzuknüpfen. [...] Ich glaube, Sie würden für die deutsche Forschung und Entwicklung eine sehr starke Förderung erreichen können, wenn Sie eine deutsche Beteiligung an diesen Aufgaben veranlassen könnten ${ }^{89}$.

Während Werner Nestel aus verständlichen Gründen für die Förderung der deutschen Farbfernsehtechnik warb, die de facto ja eine reine TelefunkenAktivität war, stand die deutsche Rundfunkindustrie dem Thema Farbfernsehen 1962 noch mehrheitlich zurückhaltend bis feindlich gegenüber. Die »Erweckung frühzeitiger Erwartungen«, so die Befürchtung, könne »eine Absatzstörung für die Schwarz-Weiß-Empfänger « erzeugen ${ }^{90}$. Das klassische

87 Laut Aufzeichnungen von Walter Bruch zeigte sich der Vorsitzende der Studienkommission XI des CCIR, der Schwede Erik Esping, beeindruckt von den Verbesserungen des SECAM-Systems. »Gemeinsame Auffassung in Bad Kreuznach: nicht endgültige Norm festzulegen, da die neuesten Untersuchungen bei CFT und Telefunken gezeigt haben, daB es auch noch Verbesserungsmöglichkeiten für NTSC gibt. [...] Dies soll nun nicht etwa heißen, daß das SECAM-System augenblicklich ein emster Konkurrent des NTSC-Systems ist, es bedeutet vielmehr, daB dieses System jetzt technisch so weit gediehen ist, daß es sich für die einzelnen Nationen lohnt, sich näher damit zu beschäftigen. « Siehe die Aufzeichnungen von Bruch über Beziehungen Telefunken/CFT, 28 maschinegeschriebene Seiten, in: Archiv des Deutschen Museums München, NachlaB Walter Bruch, Signatur NL 101, Nr. 202, hier S. 14 und 15.

${ }^{88}$ Brief von Werner Nestel an Innenminister Josef Dufhues, Ulm, 18. Juli 1962, 2 maschinengeschriebene Seiten, in: Historisches Archiv des WDR, Protokolle der Technischen Direktion 1961-1964, Signatur 526, hier S. 1.

89 Ibid. S. 1 und S. 2.

90 Siehe das Memorandum von Dr. Rindfleisch und Prof. Theile: "Technische Vorbereitungen für das Farbfernsehen«, Hamburg, München, 17. September 1962, in: Historisches Archiv des WDR, Signatur 526. 
»Sättigungsgrad-Argument « findet sich immer wieder in der Begründungsrhetorik des ZVEI. Aber auch von seiten der Programmacher wurde das Farbfernsehen sehr kritisch beäugt. Der Fernsehdirektor des Bayerischen Rundfunks, Dr. Clemens Münster, wandte sich im Dezember 1962 in einem Schreiben besorgt an seinen WDR-Kollegen, Klaus von Bismarck:

Ich habe den Eindruck, daß wir in der Weiterentwicklung der Fernsehtechnik einen falschen Weg gehen. Wichtiger als die Verbesserung des Farbfernsehens scheint mir die Verbesserung der Qualität des Schwarz-Weiß-Bildes zu sein, abgesehen davon, daß die Entwicklung des Farbfernsehens sich einem finanziellen Obligo nähert, dem wir kaum gewachsen sein werden. Ich habe dabei natürlich nicht im Auge, das Farbfernsehen zu verhindern, obwohl es meiner Meinung nach wertlos ist. Aber ich meine, man sollte die Entwicklung bremsen, statt sie zu för$\operatorname{dern}^{91}$.

Mit dieser Meinung stand Münster nicht alleine da. Für viele Fernsehfilmregisseure war der ästhetische Gewinn der Farbe im Fernsehen sehr umstritten. Aber Klaus von Bismarck beschwichtigte: Beim WDR sei keineswegs ein "Farbfernseh-Euphorismus « ausgebrochen, versichert er Münster, man habe lediglich der Technik grünes Licht gegeben, »um die Entwicklung zu verfolgen und parat zu sein, wenn für bestimmte Teile unseres Fernsehprogramms Experimente mit Farben ratsam scheinen ${ }^{92}$. Das grüne Licht bedeutete immerhin, daß der Verwaltungsrat des WDR die Einrichtung eines Farbfernsehversuchsstudios im Haushalt des Jahres 1962 eingeplant hatte. De facto beliefen sich die Ausgaben auf $960000 \mathrm{DM}$, mittels derer eine elektronische Farbfernsehkamera, ein 35 mm Farbfilmabtaster, eine Farbdiaübertragungsanlage, diverse Farbfernsehempfänger und -monitore sowie zentrale Versorgungs- und Meßgeräte angeschafft wurden ${ }^{93}$. Mit diesen Einrichtungen waren erste Untersuchungen im Bereich der Farbfernsehstudiotechnik möglich, insbesondere die Klärung von Ausleuchtungsfragen, Farbfragen beim Kulissenbau und bei der Schminktechnik. Das Fernfernsehversuchsstudio des WDR unter der Leitung von Dr. Franz-Josef In der Smitten entwikkelte sich in den folgenden Jahren zur zentralen Anlaufstelle aller technischen Fragen im Bereich der Farbfernsehstudiotechnik für die bundesdeutschen Rundfunkanstalten. Ab Januar 1964 wurden von hier aus alle Farbversuchssendungen für das Sendernetz der ARD und der Deutschen Bundespost realisiert.

91 Brief von Dr. Clemens Münster an Klaus von Bismarck, München, 6. Dezember 1962, in: Historisches Archiv des WDR, Protokolle der Technischen Direktion 1961-1964, Signatur 526.

92 Brief von Klaus von Bismarck an Clemens Münster, Köln, 17. Dezember 1962, in: Historisches Archiv des WDR, Protokolle der Technischen Direktion 1961-1964, Signatur 526.

93 Siehe $»$ Referat des Intendanten in der gemeinsamen Sitzung der Gremien des Westdeutschen Rundfunks am 17. Dezember 1965 zum Thema Farbfernsehen«, in: Historisches Archiv des WDR, Intendanz 432/Korrespondenz UER - Technische Kommission ARD, Signatur 411. 


\subsubsection{Walter Bruch und Telefunken:}

die zentralen Industrieakteure der PAL-Entwicklung

Hatte der WDR mit der Gründung des Farbfernsehversuchsstudios eine wichtige technische Voraussetzung für die praktische Erprobung des Farbfernsehens getroffen, wurde das Thema Farbfernsehen auch im Rahmen der EBU und der CCIR immer intensiver diskutiert. Einen entscheidenden Schub erhielt diese Debatte während einer Farbfernsehtagung der EBU, die vom 19. bis 21. November 1962 in London stattfand. Über vierzig Fernsehexperten aus den sechs europäischen Ländern, in denen bereits gewisse Vorleistungen im Bereich der Farbfernsehtechnik erbracht worden waren ${ }^{94}$, diskutierten über die Möglichkeiten einer gemeinsamen europäischen Norm im Bereich des Farbfernsehens. Man stellte sich das ehrgeizige Ziel, innerhalb eines Jahres zu einer gemeinsamen Empfehlung über die europäischen Farbfernsehnormen zu gelangen. Um dieses Ziel zu erreichen, wurde die Gründung einer "ad-hoc-Kommission Farbfernsehen « beschlossen, deren Vorsitz Prof. Theile vom IRT anvertraut wurde. Mit der Gründung des »ad-hoc-committee on colour television « begann die "heiße Phase « des technischen Systemvergleichs. Wie der Technische Direktor des NDR, Dr. Hans Rindfleisch, zwei Tage nach seiner Rückkehr aus London berichtete, sollten Untergruppen in gemeinsamer Arbeit die noch offenen Fragen des Systemvergleichs - nach Sachgebieten aufgeteilt - klären. Zu diesen Sachgebieten zählten: allgemeine Fragen, Empfänger, Ausbreitung, Strahleranlagen, Leitungen (inkl. internationale Verbindungen) und Studioanlagen. Interessant an Rindfleischs Bericht ist weniger die genaue Auflistung der Arbeitsfelder der Kommission, sondern der Schluß seines Berichtes, in dem die zu vergleichenden Übertragungssysteme genannt werden. Dort heißt es: "Zur Diskussion stehen zur Zeit zwei Normenvorschläge, eine auf die europäische Zeilenzahl abgewandelte Version der amerikanischen NTSC-Norm und eine in Frankreich unter dem Namen SECAM entwickelte Variante dieses Verfahrens. Unter Umständen wird auch noch eine weitere Variante in den Kreis der Prüfung einbezogen werden. Die nächste Sitzung der ad-hoc-Kommission soll bereits Anfang Januar in Hannover stattfinden ${ }^{95}$.

Es ist erstaunlich, daß Rindfleisch in diesem Bericht vom November 1962 indirekt bereits das PAL-Verfahren als möglichen dritten Kandidaten im Bunde ankündigt, obwohl die erste öffentliche PAL-Vorführung erst zwei Monate später, am 3. Januar 1963, von Walter Bruch bei Telefunken in Hannover realisiert werden sollte. Zwar können hier nur Vermutungen darüber angestellt werden, warum die erste Tagung der ad-hoc-Kommission aus-

94 Es handelte sich um Großbritannien, Frankreich, die Bundesrepublik Deutschland, Italien, die Niederlande und die Schweiz.

95 Dr. Hans Rindfleisch: »Farbfernseh-Tagung der UER in London«, Hamburg, 23. November 1962, in: Historisches Archiv des WDR, Protokolle der Technischen Direktion, Signatur 526. 
gerechnet im Grundlagenlabor von Telefunken in Hannover stattfand, doch scheint dies alles nicht so zufällig gewesen zu sein, wie es später veröffentliche Bekundungen glauben machen. Schließlich war Walter Bruch auf Empfehlung von Hans Rindfleisch als Mitglied der ad-hoc-Kommission bestimmt worden, und Richard Theile als Vorsitzender der Kommission hatte der Einladung von Telefunken sicherlich nichts entgegenzusetzen. In einem Brief vom 3. Mai 1963 berichtet Bruch dem Telefunken Vorstandsmitglied Nowack über die erfolgreichen PAL-Experimente, die so großzügig von der Bundespost und vom IRT unterstützt worden seien. Bruch schreibt:

[Es war] nämlich Herr Dr. Rindfleisch, der veranlaßt hatte, daB ich als deutscher Industrievertreter in die Ad Hoc-Gruppe Farbfernsehen, in die Empfängergruppe Farbfernsehen und in die Studiengruppe für Systeme berufen wurde. Keine andere Firma in einem anderen Land hat einen Vertreter in so vielen Gruppen. Das Wohlwollen der Technischen Direktoren und der technischen Seite des Rundfunks steht in einem solchen Maße auf unserer Seite, wie es keine andere Firma hat ${ }^{96}$.

Diese Aussage Bruchs ist in mehrfacher Hinsicht von zentraler Wichtigkeit. Sie macht deutlich, welche Bedeutung der Besetzung entscheidender Positionen im Rahmen der technischen Diskussion um den zukünftigen europäischen Farbfernsehstandard zukam. Bruch selbst hat alle entscheidenden Schnittstellen im Netzwerk der nationalen und internationalen Normendiskussion besetzt. In Deutschland war er Leiter der Farbfernseh-Studiengruppe des ZVEI und Mitglied des »Dreierausschusses« von Bundespost, Rundfunkanstalten und Rundfunkindustrie. Als Vertreter der deutschen Rundfunkindustrie in der ad-hoc-Kommission der EBU kam schließlich das international wichtigste Entscheidungsgremium hinzu. In diesem Netzwerk, so wird sich zeigen, lernte Bruch im Laufe der Zeit ganz gezielt seine Macht in Form von Wissensvorsprung oder Informiertheit einzusetzen und zum Vorteil seiner Firma zu nutzen.

Doch erst einmal galt es, die Schwierigkeiten im eigenen Hause zu überwinden. Wie bereits erwähnt, hatten Umstrukturierungen im Hause Telefunken dazu geführt, daß Bruch die Leitung des Grundlagenlaboratoriums entzogen und ihm statt dessen die Leitung des Fernsehlabors mit einem reduzierten Mitarbeiterstamm übertragen worden war. Als sich Bruchs PAL-Vorführungen während der ersten Sitzungen der ad-hoc-Kommission immer gröBerer Zustimmung erfreuten, sah sich dieser aber nicht mehr in der Lage, die steigenden wissenschaftlich-technischen Anforderungen mit dieser "geschrumpften« Mannschaft zu bewältigen. Damit man anderenorts auch mit PAL experimentieren könne, so Bruch, würden zunehmend Bitten um tech-

96 Brief von Bruch an Nowack, 3. Mai 1963, in: Archiv des Deutschen Museums München, Nachlaß Walter Bruch, Signatur NL 101, Nr. 202. 


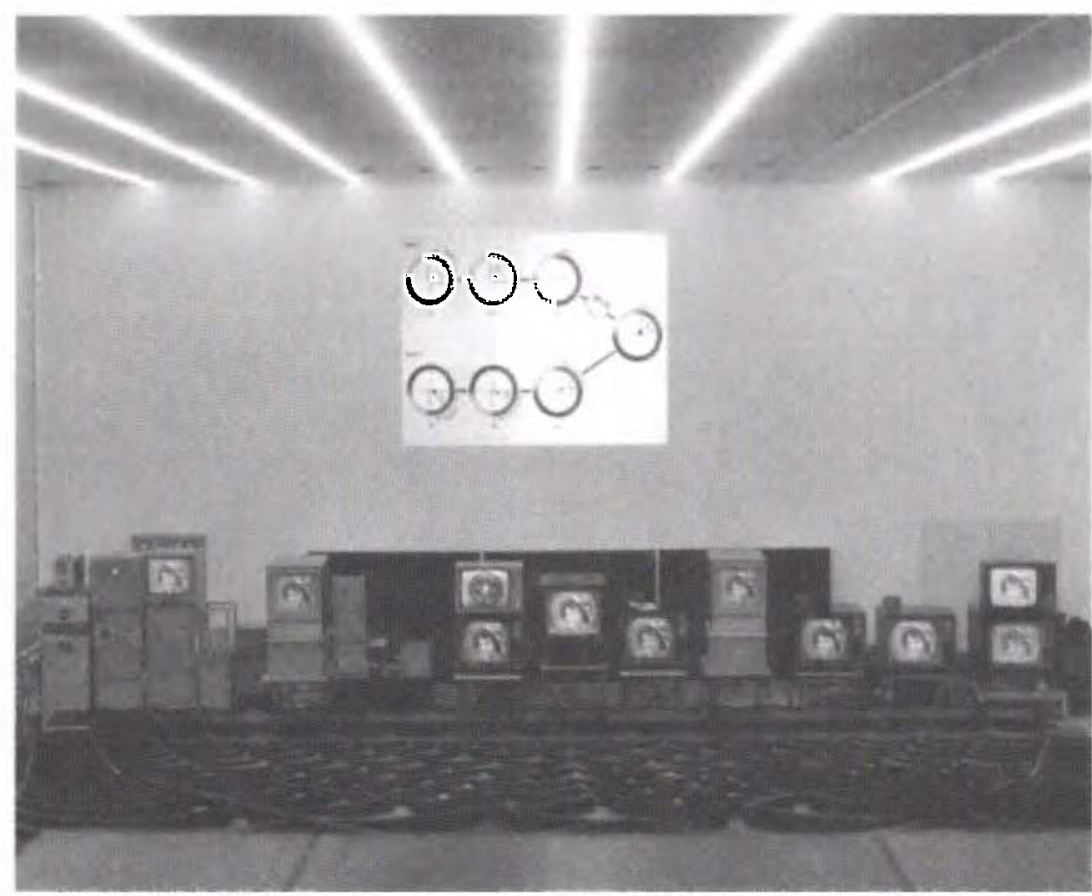

Abb. 13: PAL Demonstrationsaufbau, aus: Archiv des Deutschen Museums München, Nachlaß Walter. Bruch, Signatur. NL 101, Nr. 259.

nische Assistenz an ihn gerichtet, die er im Rahmen seiner jetzigen Möglichkeiten jedoch nicht realisieren könne. In einem Brief an den Bereichsvorstand erklärte Bruch: »Wie man [...] ersieht, hat das PAL-System eine große Resonanz gefunden und selbst wenn es nicht angenommen wird, ist die Firma Telefunken durch diese Arbeiten international weit in den Vordergrund gerückt. Auf der anderen Seite weiß ich nicht, wie ich mit meinem um neun Menschen verkleinerten Labor und dem vorgesehenen Betrag für Investitionen eine solch große Aufgabe bearbeiten kann ${ }^{97}$.

Bruchs Sorgen waren nicht unberechtigt. Schon während der ersten Tagungen der EBU ad-hoc-Kommission in Brüssel und Paris vom 21. bis 30. März 1963 war offiziell beschlossen worden, das PAL-System als dritte Systemalternative in die vergleichenden Untersuchungen aufzunehmen. Dies war mit der Bitte an Telefunken verbunden, Decoder und Encoder sowie entsprechende Schaltungen zur Verfügung zu stellen. Die großen Rundfunkanstalten wie die britische BBC, die italienische RAI oder die französische RTF waren dar-

97 Walter Bruch: »Zusammengefasster Bericht der EBU-Sitzungen vom 21.-30.3.1963 in Brtissel und Paris«, Hannover, 1. April 1963, in: Archiv des Deutschen Museums München, Signatur NL 101, Nr. 202. 
an interessiert, so schnell wie möglich Versuche mit dem PAL-System machen zu können.

Da die ad-hoc-Kommission das Ziel hatte, bereits gegen Ende des Jahres 1963 die vergleichenden Experimente soweit abzuschließen, daß man sich fachmännisch über die Wahl eines Systems unterhalten konnte, werden Bruchs Sorgen verständlich. Bereits am 8. März 1963 hatte Bruch daraufhin die Arbeitsziele seines Labors neu zu definieren gesucht. »Die Verkleinerung der Grundlagenentwicklung um neun Mitarbeiter im Verlauf des letzten Geschäftsjahres«, so Bruch in einem Brief an den neuen Leiter der Grundlagenentwicklung Bolle, »bedingt eine Beschränkung auf wenige Aufgaben, wenn das Labor Erfolg haben soll. [...] Es müssen daher alle Aufgaben, die nicht Farbfernsehen betreffen, vorläufig zurückgestellt werden, mit Ausnahme des Studiums der Fernseh-Stereophonie ${ }^{98}$. Anschließend entwarf Bruch das Arbeitsprogramm seines Fernsehlabors für die folgenden zwei Jahre. Folgende Punkte wurden aufgelistet: Weiterentwicklung des PAL-Systems und Hilfeleistung für Bundespost und IRT bei der Erstellung eigener PAL-Anlagen; Beteiligungen an den gemeinsamen deutschen und internationalen Farbfernsehversuchen; Mitarbeit an internationalen Ausschüssen für die FarbfernsehNorm (EBU); Bearbeitung von Patenten; USA-Reise zum Studium der neuesten Farbempfänger-Technik; Entwicklung eines NTSC-Empfängers und die Entwicklung eines PAL-Heimempfängers.

Glaubt man den Aussagen verschiedener Zeitzeugen ${ }^{99}$, war die schwierigste Hürde, die Bruch und "sein« PAL-System zu nehmen hatten, die Überzeugung des eigenen Arbeitgebers. Aus unternehmerischer Sicht war entscheidend, ob mit dem PAL-System überhaupt ein Geschäft zu erwarten war. Entscheidendes Kriterium zur Abschätzung dieser Frage war die Patentlage. Bereits im April 1963 richtete daher der Leiter der Forschungsabteilung, Prof. Werner Nestel, eine entsprechende Anfrage über die Patentabhängigkeit des PAL-Systems von den Grundlagenpatenten des NTSC-Systems an Walter Bruch. Bruch gab unmißverständlich zu erkennen, daB das PAL-System »in großen Zügen zunächst einmal von dem NTSC-System abhängig« sei. Doch, und dies ist eine interessante Deutung, sah Bruch in dieser Abhängigkeit keine Gefahr, sondern eher eine Chance für das PAL-System:

Es wäre wohl möglich, beim PAL-System durch eine abgeänderte Variante von diesen PhilcoPatenten freizukommen. Eine solche Entwicklung wäre aber gefährlich. Es besteht nämlich nur dann eine Chance für das PAL-System, wenn es mit möglichst geringfügiger Änderung vom NTSC-System her umgesetzt werden kann. [...] Sowohl das IRT, die Bundespost wie auch die Herren der BBC haben mich dringend davor gewarnt, vorläufig solch einschneidende Änderun-

98 Brief Bruch an Bolle, Hannover, 08.03. 1963, in: Archiv des Deutschen Museums München, Signatur NL 101, Nr. 202.

99 Dies geht aus den Interviews mit Felix Herriger, Robert Einsel, Franz Josef In der Smitten, Michael Hausdörffer und Heinwig Lang hervor. 
gen vorzuschlagen. Bei den Vorführungen hat gerade die einfache Umschaltung von NTSC auf PAL den größten Eindruck gemacht. Man muß daher alle diese Fragen zurückstellen, bis PAL noch mehr an Boden gewonnen hat und dann erst kann man vorsichtig versuchen, das PAL-System vom NTSC-Ballast zu befreien ${ }^{100}$.

Bruchs Einschätzung der Durchsetzungsfähigkeit von PAL zu dieser frühen Zeit des Systemvergleichs ist bemerkenswert und sollte sich als vollkommen richtig herausstellen. Auch die Abhängigkeit des PAL-Systems von den Grundpatenten des NTSC-Systems sah Bruch sehr gelassen: »Persönlich halte ich die Patentlage für absolut unwichtig; da das NTSC-System bereits 1953 genormt wurde, sind alle Basis-Ideen mindestens 10 Jahre alt. Bei einer Laufzeit von 17 Jahren sind diese Patente etwa 1970 erloschen und vor 1970 ist ein merklicher Umsatz an Farbfernseh-Geräten nicht zu erwarten « ${ }^{101}$.

Auch diese Einschätzung Bruchs ist bemerkenswert, waren zum Zeitpunkt dieser Aussage doch nicht weniger als 25 Philco-Patente und 17 HazeltinePatente im Bereich des NTSC-Systems als Farbfernsehpatente in der Bundesrepublik Deutschland angemeldet, deren Laufzeiten aber in der Tat meist um 1971 endeten $^{102}$. Stand der weiteren Entwicklung des PAL-Systems somit aus patentrechtlicher Situation bei Telefunken kein wesentlicher Hinderungsgrund im Wege, galt es in einem zweiten Schritt, die deutsche Rundfunkindustrie von den Vorteilen des PAL-Systems zu überzeugen.

Für die deutsche Rundfunkindustrie war die potentielle Mehrbelastung durch zusätzlich anfallende PAL-Lizenzforderungen ein entscheidendes Kriterium in der Bewertung der Systemfrage. Aus diesem Grunde bat der Fachausschuß Farbfernsehen des ZVEI den Patentanwalt von Telefunken auf einer Sitzung am 8. November 1963 in Hannover um eine Stellungnahme bezüglich der Patentlage auf dem Farbfernsehgebiet. Dr. Johannesson erläuterte, daß bei einem angenommenen Durchschnittsnettofakturenpreis für einen Farbfernsehempfänger im Jahre 1966 voraussichtlich eine Lizenzbelastung von $1,75 \%$ des Nettopreises alleine von den amerikanischen Patentrechten zu erwarten sei. Hinzu kämen einige Schutzrechte, die noch auf dem s/w-Empfänger lasteten, so daß mit einer Gesamtbelastung von $2,125 \% \mathrm{zu}$ rechnen sei. Im Falle der Benutzung von SECAM- oder PAL-Patenten sei mit einer Erhöhung der Gesamtlizenzgebühren auf ca. 3\% des Netto-Fakturenpreises

100 Brief von Walter Bruch an Werner Nestel, Betr.: "Philco-Schutzrechte auf dem Farbfernsehgebiet«, Hannover, 18.04.1963, in: Archiv des Deutschen Museums München, Signatur NL 101, Nr. 202.

101 Ibid.

102 Siehe die detaillierte Auflistung der Hazeltine- und Philco-Patente mit bundesdeutscher Patentnummer, Prioritätsanmeldedatum und Ablaufdatum in der Aktennotiz "RCA-Patente Farbfernsehen« vom 26. November 1963 (4 maschinegeschriebene Seiten) sowie der Aktennotiz »Hazeltine-Patente Farbfernsehen« vom 22. November 1963 (drei maschinegeschriebene Seiten) in: Archiv des Deutschen Museums München, Signatur NL 101, Nr. 175. 
zu rechnen ${ }^{103}$. Interessant ist, daB auf dieser Sitzung bereits das Thema einer eventuellen Patentabhängigkeit des PAL-Systems von SECAM-Schutzrechten angeschnitten wurde. Zwar verweigerte Johannesson eine Äußerung zu dieser Frage, da, wie es heißt, »Schutzrechte Dritter « betroffen seien, doch stellt er fest: "Zu beachten wird sein, daß es sich um zwei grundsätzlich verschiedene Lösungen handelt, nie kann aber sicher vorausgesehen werden, wie der Bundesgerichtshof den Schutzumfang eines Patentes endgültig festlegen wird. Sollte Abhängigkeit zwischen SECAM und PAL bestehen, so wäre es nicht ungünstig, wenn Telefunken mit verhältnismäßig niedrigen PAL-Gebühren beispielhaft vorangeht ${ }^{104}$.

Trotz dieser Versicherung von Johannesson stand die deutsche Rundfunkindustrie dem PAL-Verfahren in der Anfangszeit aus vornehmlich lizenzpolitischen Gründen feindlich gegenüber. So berichtete Dr. Hans Rindfleisch, Technischer Direktor des NDR, auf der 62. Tagung der Technischen Direktoren der ARD vom 4. bis 5. Mai 1963 in Köln über Meinungsverschiedenheiten zwischen der Empfängerindustrie und der Firma Telefunken in bezug auf die ZweckmäBigkeit des PAL-Systems, da die Netto-Produktionskosten für PAL angeblich 200 DM höher liegen würden als bei NTSC. »Der Sprecher des ZVEI «, so Rindfleisch weiter, "nannte als weiteres Argument für NTSC die Tatsache, daß dieses System allein in größerem Umfang erprobt sei ${ }^{105}$. Wie ernst man die Kritik des ZVEI am PAL-System nahm, zeigte sich unter anderem darin, daß der Leiter des IRT, Prof. Richard Theile, vorschlug, den "Dreierausschuß « von dieser Situation zu informieren und »bei dieser Gelegenheit auf eine Reorganisation des Ausschusses hinzuweisen«. Konkret sollte mit dieser »Reorganisation « die Forderung verbunden werden, daß »die Empfängerindustrie [...] zweckmäßigerweise durch Herm Boom in diesem AusschuB vertreten sein [sollte] ${ }^{106}$.

An dieser Stelle sei vorweggenommen, daß die von Theile vorgeschlagene personelle Umstrukturierung des »Dreierausschusses « nicht umgesetzt worden ist. Wie folgenreich diese für die Durchsetzungschancen des PAL-Systems in Deutschland gewesen wäre, ist leicht antizipierbar. Auch bei Telefunken war man sich der negativen Haltung des ZVEI gegenüber PAL bewuBt ${ }^{107}$. Um die deutsche Rundfunkindustrie dennoch für PAL zu gewinnen,

103 Siehe Aktennotiz Dr. Johannesson, betr.: "Sitzung ZVEI, Fachausschuß Farbfernsehen in Hannover am 8. 11.1963, in: Archiv des Deutschen Museums München, Signatur NL 101, Nr. 202.

104 Ibid.

105 Protokoll der 62. Tagung der Technischen Direktoren der ARD vom 3. bis 5. Mai 1963 in Köln, in: Historisches Archiv des WDR, Protokolle der Technischen Direktion 1961-1964.

106 Ibid.

107 Siehe $»$ Niederschrift über Besprechung am 17. Januar 1964 in Hannover über die derzeitige Situation auf dem Gebiet des Farbfernsehens", in dem Telefunken-Vorstandsmitglied Nowack über die »derzeit negative Haltung der deutschen Empfängerindustrie gegenüber PAL « berichtete, in: AEG-Telefunken Archiv, Deutsches Technikmuseum Berlin, Signatur GS 1749. 
mußte Telefunken in doppelter Weise aktiv werden. Zum einen mußte Telefunken die PAL-Lizenzgebühren für die anderen deutschen Fernsehgerätehersteller so niedrig halten, daß diese keine wesentliche Mehrbelastung für die Herstellerfirmen bedeutete. Zum anderen galt es, die deutsche Rundfunkindustrie von den internationalen Marktchancen des PAL-Systems zu überzeugen. Nur wenn ein größeres Exportgeschäft für PAL-Empfänger zu erwarten war, ließen sich zusätzliche Lizenzgebühren sowie der Mehraufwand an Investitionen in neuartiges Produktionswissen rechtfertigen.

Welchen Drahtseilakt diese Situation für die Person Walter Bruchs gleichermaßen als Vertreter der Firma Telefunken im »Unterausschuß Farbfernsehen « des Studienkreises 14 des ZVEI sowie als Sprecher der gesamten deutschen Rundfunkindustrie im "Dreierausschuß « und der EBU ad-hocKommission bedeutete, wird in einem Dokument aus dem Jahre 1967 deutlich, in dem Bruch über die Mitarbeit anderer deutscher Rundfunkunternehmen an der PAL-Entwicklung Rechenschaft ablegt. In diesem Dokument gibt Bruch unverhohlen zu, daß die Technische Kommission des ZVEI unter Leitung von Herrn Boom anfangs eindeutig "pro-NTSC « gewesen sei. Er versichert: »Als Vertreter der deutschen Industrie hatte ich diesen Standpunkt auch bei den Sitzungen der EBU zu vertreten«. Doch schon im nächsten Satz kommt die ambivalente Verhaltensweise Bruchs in dieser Frage deutlich zum Ausdruck: »Ich habe dort [in der ad-hoc-Kommission der EBU, A.d.V.] immer ganz deutlich meine eigene Meinung vertreten, indem ich mich leidenschaftlich für PAL eingesetzt habe, und dann aber namens der deutschen Industrie erklärt, daß diese in ihrer Mehrheit noch für NTSC ist aber wohlwollend PAL weiter prüft. In dieser Zeit haben sich nur die RAI und Dr. Bernath von der Schweizer PTT für PAL eingesetzt ${ }^{108}$. Die Entscheidung der deutschen Rundfunkindustrie für PAL sei letztlich aber aus rein wissenschaftlich-technischen Gesichtspunkten getroffen worden, so versicherte Bruch. Es sei doch »die selbstverständliche Pflicht eines jeden verantwortlichen Technikers « gewesen, so Bruch weiter, sich eingehend mit PAL zu beschäftigen: "Genau so, wie wir ständig das SECAM-System untersucht haben, obwohl meine Meinung als verantwortlicher Techniker längst für PAL war ${ }^{109}$ !

Es bedarf einiger Argumentationsakrobatik, den Bruchschen »Pflicht- und Verantwortungsbegriff« im Sinne einer wertneutralen Berufsethik oder einer wissenschaftlich-technischen Logik zu deuten. Dies wäre aber auch nicht sinnvoll. Vielmehr ist dieses Dokument ein deutlicher Beweis dafür, wie stark sich subjektive und objektive Kriterien bei der beruflichen Selbstdefinition vermischen können. Sicherlich darf man den zeitlichen und inhalt-

108 »Bericht von Bruch zur Frage der Mitarbeit von SEL bzw. Graetz bei PAL«, Hannover, 14.8. 1967, in: AEG-Telefunken Archiv, Deutsches Technikmuseum Berlin, Signatur GS 1648. 109 Ibid. 
lichen Kontext, in dem dieses Dokument entstanden ist, nicht vernachlässigen. Schließlich stand Bruch im August 1967 als "PAL-Vater « auf dem Höhepunkt seines gesellschaftlichen Ansehens, und die Frage nach dem Anteil anderer Firmen an der Durchsetzung oder Entwicklung von PAL hat ihn vielleicht in seinem Ehrgefühl verletzt, zumal damit die Frage nach der Erfindervergütung verbunden war. Diese Umstände machen sein leidenschaftliches Plädoyer für die Bedeutung seiner Leistung verständlicher:

Ich darf hier einmal feststellen, daß die Einführung von PAL in der ersten Zeit ausschließlich von mir ganz alleine vorangetrieben wurde. [...] In der ersten Zeit hat keine einzige Stelle, auch nicht die Deutsche Bundespost oder das Deutsche Fernsehen - abgesehen von Herrn Tielke vom NDR - irgendeine dieser Arbeiten durch eigene Geräte unterstützt. [...] Bis heute ist kein einziger Beitrag zur Schaltungstechnik der Empfänger von einer Industriefirma in Deutschland geliefert worden. Man kann also von mir auch nicht erwarten, daß ich auf die Lizenzanteile, die mir laut dem Deutschen Erfinderrecht, das dem Erfinder eine sangemessene Vergütung، zusichert, verzichte ${ }^{110}$.

In einem Interview mit Funkschau-Chefredakteur Karl Tetzner wenige Jahre später sah Walter Bruch die Sache schon wieder ein wenig anders. Dort hieß es zur Durchsetzung des PAL-Systems: »Hier muß ich mich ganz groß bei der Bundespost und dem NDR bedanken. Ohne die Freundschaft zu beiden Stellen hätte ich das nicht machen können. Wissen Sie, wenn man so sagt, es sei ein Team, das PAL durchgezogen habe, nein, es gehört eine ganze Gesellschaft dazu ${ }^{111}$ !

Auf die zentrale Rolle des Akteurs Walter Bruch bei der Durchsetzung des PAL-Systems im nationalen wie internationalen Kontext wurde bereits mehrfach hingewiesen. Dennoch hing die Entscheidung der deutschen Rundfunkindustrie, wie eben erwähnt, mit Sicherheit nicht nur vom Engagement Walter Bruchs ab. Um PAL für die deutsche Rundfunkindustrie attraktiv zu machen, galt es als erstes die Lizenzgebühren auf ein verträgliches $\mathrm{Ma} B$ fest $\mathrm{zu}$ legen. Bereits im Januar 1964 wurde Telefunkens Patentanwalt Dr. Johannesson mit dem Verfassen eines entsprechenden Lizenzangebotes an die Adresse des ZVEI beauftragt. Mit 0,3\% des Netto-Fakturenpreises eines PAL-Empfängers entschied man sich bei Telefunken für eine sehr moderate Lizenzpolitik gegenüber der deutschen Rundfunkindustrie, die zudem bis Ende des Jahres 1968 von jeglichen Lizenzzahlungen befreit wurde, um den Start des Farbfernsehens in der Bundesrepublik zu erleichtern ${ }^{112}$. Mit Ausnahme der DDR und dem heiß umkämpften Italien, denen man später ebenfalls diesen

110 Ibid.

111 Interview von Prof. Karl Tetzner mit Walter Bruch am 9.2.1973 in Icking, 17 maschinegeschriebene Seiten, hier S. 8, in: Privatarchiv Prof. Tetzner, Icking.

112 Brief von Prof. Wemer Nestel an die Dresdner Band AG, Ulm, 14. Juli 1967, in: AEG-Telefunken-Archiv, Deutsches Technikmuseum Berlin, Signatur GS 1646. 
günstigen Lizenzprozentsatz von 0,3 anbot, forderte Telefunken von allen ausländischen Lizenznehmern 0,5\% des Ab-Werk-Preises der Empfänger ${ }^{113}$.

Wichtiger noch als die Höhe der PAL-Lizenzgebühren war für die deutsche Rundfunkindustrie die Frage, wie hoch die Chancen einzuschätzen waren, daß das PAL-System als europäische Alternative zum NTSC-System eingeführt werden würde. Hiervon hingen die Exportmöglichkeiten und damit die Gewinnerwartungen bei einer Serienfertigung von PAL-Empfängern ab. Wie es letztlich gelang, die im ZVEI organisierte deutsche Rundfunkindustrie für die Telefunken-Entwicklung zu gewinnen, kann mangels eindeutiger Quellen nicht rekonstruiert werden. Dr. Felix Herriger, damals Vorstandsvorsitzender der Telefunken AG, gab in einem Interview mit dem Autor zu erkennen, daß er sich persönlich bei den führenden Männern der Rundfunkbranche, allen voran bei den Herren Grundig und Mende, um die Übernahme des PAL-Systems bemüht habe ${ }^{114}$.

Ein wichtiger Gesichtspunkt in diesen Verhandlungen war die Frage der Mehrkosten, die durch die kompliziertere PAL-Schaltung mit UltraschallVerzögerungsleitung verursacht wurden. Ende November 1964 sicherte Telefunken dem Vorsitzenden des ZVEI schließlich zu, Telefunken werde der deutschen Empfängerindustrie im Falle der Einführung von PAL-Laufzeitleitungen für die Massenproduktion liefern, deren Preis nicht über dem von Corning Glass, das heißt 5 DM pro Stück liege ${ }^{115}$. Von größerer Bedeutung als die pro-Stïck-Kosten der Verzögerungsleitungen war die Frage der Farbbildröhre. Die Farbbildröhre stellte das technologische Herzstück des Farbempfängers dar, deren Massenfertigung zu den anspruchsvollsten produktionstechnischen Herausforderungen der Elektroindustrie zählte. Bei Telefunken selbst hatte man keinerlei Produktionserfahrung mit Farbbildröhren und war somit auf die Übernahme fertiger Röhren aus den USA oder England angewiesen. Felix Herriger berichtet, er sei damals persönlich nach Eindhoven zu Fritz Philips gereist, um diesen zu einer Kooperation mit Telefunken auf dem Gebiet der Farbempfängerproduktion zu gewinnen. Folgendes Kalkül soll Fritz Philips schließlich für die Kooperation gewonnen haben: Wenn Telefunken in Lizenz Farbbildröhren von Philips nachbaue und sich Philips im

113 In einem Brief von Dr. Johannesson an Dr. Jelinek, VVB Rundfunk und Fernsehen, vom 17.2.1965 teilte Johannesson Jelinek mit, daB Telefunken die Lizenzgebühren für PAL in der DDR von 0,5 auf $0,3 \%$ des Nettopreises des Farbfernsehgerätes gesenkt habe! Somit würden in der DDR die gleichen Bedingungen wie in der BRD herrschen. Siehe Deutsches Museum München, NachlaB Walter Bruch, Signatur: NL 101, Nr. 202. Zum Kampf um den italienischen Markt siehe Andreas Fickers, »Pourqui ne feraient-ils pas un procès à Telefunken?« Georges Pompidou et la promotion du SECAM, in: Pascal Griset (Hg.), Georges Pompidou et la modernité. Les tensions de l'innovation (1962-1974), Brüssel u.a. 2006, S.171-192.

114 Interview mit Dr. Felix Herriger, Ulm, 7. August 1997.

115 Telefonnotiz von Mantz nach Gespräch mit Boom, Hannover, 30.11.1964, in: AEG-Telefunken Archiv, Deutsches Technikmuseum Berlin, Signatur GS 1648. 
Gegenzug bei den Engländern zugunsten von PAL stark machen würde, würden beide Firmen von der Einführung des PAL-Systems profitieren ${ }^{116}$.

Fest steht, daß der Fachverband 14 (Rundfunk und Fernsehen) des ZVEI in der Sitzung seiner Technischen Kommission vom 12. November $1964 \mathrm{zu}$ einer abschließenden Bewertung der Farbfernsehsystemfrage gekommen ist. Aus einem Kolloquium des Verbandes, das am 5. und 6. November beim NDR in Hamburg veranstaltet wurde, war ein sechzigseitiger Untersuchungsbericht hervorgegangen, in dem alle drei Systeme einer gründlichen Analyse unterzogen worden waren. Als Ergebnis dieses Kolloquiums wurde festgehalten:

Alle Interessenten [...] bevorzugen PAL, da man sich sleichter tut«. Wegen der Möglichkeit apparativer Verbesserungen und der Transcodierbarkeit PAL-NTSC erklärt man aber, jedes System machen zu können, mit deutlicher Präferenz für die ,NTSC-Familie، PAL/NTSC. [...] Tendenz allgemein: Rundfunkanstalten und Deutsche Bundespost bevorzugen >NTSC-Familie<, möchten aber zwischen NTSC und PAL das Gewicht der Entscheidung auf die Industrie verlagern ${ }^{117}$.

Kurioserweise war das französische SECAM-System, mit dem sich im Rahmen des Unterausschusses Farbfernsehen ebenfalls einige Fernsehexperten unter Leitung des Ingenieurs A. Rappold von der Firma Standard Elektrik Lorenz A.G. beschäftigt hatten, zu keinem Zeitpunkt als ernsthafte Systemalternative diskutiert worden. Wie ein Brief von Rappold an Bruch vom 23. April 1964 beweist, war den Herren des Farbausschusses auch nicht daran gelegen, sich ernsthaft mit dem französischen System zu beschäftigen. Bereits im Anschreiben heißt es: »Beiliegend erhalten Sie den Entwurf zu einem Statement gegen SECAM. Vielleicht können wir in Hannover, zunächst in kleinerem Kreis, über die weitere Formulierung oder Verbesserungen sprechen ${ }^{118}$.

Schon die "Vorbemerkung « des anschließenden Entwurfs zu einer "Stellungnahme zu den Eigenschaften des SECAM-Farbfernsehsystems« machte die Intention des Schreibens mehr als deutlich:

Nachdem es den Anschein hat, daB die Diskussion um ein optimales, für Gesamteuropa verbindliches Farbfernsehsystem die sachlich-technische Ebene zu verlassen droht, dagegen firmenpolitische Argumente und Prestigemomente in den Vordergrund treten, wurde gelegentlich der letzten Sitzung der TK [Technischen Kommission, A.d.V.], UnterausschuB Farbfernsehen, beschlossen, einen aus Vertretern dreier Mitgliedsfirmen bestehenden Arbeitskreis zu bilden, der sich insbesondere mit den Vor- und Nachteilen des SECAM-Systems befassen soll. Man war sich einig, daß das SECAM-System Nachteile gegenüber anderen gezeigt hat. Es wird angestrebt, diese Feststellung durch technische Ausarbeitungen und eigene Untersuchungen zu untermauern und

116 Ibid.

117 Bericht über die Sitzung der Technischen Kommission am 12. November 1964 um 14.30 Uhr in Bad-Nauheim, in: Archiv des Deutschen Museums, NachlaB Walter Bruch, Signatur NL 101, Nr. 203.

118 Brief von A. Rappold an Walter Bruch, Pforzheim, 23.4.1964, in: Archiv des Deutschen Museums München, NachlaB Walter Bruch, Signatur NL 101, Nr. 202. 
möglichst als CCIR-Beitrag so rechtzeitig vorzubereiten, daß er der nächsten Konferenz im Frühjahr 1965 vorliegt $^{119}$.

In der Zusammenfassung schließlich hieß es:

Wenn alle Argumente zur Notwendigkeit eines besseren Systems als NTSC berechtigt wären, dann müßte die Wahl des PAL- und nicht des SECAM-Systems die logische Folge sein. [...] Eine Einführung des SECAM-Systems würde eine Wiederholung der gleichen Fehler bedeuten, die man bei der Wahl der verschiedenen Zeilenzahlen in Europa machte. Die Korrektur dieser damaligen Fehler verursacht heute, insbesondere in Frankreich, unübersehbare Kosten. Man sollte sich die damaligen Vorgänge, die eine gewisse Parallele zu den heutigen Verhandlungen um ein Farbfernsehsystem haben, ins Gedächtnis zurückrufen ${ }^{120}$.

Glaubwürdiger hätte sich die deutsche Rundfunkindustrie im Kampf gegen »firmenpolitische Argumente und Prestigemomente « wohl kaum engagieren können! Nachdem alle Mitglieder des Untersuchungsausschusses Gelegenheit hatten, die einzelnen Berichte ausführlich zu studieren, kam es am 12. November zu folgender Abstimmung: 7 Kommissionsmitglieder stimmten für PAL, 3 für NTSC, 2 blieben indifferent und zwei ohne Stimmabgabe. Damit hatte sich die deutsche Rundfunkindustrie wenige Monate vor der ersten entscheidenden CCIR-Konferenz in Wien hinter Telefunken und PAL gestellt. Nach dieser Entscheidung wurde der Unterausschuß Farbfernsehen der Technischen Kommission des ZVEI aufgelöst.

Nachdem die Entscheidung für PAL gefallen war, wandte sich Bruch in einem Dankesschreiben an den Vorsitzenden der Technischen Kommission, Herrn Boom, und bekannte diesem, er sei »überrascht und erfreut, daß die deutsche Industrie mit ihrer Referenz für PAL mir eine echte Anerkennung meiner Arbeit ausgesprochen hat «. Da er sich als Leiter des Unterausschusses Farbe so sehr für PAL eingesetzt habe, seien in ihm sogar Rücktrittsgedanken in den Sinn gekommen. »Man hat mir aber trotzdem zugesprochen «, so Bruch weiter, »daß ich die Geschäfte des Arbeitsausschusses einigermaßen neutral leitete«. Das, was man sich einmal unter dem Arbeitsausschuß Farbfernsehen vorgestellt habe, eine »echte gleichberechtigte, neutrale Gemeinschaftsarbeit « sei aber in dieser Art nie zum Tragen gekommen - „verständlich, weil eine große Zahl der Beteiligten ja sozusagen erst Farbfernsehen lernen muß ${ }^{121}$.

Trotz der anfänglich negativen Haltung der deutschen Rundfunkindustrie gegenüber PAL ist es Bruch und Telefunken gelungen, die Stimmung in Richtung einer positiven Einschätzung von PAL zu beeinflussen. Neben dem hohen persönlichen Einsatz des zentralen PAL-Akteurs Walter Bruch war

119 Ibid.

120 Ibid.

121 Siehe Briefentwurf von Bruch an Boom, von Bruch auf Band diktiert und von seiner Sekretärin auf 5 maschinegeschriebene Seiten abgetippt, in: Archiv des Deutschen Museums München, Nachlaß Walter Bruch, Signatur NL 101, Nr. 202, hier S. 2. 
dies auch der gelungenen Überzeugungs- und Lobbyarbeit des Telefunken Vorstandsvorsitzenden Felix Herriger zu verdanken. Die von Herriger ausgehandelte Kooperation im Bereich der Röhrenproduktion mit dem Branchenriesen aus den Niederlanden war ein wichtiger Meilenstein auf dem Weg zur bundesdeutschen Unterstützung des PAL-Verfahrens nicht nur in der Bundesrepublik sondern auch im Ausland. Nicht zuletzt förderten die günstige PAL-Lizenzpolitik sowie die garantierten Absatzpreise für wichtige PAL-Bauteile ein positives PAL-Klima. Wenige Monate vor der CCIR-Konferenz in Wien im März 1965 war es Telefunken somit gelungen, die wirtschaftlich mächtige deutsche Rundfunkindustrie hinter den Fahnen des PALSystems zu versammeln.

Die Unterstützung des PAL-Systems durch die in Europa marktführende bundesdeutsche Rundfunkindustrie war ein nicht zu unterschätzender Argumentationsfaktor in den CCIR-Verhandlungen. Die symbolische Verschmelzung des PAL-Systems mit dem Image deutscher Rundfunktechnik war durchaus in der Lage, die Attraktivität des PAL-Systems für kleinere oder weniger potente Rundfunkländer wesentlich zu steigern. Aber, wie zu zeigen sein wird, sollte sich auch die französische Seite für die Wiener Zusammenkunft rüsten, und zwar mit Waffen, die der bundesdeutschen Delegation nicht zur Verfügung standen. Bevor die Wiener Konferenz in den Mittelpunkt der Aufmerksamkeit gerückt wird, ist es notwendig, sich die wirtschaftspolitische Ausgangssituation der französischen Rundfunkindustrie vor Augen zu führen. 
Wie bereits beschrieben, gab es durchaus unterschiedliche Muster und Entwicklungspfade bei der Rekonstruktion der europäischen Volkswirtschaften nach 1945. Der französische Weg unterscheidet sich in vielfacher Weise von dem der Bundesrepublik Deutschland. Um die Entwicklung der französischen Rundfunk- bzw. Elektroindustrie in diesen nationalen Kontext einbetten zu können, ist es ratsam, die generellen Charakteristika des französischen Modernisierungsweges im industriellen und wirtschaftspolitischen Sektor kurz zu skizzieren. In einem zweiten Schritt kann dann die kulturgeschichtliche Dimension dieses Wandels beschrieben werden, die es erlaubt, die Besonderheiten der »modernisation à la française « zu fassen.

\subsubsection{Das französische Wirtschaftswunder: die »trente glorieuses«}

Ähnlich wie für Deutschland kann auch die Beschreibung der industriellen Entwicklung Frankreichs unterschiedlichen Phasen wirtschaftshistorischer Betrachtung zugewiesen werden. Wie Jean Bouvier treffend zusammenfaßt, war die Historiographie der industriellen Entwicklung Frankreichs lange Zeit von der "Litanei« um die sogenannte "société bloquée « bestimmt ${ }^{122}$. Grund für diese Einschätzung, die meist auf einem direkten Vergleich der französischen mit der englischen oder deutschen Entwicklung basierte, waren u.a. die Postulierung einer direkten Beziehung zwischen demographischer Entwicklung und industriellem Wachstum sowie simplifizierende Klassifizierungen bestimmter gesellschaftlicher Schichten und Strukturen - beispielsweise der Landwirtschaft - als »rückständig « oder »hemmend«.

Mit dem Ziel, diese verengte Sichtweise zu relativieren oder gänzlich in Frage zu stellen, sind die sogenannten »Revisionisten« in den letzten Jahrzehnten angetreten ${ }^{123}$. Meist lag der historische Fokus dieser Arbeiten jedoch auf der ersten Phase der Industrialisierung, auch »Erste Industrielle Revolution « genannt. Das, was die französische Wirtschaft während der Zwischenkriegszeit und vor allem nach dem Zweiten Weltkrieg kennzeichnete, hat jedoch nur wenig oder gar nichts mit dem gemein, was man als "société bloquée« bezeichnet hat. Der Wirtschaftshistoriker François Caron bezeichnet die Phase zwischen 1945 und 1954 als Zeit einer »explosion du capitalisme«, Wilfried Loth spricht in diesem Zusammenhang von der "take-off-Phase französischer Dynamisierung « ${ }^{124}$. Fragt man nach den Gründen dieser »Ex-

122 Bouvier, Libres propos autour d'une démarche révisionniste.

123 Beispielhaft für diese Schule seien nur die Namen von Patrick Verley und Louis Bergeron genannt.

124 Wilfried LOTH, Geschichte Frankreichs im 20. Jahrhundert, Frankfurt a.M. 1995. Siehe v.a. Kapitel 13 »Das französische Wirtschaftswunder«, S. 188-200. 
plosion « oder »Dynamisierung «, tauchen in der Literatur immer wieder zwei Stichworte auf, die als Programm des französischen Wirtschaftsaufschwungs fungieren: "planification " und "nationalisation«. Hans-Rudolf Peters beschreibt das französische Wirtschaftsmodell auch als System der »indikativen Wirtschaftsplanung «. Von der imperativen Zentralplanung - wie sie in den sozialistischen Zentralverwaltungswirtschaften Osteuropas üblich war - unterschied sich die indikative Strukturplanung durch ihren nur orientierenden Charakter und ihre Unverbindlichkeit ${ }^{125}$.

Die indikative Strukturplanung ist ein Plansystem, das unter Bewahrung der Entscheidungsdezentralisierung im mikroökonomischen (einzelwirtschaftlichen) Bereich eine Informationszentralisierung auf makroökonomischer (gesamtwirtschaftlicher) Ebene und eine Informationsweitergabe in Form sektorspezifischer Prognosen an den mesoökonomischen (branchenmäßigen) Bereich sowie eine freiwillige Plankoordinierung der Einzelwirtschaften in Orientierung an den sektoralen Zielprojektionen anstrebt ${ }^{126}$.

Doch zuerst einige Zahlen, die den rapiden Aufschwung der industriellen Produktion nach 1945 verdeutlichen sollen. Ende 1944 war die französische Industrieproduktion auf $40 \%$ des Standes von 1938 gesunken. Selbst die landwirtschaftliche Produktionsrate blieb 20\% hinter der des Jahres $1938 \mathrm{zu}-$ rück $^{127}$. In der gleichen Zeit waren die Gehälter gesunken und die Inflation kräftig gestiegen. In dieser schwierigen Lage versuchte der französische Wirtschaftsminister Pierre Mendès France die wirtschaftliche und monetäre Situation mittels einer dirigistischen Planpolitik zu stabilisieren. Obschon Mendès France bereits im April 1945 von seinem schwierigen Amt zurücktrat, überlebte die Idee der Planpolitik. Am 3. Januar 1946 wurde per Regierungsdekret das »Commissariat Général au Plan« geschaffen, an dessen Spitze der Finanzexperte Jean Monnet berufen wurde. Jean Monnet, der zu dieser Zeit als Leiter des französischen Versorgungskomitees in Washington tätig war, sollte die amerikanische Wiederaufbauhilfe im Rahmen des MarshallPlans mit der Idee einer planmäßigen Modernisierung der französischen Großindustrie verbinden ${ }^{128}$.

Die planmäßige Strukturierung der industriellen Produktion war aber keine Erfindung Monnets, sondern langjährige Praxis zahlreicher totalitärer Staaten wie der Sowjetunion oder auch dem nationalsozialistischen Deutschland gewe-

125 Das bedeutet jedoch nicht, wie Peters betont, daß von ihr praktisch überhaupt keine Wirkungen ausgehen. Im Gegenteil, die Konzeption der reinen indikativen Strukturplanung geht von einer `Logik des Plans` aus, die angeblich eine gewisse Selbstverwirklichungskraft des indikativen Plans schafft. Zur Realisierung des Plans ist demnach ein zentrales Planungsgremium notwendig. 126 Hans-Rudolf PeTERs, Grundlagen der Mesoökonomie und Strukturpolitik, Bern 1981, S. $372 f$.

127 Siehe Jean-François Sirinelli, Robert VANDEnbussche, Jean Vavasseur-DesPierRes, La France de 1914 à nos jours, Paris 1993, S. $228 \mathrm{f}$.

128 Zur Person und Aufgabe Jean Monnets siehe Eric Roussel, Jean Monnet (1888-1979), Paris 1996. 
sen. Auch die französische Wirtschaft des Vichy-Regimes praktizierte eine Form der Planwirtschaft, die durch Korporatismus, zentralistische Planung und dem Willen zur Kollaboration mit dem nationalsozialistischen Deutschland gekennzeichnet war $^{129}$. Die typisch französische Färbung erhielt diese Form der Wirtschaftspolitik und -organisation aber dadurch, daB es zu einer funktionierenden Symbiose zwischen industriellen und administrativen Eliten kam:

Dix-huit commissions de modernisation sont chargées de fixer les objectifs de chaque branche. Elles sont composées de hauts fonctionnaires, de représentants des centrales syndicales, de chefs d'entreprises et d'experts. La concertation a l'avantage de garantir la qualité des travaux préparartoires et d'impliquer les agents de l'économie dans l'élaboration. Le plan se présente comme l'outil de la modernisation ${ }^{130}$.

War die Planpolitik also einerseits eine staatliche Reaktion auf die durch den Zweiten Weltkrieg verursachten beispiellosen materiellen Dringlichkeiten ${ }^{131}$, kann sie im französischen Fall zudem als Ausdruck eines kulturelles Bruchs verstanden werden. Wie Robert Frank überzeugend nachweist, war die staatliche Planpolitik auch der Versuch der französischen Gesellschaft, sich ihres durch die »étrange défaite« verlorengegangenen Nationalstolzes zu vergewissern. Das »Syndrom von Vichy « - die Kapitulation von 1940 -, so Robert Frank, habe im Nachkriegsfrankreich ein tiefempfundenes Bedürfnis nach wirtschaftlicher Modernisierung und nach einer wirksamen Verteidigung geschaffen ${ }^{132}$. Die Staatsidee - und damit auch die Möglichkeit zentralstaatlicher Eingriffe in die Wirtschaft - war, wie Jean-Pierre Rioux betont, eine der wenigen Kräfte, die das erschöpfte Frankreich nach 1945 aufrechterhielt ${ }^{133}$. In diesem nationalen Konsens, so der Politologe Pierre Rosanvallon, fand die Einheit der Résistance ihre Fortsetzung:

129 Siehe hierzu Richard F. KuIsel, Vichy et les origines de la planification économique 1940-1946, in: Le mouvement social 98 (1977) S. 77-102, sowie Henry Rousso, L'économie, pénurie et modernisation, in: Jean-Pierre Azéma. François BÉdarida (Hg.), La France des années noires, Bd.1, De la défaite à Vichy, Paris 2000, S. 441-453.

130 Denis Woronoff, Histoire de l'industrie en France du XVI ${ }^{e}$ siècle à nos jours, Paris 1998, S. 493.

131 Auch in anderen europäischen Ländern wurden nach dem Zweiten Weltkrieg wirtschaftspolitische Pläne entwickelt, mittels derer die Volkswirtschaft wieder auf die Beine kommen sollten. So wurde 1946 in den Niederlanden ein Vierjahresplan verabschiedet, der anschließend bis 1952 verlängert wurde, und in Belgien wurde ein Bureau de programmation « etabliert. Auch in Italien und sogar in Grobbritannien wurde mit planwirtschaftlichen Behörden experimentiert. Siehe hierzu Eric Bussière, Pascal Griset, Christophe BouneaU, Jean-Pierre Willior, Industrialisation et sociétés en Europe occidentale 1880-1970, Paris 1998, S. 78 f.

132 Frank, Mentalitäten, in: Loth, Osterhammel (Hg.), Internationale Geschichte, S. 187 f. sowie DERs., La hantise du déclin. Le rang de la France en Europe, 1920-1960. Finances, défense et identité nationale, Paris 1994.

133 Siehe Vorwort von Jean-Pierre Rioux in: Jean Bouvier, François Bloch-LAINE, La France restaurée, 1944-1954, Paris 1986. 
Die wichtigste Ursache für die gewachsene wirtschaftspolitische Bedeutung des Staates waren also die politischen Verhältnisse. [...] 1945 feierte man den Staat wie man 1789 die Souveränität der Nation gefeiert hatte. [...] Deshalb wurde staatliche Politik jetzt auch nicht mehr nur als zeitweilige und rückgängig zu machende Intervention verstanden, wie dies noch in den Jahren nach dem Ersten Weltkrieg der Fall gewesen war. Staatliche Politik erhielt jetzt gewissermaßen eine langfristige Perspektive. Das kommt in den beiden großen Strukturreformen, den Nationalisierungen und der Planification, zum Ausdruck ${ }^{134}$.

Die französische Politik der »planification« kann aus heutiger Perspektive als der gelungene Versuch einer »modernisation par en haut « (Patrick Fridenson) angesehen werden. Mittels einer staatlichen Industriepolitik, die gezielt ganze industrielle Sektoren durch Subventionen förderte oder einzelne Betriebe durch Nationalisierung vor internationaler Konkurrenz schützte ${ }^{135}$, sollten die verschiedenen Pläne eine gezielte Modernisierung der industriellen Landschaft Frankreichs herbeiführen ${ }^{136}$. Als technopolitische Hybride waren die Pläne der Versuch, die gesamte französische Nation in ein ehrgeiziges Projekt soziotechnischer Modernisierung einzubinden ${ }^{137}$.

Die verschiedenen Pläne hatten jeweils unterschiedliche Schwerpunkte. Der erste Plan war ganz dem Wiederaufbau der alten schwerindustriellen Leitsektoren (Kohle und Stahl) gewidmet, während der zweite Plan staatliche Förderungen im Bereich der Konsumgüterindustrie vorsah, die auch »dem kleinen Mann« zugute kommen sollten. Der zweite Plan war somit auch eine Reaktion auf den zunehmenden Unmut der arbeitenden Bevölkerung in Frankreich. Ab April 1947 kam es zu einer Welle oftmals lang anhaltender Streiks, da die Einkaufskraft eines durchschnittlichen Arbeiters 1947 noch immer um ein Drittel niedriger als 1938 war $^{138}$.

134 Pierre Rosanvallon, Der Staat in Frankreich. Von 1789 bis heute, Münster 2000, S. $169 \mathrm{f}$.

135 Es darf jedoch nicht vergessen werden, daB es eine lange Tradition staatlicher Intervention in die Privatwirtschaft gibt. Nach 1945 konnten Nationalisierungen zudem die ‘Quittung، für Kollaborationen mit den Deutschen während des Zweiten Weltkrieges sein. Die Nationalisierung der Renault-Werke im Januar 1945 war eine solche Maßnahme. Siehe Bussİ̀rE u.a., Industrialisation et sociétés en Europe occidentale, S. 80.

136 Zur Industriepolitik Frankreichs im Vergleich mit der Bundesrepublik siehe die aufschluBreiche Arbeit von Neumann, UtERWEDde, Industriepolitik. Eine Zusammenfassung der Forschungsresultate dieser Arbeit liefert der Aufsatz Wolfgang Neumann, Henrik UTERWEDDE, Industrie- und Technologiepolitik in Frankreich und in der Bundesrepublik seit 1945, in: Yves Cohen, Klaus Manfrass (Hg.), Frankreich und Deutschland. Forschung, Technologie und industrielle Entwicklung im 19. und 20. Jahrhundert, München 1990, S. 433-449.

137 Siehe Gabrielle HECHT, Planning a Technological Nation: Systems Thinking and the Politics of National Identity in Postwar France, in: Agatha and Thomas Hughes (Hg.), Systems, Experts, and Computers: The Systems Approach in Management and Engineering, World War II and After, Cambridge u.a. 2000, S. 133-160, hier S. 153.

138 Woronoff, Histoire de l'industrie en France, S. $505 \mathrm{f}$. 
Es muß an dieser Stelle darauf verzichtet werden, die zahlreichen Faktoren und Einflüsse zu rekonstruieren ${ }^{139}$, die schließlich zu jenem dynamischen "take-off « der französischen Wirtschaft geführt haben, der sich in den folgenden Zahlen wieder spiegelt: Bereits 1948 erreichte das französische $\mathrm{Na}-$ tionaleinkommen wieder den Vorkriegsstand, 1950 das Niveau der Zeit vor der Weltwirtschaftskrise. Die durchschnittliche Steigerung des Bruttoinlandproduktes zwischen 1949 und 1959 betrug jährlich 4,5\%, zwischen 1955 bis 1968 durchschnittlich 5,7\% und von 1969 bis 1973 sogar 6,1\%. Die Expansion zeigt sich besonders, wenn man die Zuwachsraten der industriellen Produktion betrachtet. Legt man den Produktionsindex des Jahres 1938 als Marke $(=100)$ fest, wuchs dieser bis 1958 auf 213 an, stieg bis 1967 noch einmal knapp um die Hälfte auf 338 um bis 1973 auf 452 Punkte zu steigen. Dies bedeutet, daß die Industrieproduktion in den "trente glorieuses « von 1944 bis 1974 auf das Viereinhalbfache des Vorkriegsstandes stieg und damit deutlich über den Zuwachsraten in den USA, in Großbritannien oder in Belgien lag. Lediglich die Bundesrepublik und Japan konnten einen steileren Anstieg der Industrieproduktion im gleichen Zeitraum verzeichnen ${ }^{140}$.

War dieses dynamische Wachstum nun einzig das Resultat des französischen Weges von "planification« und "nationalisation«? Mit Sicherheit nicht. Aber, so Wilfried Loth mit kritischem Blick auf den »Mythos soziale Marktwirtschaft« der Bundesrepublik, der französische Weg zeige, daß eine weitgehende Liberalisierung der Wirtschaftspolitik keineswegs eine notwendige Voraussetzung für eine wirtschaftliche und gesellschaftliche Dynamisierung sei: "Der offenkundige Erfolg der französischen splanification gibt zu der Frage $A n l a ß \ll$, so Loth, »ob eine weitgehend staatlich initiierte und moderierte Modernisierung für nachholende Gesellschaften nicht den geeigneten Weg zur Integration in einen entwickelten Markt darstellt $\aleph^{141}$.

Trotz des von Loth konstatierten »technokratischen Elans« gibt es durchaus auch kritische Beurteilungen der französischen Wirtschafts- und Industriepolitik nach 1945. In Frankreich hat es immer wieder prominente liberale Stimmen gegeben, die vor einer allzu starken etatistischen Wirtschaftsfüh-

$139 \mathrm{Zu}$ diesen zählen unzweifelhaft der europäische Kontext (EGKS, EWG), die Dekolonialisierung und die Bedeutung der Absatzmärkte in »outre-mer«, währungspolitische Entscheidungen sowie der generelle Nachfrageüberhang. Siehe hierzu WORONOFF, Histoire de l'industrie en France, Fourastí, Les trente glorieuses, sowie Hubert Bonin, Histoire économique de la IV ${ }^{e}$ République, Paris 1987.

$140 \mathrm{Zu}$ den Zahlen siehe Loth, Der Durchbruch zur Dynamisierung, in: ScHILDT, SYwotTeK (Hg.), Modernisierung im Wiederaufbau, S.70f. sowie WoRONOFF, Histoire de l'industrie in France, S. $535 \mathrm{f}$.

141 LoTh, Der Durchbruch zur Dynamisierung, S. 78. Zur Debatte um das Konzept der »nachholenden Modemisierung « siehe Roger MaGRAw, »Not backward but different?« The debate on French »economic retardation«, in: Martin S. ALEXANDER (Hg.), French History since Napoleon, London 1999, S. 336-363. 
rung gewarnt haben. Eine differenzierte Bewertung der "planification « lieferte der französische Wirtschaftshistoriker Patrick Fridenson 1987 in dem Aufsatz "Atouts et limites de la modernisation par en haut: les entreprises publiques face à leurs critiques (1944-1986) ${ }^{142}$. Obwohl kritische Einschätzungen der französischen Planpolitik bis heute in abgewandelter Form immer wieder zu hören sind, warnt Fridenson davor, bei der Bewertung der Nationalisierungen alle Betriebe ohne Unterscheidungen über einen Kamm zu scheren. Vielmehr müsse man genau unterscheiden, ob man es mit Betrieben zu habe, die vornehmlich auf dem nationalen Markt agierten (z.B. im Bereich der Elektrizität, Eisenbahn, Metro, Banken und Versicherungen), und jenen, die der internationalen Konkurrenz ausgesetzt seien (beispielsweise Flugverkehr, Atomenergie, Öl und Raumfahrt). Vor allem bei Betrieben der ersten Kategorie sei es im Laufe der Zeit zu wachsenden Problemen gekommen ${ }^{143}$. Die zweite Kategorie von Staatsunternehmen seien aber jene, die eher der internationalen Konkurrenz ausgesetzt seien, und die daher zu Recht als strategische Bereiche bezeichnet werden könnten. $\mathrm{Zu}$ diesen strategischen Bereichen zählt laut Fridenson auch die Fernsehindustrie. Die Strategien des Staates, um die industrie- oder technologiepolitischen Ziele zu erreichen, können dabei unterschiedliche Formen annehmen:

142 Patrick Frudenson, Atouts et limites de la modemisation par en haut: les entreprises publiques face à leurs critiques (1944-1986), in: Frudenson, Srraus (Hg.), Le capitalisme francais (XIX $\mathrm{XX}^{e}$ siècle). Blocages et dynamismes d'une croissance, Paris 1987, S. 175-196. Fridenson faBt fünf der zentralen Kritikpunkte am System der planification wie folgt zusammen: 1) Staatliche Betriebe hätten nur technische Perfektion im Sinn, jedoch keine Ader für das Geschäft. Ein Ausspruch von Antoine Pinay bringt diese Meinung auf den Punkt: "La SNCF a le culte de la minute et le mépris du milliard«. 2) Den Staatsbetrieben wird schlechtes Management vorgeworfen. Grund dafür sei die Besetzung der zentralen Führungsposition mit hochrangigen Verwaltungskadem (z. B. ENA-Absolventen), die jedoch wie Staatsbeamte denken würden, nicht wie Industriemanager. 3) Die staatlichen Großbetriebe hätten aufgrund ihrer Größe und Statik anhaltend mit strukturellen Defiziten zu kämpfen. 4) Die Politisierung: Durch die Besetzung der Führungsschichten mit staatlichen Eliten wechseln die Führungspositionen mit den politischen Mehrheiten im Parlament. Zudem führe diese Politisierung zu einem ständigen Abschieben von Verantwortung auf die nächst höhere politische Ebene. 5) SchlieBlich das Risiko, daB Frankreich den Status eines "freien Landes« verliere. Fridenson zitiert hier einen der bekanntesten Wortführer dieser Kritik, Valérie Giscard d'Estaing: "Non seulement le capitalisme d'État est le plus tyrannique, le plus étouffant qui soit, mais son extension risquerait d'imposer au pays une expérience thérique dont il ferait les frais."

143 Zum Thema Nationalisierung der Wirtschaft siehe auch Jean-Charles Asselain, Nationalisations: la grande vague de la Liberation, in: Jacques MARSELLLE (Hg.), Puissance et faiblesses de la France industrielle (XIX ${ }^{\mathrm{c}}-\mathrm{XX}^{\mathrm{e}}$ siècle), Paris 1997, S. 197-228. In diesem Sammelband finden sich zahlreiche Fallstudien zu einzelnen Branchen oder Unternehmen der Industrie sowie zu einfluBreichen Akteuren des französischen Wirtschaftslebens, die als »capitaines« oder »soldats de l'industrie « beschrieben werden. 
1) Das Abschirmen nationaler Interessen durch die Einführung international nicht gebräuchlicher Normen oder Standards (Fridenson nennt hier das Beispiel der 819 Zeilen beim s/w-Fernsehen);

2) Der Staat hebt die internationale Konkurrenz auf, indem er ein nicht rentables Produkt so subventioniert, da $\mathrm{B}$ es dennoch gebaut wird (Bsp. Concorde);

3) Überinvestitionen wegen unbeschränkter Kreditvergabe seitens des Staates (Bsp. Elf-Aquitaine).

Fridenson plädiert aus diesem Grund dafür, zwei Aspekte des staatlichen Eingriffs in die Wirtschaft zu unterscheiden: erstens die Industriepolitik des Staates, zweitens die Finanzierung der Staatsbetriebe. Was die Industriepolitik betreffe, sind sich die Forscher einig, daß die staatlichen Interventionen im Bereich der öffentlichen Unternehmen entweder ineffizient oder gar schädlich für die Entwicklung dieser Unternehmen gewesen ist. Was die Finanzierungshilfen angehe, so habe sich der Staat in dieser Phase als ein »actionnaire qui n'est pas très généreux « herausgestellt. Hierzu zählt Fridenson aber nicht die staatlichen Leihgaben oder Kredite für Forschung und Entwicklung, die durchaus beträchtlich sein konnten ${ }^{144}$.

Erst mit dem Beginn der sozialistischen Präsidentschaft François Mitterrands im Jahre 1982 sind die Nationalisierungsbestrebungen wiederaufgeflammt. Der in dieser Zeit einsetzende massive Kapitalfluß vom Staat in die Privatindustrie wurde in Frankreich auch als »révolution financière« oder "leçon de capitalisme« bezeichnet. Im Bereich der Elektroindustrie hat diese massive Finanzspritze seitens des französischen Staates für einige Betriebe die Rettung (Bull) oder die erfolgreiche Stabilisierung (CIT-Alcatel, Thomson, Matra) bedeutet. Der unbestreitbare Erfolg dieser "zweiten Welle« der Nationalisierungen im Gegensatz zu den eher mageren Resultaten der »ersten Welle« liegt laut Fridenson darin begründet, daß der Staat nicht versucht habe, die industrielle Landschaft unter staatlicher Kontrolle umzustrukturieren, sondern durch finanzpolitische Regulierungen (Kreditvergabe, Beteiligung als Aktionär) eingewirkt habe: "La rentabilité financière devient un objectif pour l'État ${ }^{145}$. Die staatlich kontrollierten Banken haben eine zentrale Rolle in der Kreditvergabe und damit in der erfolgreichen Kapitalpolitik in der zweiten Welle der Verstaatlichungen von 1982 bis 1986 gespielt.

Ähnlich wie Fridenson beurteilt auch Pierre Rosanvallon die realen Wirkungen der »planification« eher kritisch. Zwar habe sich das Verhältnis zwischen Staat und Wirtschaft in Frankreich nach 1945 tatsächlich grundlegend

144 Ibid. S. 183.

145 Ibid. S. 189. Als weiteren Vorteil der Nationalisierungen sieht Fridenson, daB die Verstaatlichung den Angestellten im Bereich der Altersversorgung und Sozailleistungen zugute gekommen sind. Aus das sei ein nicht zu unterschätzender Beitrag zur »modernisation de la société française« gewesen. 
gewandelt, aber in diesem Wandlungsprozeß sei die "planification « eher als symbolischer Ausdruck von Veränderungen zu sehen, deren Ursache auf anderen Ebenen lagen: "Um zu verstehen, wie sich die Beziehung zwischen Staat und Wirtschaft nach 1945 wirklich veränderten, muß man, zumindest für einen kurzen Moment, die Existenz der Pläne vergessen. Dann treten zwei andere Faktoren in den Vordergrund: die keynesianische Revolution und der Amtsantritt einer neuen Generation hoher, der Modernisierung verpflichteter Beamter ${ }^{146}$.

Für Rosanvallon war die Durchsetzung der keynesianischen Ideen eine intellektuelle Revolution, die auch das Selbstverständnis des Staates grundlegend veränderte, da dieser sich vom allenfalls punktuell eingreifenden Marktbeobachter zum strategischen ökonomischen Akteur wandeln mußte. Erst aus dieser Einsicht ergab sich die Staatsfunktion der Regulierung, die sịch von den früheren Formen staatlicher Intervention deutlich unterscheidet. »Die vom alltäglichen Funktionieren des Staates abhängigen Variablen«, so Rosanvallon, »wurden zu Instrumenten einer das Gesellschaftsganze umfassenden Politik erhoben ${ }^{147}$. Eben diese "régulation «, von Peters »indikative Wirtschaftsplanung « genannt, war nur mittels eines neuen Steuerungsapparates möglich, der im »Commissariat Général du Plan« eine Konkretisierung erfuhr. Dieser Apparat konnte aber nur funktionieren, wenn in ihm die besten Fachleute - Verwaltungs- und Finanzexperten, Wissenschaftler oder Industriekapitäne - zusammengefaßt wurden. Zur Ausbildung dieser »technokratischen Elite« wurde auf Initiative von Michel Debré 1945 die École Nationale d'Administration (ENA) gegründet, die ihren Ruf als oberste französische Kaderschmiede bis heute verteidigt. Aus ihr sollten jene Männer - denn Frauen waren und sind dort die Ausnahme - kommen, die Frankreich den Weg in die Moderne weisen sollten ${ }^{148}$.

Die Besetzung zentraler Entscheidungsstellen in Verwaltung, Wirtschaft und Politik mit Absolventen der ENA, deren Gebäude sich, wie der Soziologe Alain Touraine in einem ironischen Nebensatz formulierte, »symbolisch auf halbem Wege zwischen Regierungsviertel und dem Quartier Latin« befänden ${ }^{149}$, hat dazu geführt, daß die Grenzen zwischen »öffentlichen « und "privaten« Interessen in vielen Fällen nur noch sehr schwer auszumachen

\footnotetext{
146 Rosanvallon, Der Staat in Frankreich, S. 174.

147 Ibid. S. 175.

148 Siehe hierzu den Aufsatz von Alfred Diamant, Tradition und Innovation in der französischen Verwaltung, in: Gilbert ZIEBURA, Gerhart HAUPT (Hg.), Wirtschaft und Gesellschaft in Frankreich seit 1789, Gütersloh 1975, S. 331-346.

149 Alain TOUraINE, Die französische Gesellschaft: Wachstum und Krise, in: Zrebura, HaUPT (Hg.), Wirtschaft und Gesellschaft in Frankreich seit 1789, S. 347-358, hier S. 356.
} 
sind $^{150}$. Ezra Suleiman sieht in den Eliten dieser »Technostruktur« sogar die Elite der französischen Elite: eben jene, die Wissen und Macht in Personalunion vereinen. Der Modernisierungsschub und Wiederaufbau Frankreichs in den fünfziger und sechziger Jahren hat diesen Männern eine besondere Stellung im politischen Leben gegeben: "La permanence des Grands Corps et du pouvoir de la technostructure repose en fait sur deux principes: savoir s'adapter et savoir se rendre indispensable $\ll^{151}$.

Gabrielle Hecht geht sogar so weit, das Selbstverständnis mancher Technokraten, dem »Plan zu dienen«, als quasi-religiöses Experiment zu deuten: »Thus the Plan could furnish a means for enacting the spiritual dimension of the material world, of invention. A quintessential manifestation of the sattitude prospective $<$, the Plan, by its very existence, would turn the nation into a system $\aleph^{152}$. Simon Nora, einer der führenden Technokraten dieser Zeit, der für kurze Zeit auch das Amt des »Délégué interministériel pour la propagation du SECAM « innehatte, schrieb 1986 in einem selbstkritischen Rückblick auf seine eigene Tätigkeit als Staatsdiener:

Wir waren die kleine Zahl derer, die besser als alle anderen wußten, was gut war für dieses Land - und damit lagen wir völlig falsch. Wir hielten uns für die Schönsten, die Intelligentesten, die Ehrlichsten und für die Hüter der Legitimität. Man muß sich klar machen, daß diese hier ein wenig ironisierend formulierte Sicht der Technokraten dreißig bis vierzig Jahre lang von der öffentlichen Meinung geteilt wurde ${ }^{153}$.

Insgesamt werden die staatlichen Eingriffe in die französische Industrie- oder Wirtschaftspolitik während der »trente glorieuses « daher recht ambivalent bewertet ${ }^{154}$. Will man den Verlauf der staatlich moderierten »modernisation à la française « verstehen, kommt man jedoch nicht daran vorbei, sich mit den zentralen Akteuren dieses Prozesses, der »technokratischen Elite«, zu be-

150 Diamant, Tradition und Innovation in der französischen Verwaltung, S. 334. Zur Rolle des französischen Elite-Ausbildungssystems siehe u. a. Pierre Birnbaum, Les sommets de l'État. Essai sur l'élite du pouvoir en France, Paris 1994 sowie Pierre Bourdieu, La noblesse d'État. Grandes écoles et esprit de corps, Paris 1989.

151 Ezra N. Suleiman, Politique et technostructure, in: Soutou, Beltran (Hg.), Pierre Guillaumat, S. 163.

152 Hecht, Planning a Technological Nation, S. $149 \mathrm{f}$.

153 Simon Nora, Servir l'État, in: Le Débat, 40 (mai/séptembre 1986), S. 102, hier zitiert nach Rosanvallon, Der Staat in Frankreich, S. 179.

154 Siehe hierzu u.a. Bernard Cazes, Philippe Mioche (Hg.), Modernisation ou décadence. Études, témoignages et documents sur la planification française, Aix en Provence 1990; Henry Rousso (Hg.), De Monnet à Massé. Enjeux politiques et objectifs économiques dans le cadre des quatre premiers plans 1946-1965, Paris 1986; DERS.: La planification en crises (1965-1985), Paris 1988; Pierre Bauchet, La planification française du $I^{e r}$ au VI $I^{e}$ Plan, Paris 1970; Saul Estrin, Peter Holmes, French Planning in Theory and Practice, London 1983. Eine Fallstudie zur Nationalisierung und planification im Bereich der Petrochemie und Ölindustrie liefert der Band von Georges-Henri Soutou, Alain Beltran (Hg.), Pierre Guillaumat: La passion des grands projets industriels, Paris 1995. 
schäftigen. Bevor dies am Beispiel der französischen Elektroindustrie und spezieller anhand der an der »bataille du SECAM « beteiligten Institutionen und Akteure versucht wird, soll neben der »keynesianischen Dimension« des französischen Modernisierungsprozesses auch die kulturelle Dimension kurz angedeutet werden, ohne die die "politique des champions nationaux « nicht verständlich wird.

\subsubsection{Frankreichs Weg in die Moderne im Spannungsfeld zwischen Tradition und Vision}

Die Konzentration der Darstellung auf industrielle oder technologische Phänomene bedeutet nicht, daß die französischen Modernisierungsbestrebungen auf diese Sektoren zu beschränken wären. Die Spannung zwischen Tradition und Vision ließe sich aus gesellschafts- oder kulturhistorischer Perspektive ebensogut am Beispiel der Landwirtschaft, der Städteplanung, der Kulturpolitik oder an allgemeinen außenpolitischen Themen wie der Dekolonialisierung oder der Verteidigungspolitik demonstrieren. Die Beschränkung auf den technisch-industriellen Sektor geschieht mit der Intention, die Analyse der französischen SECAM-Politik in die großen Linien der französischen Industriepolitik und Modernisierungsbemühungen einzubetten. $\mathrm{Da} B$ auch in diesen Sektoren ähnlich wie in der Landwirtschaft Widerstände gegen die Fortschrittseuphorie der Technokraten aufzufinden ist, mag nicht weiter verwundern. Wie Alain Touraine bemerkt, war das französische Leben trotz der Reformen, die aus der Energie der »libération« in Gang gesetzt worden waren, »voller Bezüge auf die Vergangenheit ${ }^{155}$. Touraine deutet hier die besonders für den de Gaulleschen Politikstil charakteristische Verschmelzung rückwärts- und vorwärtsgewandter Entwürfe über die Zukunft Frankreichs an, die zu jener schwer faßbaren politischen Identität des Nachkriegsfrankreichs der fünfziger und sechziger Jahre führten.

Entsprechend dieser Ambivalenz können sowohl "modernistische" als auch »konservative « Elemente im französischen Modernisierungsprozeß ausgemacht werden. Die Sprache der »Fortschrittlichen « war deutlich: "Modernisierung oder Untergang «, so lautete der wirtschaftspolitische Imperativ Jean Monnets ${ }^{156}$. Hinter diesem Slogan verbarg sich aber nicht nur die Forderung des wirtschaftlichen Wiederaufbaus Frankreichs nach dem Zweiten Weltkrieg, sondern die Modernisierung der ganzen französischen Gesellschaft als nationale Aufgabe. Daß die Franzosen von der Notwendigkeit dieser Aufgabe erst überzeugt werden mußten, zeigt folgendes Zitat des Planungskommissars Pierre Massé:

155 Touraine, Die französische Gesellschaft, S. 350.

156 Zitiert nach NeUMANN, UTERWEDDE, Industriepolitik, S. 38. 
My profession was to send a message that would not falsify the truth, but that would be accessible to labor union members, politicians, [and] public opinion. I had to convince the Government to adopt my plan project, to convince the Economic and Social Council to emit a favorable overall opinion, [and] to convince the Parliament to vote it [into effect]. I repeat the word sconvinces three times because this was an essential part of my job, carried out for seven years with a respectable measure of success. Voting for the plan [into effect] is an important act - the Nation's commitment to itself [...] In sum, I had a responsability of a political nature that went beyond the mission of the experts ${ }^{157}$.

Im Unterschied zur Bundesrepublik, wo es beim Wiederaufbau primär um die Rekonstruktion bereits angelegter Wirtschaftsstrukturen ging, galt dies für die französische Gesellschaft nicht. Hier waren es sozio-ökonomische Modernisierungsdefizite, die es in einem umfassenden "Plan der Modernisierung und Ausrüstung « (Monnet) aufzuholen galt ${ }^{158}$. Die Sprache der Bewahrer war meist indirekter Natur, und da sie nicht in den Pariser Magazinen oder Verlagshäusern reproduziert wurde, droht sie leicht in Vergessenheit zu geraten. Daß die französische Gesellschaft in dem überwiegend agrarisch geprägten Land noch tief in den traditionalen Strukturen einer Klassengesellschaft verwurzelt war, sollte bei aller Prominenz des Fortschrittsdiskurses nicht übersehen werden. In seinem Buch "La République se meurt « hat der französische Historiker Michel Winock den spannungsreichen »Geisteszustand « dieser Zeit mit einiger Ironie nachgezeichnet:

Frankreich war damals nicht zwischen der Rechten und der Linken zerrissen, sondern zwischen den Anhängern der Modernität und den Verteidigern der vorkapitalistischen und malthusianischen Gesellschaft [...] Zum ersten Lager zählte man alle Sektierer des Fortschritts, die saintsimonistischen Ingenieure, die Polytechniker, die Freunde der menschlichen Gattung, die fortschrittlichen Pfarrer, die gelehrten Frauen, die Studenten der ENA, die Automobilbauer, die Gewerkschafter, die Leser von Fourastié, die Wachstumsökonomen, die Verkünder des Marxismus, die keynesianischen Professoren, die Eisen- und Stahlwerker, die Bediensteten der INSEE, die Journalisten von Le Monde, der Verlag Éditions du Seuil und die militanten Vertreter der birth control [...] Im anderen Lager tummelte sich, wer das Landleben pries [...], die kleinen Händler, die Schankwirte, die Bistros, die Monsieur Paul Ricard reich machten, das radikale, protektionistische, flaggenschwenkende Frankreich des 19. Jahrhunderts, mit allem, was dazugehört: Notare, Anwälte, Amtsdiener, traditionelle Pfarrer, Boulespieler mit Baskenmütze, bellende Hunde, mit Glasscherben eingefaßte Mauern, aktive Mitglieder des Guillaume-Budé-Verbandes, Branntweinbrenner, Kolonialverwalter und alte Bordellinhaber. Zu ihnen allen gesellten sich jene hinzu, die Marschall Pétain treu geblieben waren ${ }^{159}$.

Diese ironisch überspitzte Darstellung bringt die Spannungen innerhalb der französischen Gesellschaft auf den Punkt. Um diese konkreter zu veranschaulichen, wird im folgenden versucht, einige exponierte technologische Projekte zu beschreiben, die als »champions nationaux« stellvertretend für

157 HeCHT, Planning a Technological Nation, S. 154.

158 Werner ABelshauser, Westeuropäische Trends und Außenhandelsverflechtungen, in: SCHILDT, SYwotTEK (Hg.), Modernisienung im Wiederaufbau, S. 44.

159 Michel Winock, La République se meurt, zitiert nach Rosanvallon, Der Staat in Frankreich, S. 180. 
den Versuch einer staatlich geplanten Modernisierung in Frankreich analysiert werden.

Nach Pierre Rosanvallon stellte die Politik der Initiierung großer industrieller Projekte neben der Strategie der »ökonomischen und industriellen Erziehung der Nation« und der Praxis einer korporatistischen Administration den dritten Pfeiler der Beziehungen des modernisierenden Staates zur französischen Wirtschaft in der Zeit zwischen 1945 und 1970 dar $^{160}$. Während die beiden letzteren Pfeiler auch als Konzept einer »horizontalen Industriepolitik « beschrieben werden könnten, die darauf abzielte, ein flächendeckendes industrielles Wachstum zu fördern, wurde mit der Präsidentschaft de Gaulles zunehmend eine »selektive Industriepolitik« betrieben, die durch gezielte sektorale Eingriffe vorangetrieben wurde. Spiegel dieser selektiven Industriepolitik sind zum einen die zahlreichen Konzentrationsprozesse in Form von Unternehmensfusionen, zum anderen die ehrgeizigen technologischen Großprojekte in einer Reihe strategischer Industriezweige.

Die komplexen Verflechtungen des französischen Staates mit der Privatwirtschaft (Beteiligungen, Kreditvergabe, Subventionen) machen die wirtschaftshistorische Rekonstruktion dieser Beziehungen zu einem hochkomplizierten Geflecht, das zu analysieren an dieser Stelle nicht einmal annähernd unternommen werden kann. Fernand Braudel und Ernest Labrousse bringen diesen komplexen Sachverhalt in ihrer Wirtschafts- und Sozialgeschichte Frankreichs in einem Satz auf den Punkt. »Der Staat«, so heißt es dort kurz und bündig, »war bei den großen Fusionen, die sich Ende der 60er Jahre vollzogen haben, niemals abwesend ${ }^{161}$. An dieser Stelle sollen lediglich einige dieser Großprojekte skizzenhaft vorgestellt und stellvertretend als Symbole der »modernisation à la française« analysiert werden.

\subsubsection{Technologische Großprojekte und »champions nationaux«}

Et enfin, il y avait une valeur de prestige, d'intérêt national, qui s'attachait à tout ça, notamment notre prestige auprès des pays du tiers-monde; il s'agit de montrer que notre pays, qui à la réputation d'être le pays des parfums, des fromages et de la mode, est aussi une grande nation scientifique et technique ${ }^{162}$.

Dieses Zitat des französischen Staatspräsidenten Charles de Gaulle ist nur eines von vielen, das man anführen könnte, um jenen Stellenwert zu demonstrieren, den de Gaulle der modernen Technik im Prozeß der französischen Identitätskonstruktion nach 1945 zusprach. Trotz der bekannten Zitate zu diesem Thema aus dem reichen Bestand seiner »Mémoires« ist de Gaulles Ver-

160 RosanVallon, Det Staat in Frankreich, S. $180 \mathrm{ff}$.

161 Fernand Braudel, Emest Labrousse (Hg.), Histoire économique et sociale de la France, Bd. 4, L'ère industrielle et la société d'aujourd'hui (1880-1980), Paris 1982, S. 1134.

162 Alain Peyrefitte, C'était de Gaulle, Bd. 2, Paris 2000, S. 400. 
hältnis zu Technik und Wissenschaft bislang kaum thematisiert worden ${ }^{163}$. In einem der wenigen Artikel zu diesem Thema weist Olivier Wieviorka auf den Einfluß von Denkern wie Maurice Barrès oder Henri Bergson auf de Gaulles Technikverständnis hin ${ }^{164}$. Während die reine Wissenschaft kaum de Gaulles Interesse fand, hat er der angewandten Technik, auch wegen ihrer großen militärischen Bedeutung, immer besondere Aufmerksamkeit geschenkt. Im Gegensatz zur Wissenschaft, in der es laut de Gaulle alleine um die Frage der Wahrheit geht, habe die Technik immer einen direkten Einfluß auf den menschlichen Handlungsspielraum gehabt. Wieviorka charaktersiert de Gaulles Verhältnis zur Technik mit den Worten: »Aucune technique n'est, en soi, bonne ou mauvaise. La technique subordonnée à l'action, la matière rejetée dans le domaine des forces mécaniques. [...] Charles de Gaulle se situe décidément dans le droit fil d'une tradition philosophique qu'il complète par une lecture historique de la société technicienne ${ }^{165}$.

Es verwundert daher nicht, daß die Anwendung einer gänzlich neuen und politisch wie militärisch machtvollen Technologie bereits $1945 \mathrm{zu}$ einem der zentralen Anliegen de Gaullescher Politik wurde: die Entwicklung einer französischen Atombombe. Allerdings nuanciert Robert Frank die pur militärische Dimension der Atombombe im Politikdesign de Gaulles. Laut Frank waren de Gaulles Atombombenpläne von Anfang an als Antwort auf die Krise der nationalen Identität Frankreichs gedacht und nur zum Teil den objektiven Sicherheitsbedürfnissen Frankreichs geschuldet ${ }^{166}$.

Doch soll an dieser Stelle nicht die französische Sicherheitspolitik (Stichwort »force de frappe«) diskutiert werden, sondern gezeigt werden, welche industriepolitischen Weichen und kulturellen Modernisierungsbestrebungen mit dem Aufbau einer französischen Nukleartechnik verbunden waren ${ }^{167}$. Mit der 1945 initiierten Gründung des Commissariat à l'Énergie Atomique (CEA) hatte de Gaulle die Weichen für Frankreichs Eintritt in das »nukleare Zeitalter« gestellt. Die Atombombe war für de Gaulle aber nicht nur Symbol

163 Dies hat sicherlich auch mit der schwierigen Quellenlage zu tun. Dem Autor war es nicht gestattet, den Nachlaß von Charles de Gaulle einzusehen, der im Centre d'Études Charles de Gaulle konserviert wird. Auch die Präsidentschaftspapiere des Elysées unterliegen noch der archivalischen Sperffrist von personengebundenen Akten.

164 Olivier Wieviorka, Charles de Gaulle, la technique et les masses, in: Institut Charles de Gaulle (Hg.), De Gaulle en son siècle, Bd. 3, Paris 1993, S. 713-723.

165 Ibid. S. $714 \mathrm{f}$.

166 Frank, Mentalitäten, S. 178.

167 Zur Rolle der Atomenergie im französischen Sicherheitsdenken siehe Philip G. CERNY, Frankreich und die Nukleardebatte der Atlantischen Allianz 1956-1966, Opladen 1998. Aus wissenschaft- und technikhistorischer Sicht siehe die Beiträge Paul Rigal, Marcel Duval, André Cachin, Henri Piatier, Pierre Lurien und Paul Bonnet in dem vom Comité pour l'histoire de l'armement herausgegebenen Band »Les ingénieurs militaires et l'émergence d'une nouvelle industrie française de l'armement (1945-1960)«, Paris 2000. 
technischen Forschritts und militärischer Macht, sondern auch Ausdruck der amerikanischen Überlegenheit. Insofern verkörpert das französische Nuklearprogramm neben dem Bedürfnis, sich der eigenen wissenschaftlich-technischen Leistungsfähigkeit zu vergewissern, auch eine klare machtpolitische Demonstration, die als Ausdruck eines unterschwelligen Anti-Amerikanismus gedeutet werden kann. Bereits 1968 deutete der amerikanische Politologe Robert Gilpin die französische Planpolitik im Bereich der Forschung und Entwicklung als modernistische Variante französischen Politikverständnisses im Sinne der "politique de grandeur « und des »besoin de rayonnement «:

This capacity to express French genius in the world (le besoin de rayonnement) is believed to be threatened by the expansion of American power and influence throughout the world [...] In place of the callous competition and Babel of modern materialism which Frenchmen identify with business-dominated American society, the plan is considered to be an essential instrument by means of which the state can guide economic and social modernization while preserving the integrity of French civilization ${ }^{168}$.

Auch wenn der Anti-Amerikanismus als Faktor in der französischen nationalen Identitätsbildung nicht überschätzt werden sollte, bringt Gilpin einen zentralen Gedanken der französischen Planpolitik auf den Punkt: Modernisierung ja, aber: à la française! Das heißt, ohne das missionarische Projekt der "civilisation française« zu gefährden. Der innige Zusammenhang zwischen Modernisierungsbestrebungen auf der einen und der Wahrung einer wie auch immer gearteten »Frenchness«, "civilisation française « oder "nationalen Identität « auf der anderen Seite zeichnet den ambivalenten Prozeß französischer Modernisierung nach 1945 aus. Diese Ambivalenz von Modernisierung und Bewahrung, Tradition und Vision verlangte von den politischen, intellektuellen oder wirtschaftlichen Eliten Frankreichs aber, daß sie ständig deutlich machen mußten, was denn nun das eigentlich französische ihrer Modernisierungsbestrebungen war. Schließlich wurde nicht nur in Frankreich im Bereich der Atomenergie geforscht, wurde nicht nur in Frankreich an der Entwicklung neuer Technologien im Bereich des Transports oder der Telekommunkation gearbeitet.

Die oft wiederkehrende Gegenüberstellung »französischer Zivilisation« und "amerikanischer Kommerzialisierung « wurde diesem Kunstgriff nicht gerecht $^{169}$. Es bedurfte schon besonderer sprachlicher Fähigkeiten, diese Ambivalenz in einprägsame Formulierungen zu übersetzen. Wie so häufig gelang dies Charles de Gaulle - auch bezüglich des französischen Atombombenprogramms - auf beeindruckende Weise. Es gehe darum, wie der Meister

168 Grlpin, France in the Age of Scientific State, S. $12 f$.

169 Siehe hierzu den Literaturbericht von Herrick ChAPMAN, Modernity and National Identity in Postwar France, in: French Historical Studies 22 (1999) 2 S. 291-314. 
wohlüberlegter Worte ${ }^{170}$ knapp formulierte, zu zeigen, »que la défense de la France soit française « ${ }^{171}$ ! Als am 13. Februar 1960 die erste französische Atombombe in der Sahara geziundet wurde, telegrafierte de Gaulle dem ehemaligen Leiter der CEA und damaligen Verteidigungsminister Pierre Guillaumat seine herzlichsten Glückwünsche: "Hourra pour la France! Depuis ce matin, elle est plus forte et plus fière. Du fond du coeur, merci à vous et à ceux qui ont pour elle remporté ce magnifique succès ${ }^{172}$.

Es ist der amerikanischen Technikhistorikerin Gabrielle Hecht zu verdanken, die komplexe Beziehung zwischen dem Aufbau der französischen Nukleartechnik und der Konstruktion nationaler Identität im Nachkriegsfrankreich in ihrem Buch »The Radiance of France: Nuclear Power and National Identity after World War $\Pi \ll$ analysiert zu haben ${ }^{173}$. Für Hecht stellt der französische Diskurs über nationale Identität nach 1945 jene Brücke dar, welche »a mythologized past and a coveted future « verbinde:

In postwar France, the notion of radiance is precisely such a bridge: radiant through its empire before the war, France must maintain its radiance to maintain its Frenchness.[...] Technological prowess has staked a firm claim as a basic element of French national identity. At least rhetorically, the builders of a high-speed train (the TGV), the Minitel communication system, the Concorde airliner, the Ariane rocket, and numerous other technological systems continue to cultivate the association between technology and French radiance - even when these systems are developed in cooperation with other European nations ${ }^{174}$.

Sich konzentrierend auf die beiden Institutionen Commissariat à l'Énergie Atomique (CEA) und der nationalen Elektrizitätsgesellschaft Electricité de France (EDF) hat Hecht die in politischen oder wirtschaftlichen Entscheidungsgremien oftmals unterschiedlichen Vorstellungen über die Zukunft Frankreichs als Atommacht untersucht. Interessanter noch als die Analyse der unterschiedlichen Modernisierungsstrategien, die anhand der konkurrierenden Vorstellungen über die einzuschlagende Reaktortechnik sichtbar werden, ist Hechts Beschreibung der Reaktion der ländlichen Bevölkerung auf den Bau von Atomreaktoren in ihrer Umgebung. Dadurch gelingt es ihr, das abstrakte Phänomen der »modernisation à la française« auf die Ebene vergleichender Regionalgeschichte "herunterzudimmen«. Dabei weist sie nach, daß der Bau und der Betrieb von Atomkraftwerken als nationale »Spektakel«

170 Zur Bedeutung der Sprache im politischen Auftreten de Gaulles siehe: Frank CostiglioLA, Power and Language: The French Connection, in: Contemporary European History 2 (1993) 1 S. 69-80. Dort heißt es: »De Gaulle's entire career demonstrated that language, carefully crafted and masterfully delivered, was power «, S. 77.

171 Zitiert nach Jean ToucharD, Le Gaullisme (1940-1969), Paris 1978, S. 199.

172 Ibid.S. 200.

173 Gabrielle Hecht, The Radiance of France. Nuclear Power and National Identity after World War II, Cambridge, London 1998. Siehe auch die Rezension, die der Autor in der Zeitschrift Technikgeschichte 68 (2001) 3 S. 288-289, veröffentlicht hat.

174 HeChT, The Radiance of France, S. 13 und 329. 
inszeniert wurden, welche die Form eines Dramas oder einer Zurschaustellung annehmen konnten. Während die dramatische Form der Inszenierung darauf abzielte, die französischen Atomkraftwerke als den wiedergewonnenen AnschluB Frankreichs an die technologische Weltspitze zu feiern, machte die Zurschaustellung die Atomkraftwerke zu modernen Kathedralen und Touristenattraktionen: »Both kinds of spectacle«, so Hecht, »made large-scale technological change into something the public could consume - be regarding, gazing, and touring. [...] The spectacle of nuclear development in the Gard [Region im Rhônetal, A.d.V.] took the form of dramatic narratives in which modernity became reconciled with the tradition in order to save the region from decline $\ll .{ }^{175}$

Der Vergleich von Atomkraftwerken mit architektonischen Kunstwerken wie dem Eiffelturm, dem Arc de Triomphe oder Notre-Dame machte es möglich, auch die entlegensten Ortschaften in der französischen Provinz zu Zentren des Fortschritts und kultureller Größe zu erheben. Im Gegensatz zu den verschmutzten Kohlekraftwerken konnten Atomkraftwerke problemlos zu »strahlenden« Kunstwerken mutieren, die als Ausflugsziel sonntäglicher Spazierfahrten dienten. Das Kernkraftwerk in Marcoule an der Rhône konnte sich so mühelos in die Tradition einer Urlaubs- und Erhohlungslandschaft einreihen, denn »esthetic considerations concerned local officials more than safety issues « ${ }^{176}$ !

Gehören die französischen Modernisierungsanstrengungen im Bereich der Nukleartechnik zu den markantesten Beispielen französischer Wissenschafts- und Industriepolitik der Nachkriegszeit, könnten zahlreiche weitere Beispiele angeführt werden. So etwa die international bekannten Bemühungen im Bereich der zivilen (Concorde ${ }^{177}$, Airbus ${ }^{178}$ ) wie militärischen (Mi-

175 Ibid.S. 202 und 220.

176 Ibid. S. 121. Das Beispiel Marcoule führt Hecht auch in dem Aufsatz »Peasants, Engineers, and Atomic Cathedrals: Narrating Modernization in Postwar Provincial France « weiter aus. Siehe French Historical Studies 20 (1997) 3 S. 381-418. Zum Thema Verschmelzung von Natur und Technik siehe Sarah Pritchard, Reconstructing the Rhône: The Politics of Nature and Nation in Contemporary France (1945-1997), in: French Historical Studies 27 (2004) 4 S. 765-800.

177 Elliot J. Feldmann, Concorde and Dissent: Explaining High-Technology Project Failures in Britain and France, New York 1985; Hartmut Berg, Gerhard MAmmen, Alternative Strategien staatlicher Technologieförderung: eine Analyse der Projekte »Concorde« und »Airbus«, Essen 1981; Kenneth OwEN, Concorde and the Americans: International Politics of the Supersonic Transport, Washington 1997; Geoffrey JACKson, Concorde Diplomacy: The Ambassador's Role in the World of Today, London 1981.

178 Ulrich KiRCHNER, Das Airbus-Projekt (1965-1990). Genese, Eigendynamik und Etablierung am Markt, in: Johannes WEYER, Ulrich KIRChNER, Lars RiedL, Johannes K. SCHMIDT (Hg.), Technik, die Gesellschaft schafft. Soziale Netzwerke als Ort der Technikgenese, Berlin 1997, S. 101-146; Pierre Muller, Airbus, l'ambition européenne: logique d'Etat, logique du marché, Paris 1989; David Weldon ThORNTon, Airbus Industrie: The Politics of an International Industrial Collaboration, New York 1995. 
rage $^{179}$ ) Luftfahrt, der schienengebundenen Fahrzeugtechnologie $\left(\mathrm{TGV}^{180}\right)$, der Raumfahrt (Ariane) oder der Elektronik (Plan Calcul ${ }^{181}$ ) und Telekommunikation (Minitel ${ }^{182}$ ). Aber auch weniger spektakuläre Programme wie das 1967 beschlossene Eisenhüttenprojekt von Fos-sur-Mer ${ }^{183}$, das 1976 entwickelte Programm zur Produktion elektronisch gesteuerter Werkzeugmaschinen ${ }^{184}$, die generellen Modernisierungsbemühungen im Bereich der Landwirtschaft ${ }^{185}$ oder die großen Pariser Wohnungsbauvorhaben in La Villette oder La Défense könnte man als Beispiel staatlich initiierter und moderierter Modernisierungspolitik anführen ${ }^{186}$.

Ist der technische Output dieser Projekte in der Mehrzahl durchaus positiv zu bewerten, fällt die ökonomische Bilanz insgesamt weniger eindeutig aus ${ }^{187}$. So wurde alleine das Nettodefizit der »Opération Concorde« im Jahre 1980 auf 35 Milliarden Francs beziffert und der »Plan Calcul« als »fiasco de 40 millions « beschrieben. In der politischen Strategie der Großprojekte wurde das ökonomische Kalkül dem symbolischen Mehrwert jedoch untergeordnet. Das Konzept der staatlichen Förderung strategischer Sektoren wurde von dem politischen Bestreben getragen, nationale Prestigeobjekte zu fördern.

179 François Le Roy, The Elusive Pursuit of Grandeur and Independance: Mirage Diplomacy, French Foreign Policy and International Affairs, 1958-1970, Diss. University of Kentucky 1997.

180 Babette NIEDER, TGV und ICE im Spannungsfeld von Politik, Verwaltung und Industrie (1968-1991). Ein deutsch-französischer Vergleich, Herne 1997; E. R. PowELL, The TGV-Project: A Case of Technico-Economic Dirigism?, in: Modern and Contemporary France 5 (1997) S. 197-214; Stefan ZeILINGER, Wettfahrt auf der Schiene. Die Entwicklung von Hochgeschwindigkeitszügen im europäischen Vergleich, Frankfurt a.M. 2003.

181 Pierre Mounier-KunN, History of Computing in France, New York u.a. 1989; Ders., La compagnie des machines Bull et l'industrie informatique américaine: compétition et coopération, in: Hans PoHL ( $\mathrm{Hg}$.$) , Competition and Cooperation of Enterprises on National and International$ Markets $\left(19^{\text {th }}-20^{\text {th }}\right.$ century), Stuttgart 1997, S. 87-103; Pascal GrISET (Hg.), Informatique, politique industrielle, Europe entre Plan Calcul et Unidata, Paris 1998; Pierre GadonneIX, The plan calcul. An Attempt to Meet the U.S. Challenge in the French Computer Industry, Diss. Harvard Univ. 1975; Jean-Pierre BrulÉ, L'informatique, malade de l'État: du Plan Calcul à Bull nationalisée, un fiasco de 40 milliards, Paris 1993.

182 Michel ABAdIE, Minitel Story: le dessous d'un succès, Lausanne 1988; Jean-Yves RINCÉ, Le minitel, Paris 1994; Amy L. Fletcher, France Enters the Information Age: A Political History of Minitel, in: History and Technology, 18 (2002) 2 S. 103-117.

183 Bernard Paillard, La damnation de Fos, Paris 1981.

184 Zur metallverarbeitenden Industrie siehe Jean G. PADIOLEaU, Quand la France s'enferre, Paris 1981 sowie Michel FrEYsSENET, La sidérurgie française 1945-1975, Paris 1979.

185 Pierre Muller, Le Technocrate et le Paysan, Paris 1984.

186 Rosanvallon, Der Staat in Frankreich, S. 184. Zum Thema »aménagement du territoire « siehe Olivier Guichard, Aménager la France, Paris 1965, sowie Michel Rochefort, Catherine Bidault, Michèle Petit, Aménager le térritoire, Paris 1970.

187 Eine kritische Analyse der Politik der Großprojekte findet sich bei Elie CoHEN, Le Colbertisme "high-tech«, Paris 1992, sowie Ders., France: National Champions in Search of a Mission, in: Jack HAYWARD, (Hg.), Industrial Enterprise and European Integration. From National to International Champions in Western Europe, Oxford 1995, S. 23-47. 
Pierre Rosanvallon faßt die Bedeutung dieser Politik der Großprojekte wie folgt zusammen:

Vor allem wurden diese gefördert, weil sie den Eindruck effektiven Staatshandelns vermitteln konnten. Die Politik der GroBprojekte bildete den Kem der Rhetorik über politische Strategien. Dazu war sie besonders geeignet, weil sie den Abstand zwischen Entscheidung und der Ausführung aufhob. Dem Großprojekt ist zu eigen, daß es die Gleichzeitigkeit von Programmatik und Realisierung möglich macht. [...] Insofern vereinfacht die Lancierung eines Großprojektes die Beziehung zwischen Staat und Gesellschaft: durch die Verringerung des Abstandes zwischen Sagen und Tun wird die Möglichkeit des Scheiterns ausgeschlossen; das Großprojekt ist ein Monument, welches staatliche Herrschaft über die materielle Welt zum Ausdruck bringen soll. Insofern ist das wirtschaftliche Ergebnis in gewisser Weise von sekundärer Bedeutung. Vielmehr scheint es, als ob es vor allem darauf ankomme, daB der Staat symbolisch vorführt, daB er kann, wenn er nur will ${ }^{188}$.

Wie Michael Bess aufgrund der Analyse von Meinungsumfragen nachgewiesen hat, wurden die Großprojekte von der überwiegenden Mehrheit der Franzosen als durchaus positiv für Frankreich gewertet ${ }^{189}$. Im Gegensatz zu den teilweise heftigen Angriffen von seiten der Privatindustrie scheint das Konzept der "modernisation par en haut « aus mentalitätshistorischer Perspektive somit aufgegangen zu sein. Will man sich dem komplexen Phänomen der Modernisierung jedoch in alltagsgeschichtlicher und kulturhistorischer Perspektive nähern, kommt man an regionalhistorischen Untersuchungen nicht vorbei $^{190}$. Erst der kleinere Fokus regional begrenzter Untersuchungsräume macht es möglich, die komplexe Beziehung von staatlicher Modernisierungspolitik und Identitätsbildung halbwegs nachvollziehbar zu machen. Auch wenn zu diesem Fragenkomplex in den letzten Jahren bereits einige Arbeiten vorgelegt wurden, bleibt auf diesem Gebiet noch viel zu tun ${ }^{191}$.

Neben dem geographischen Fokus sind generationenspezifische Untersuchungen eine weitere Möglichkeit, makro- und mikrohistorische Fragestellungen in einen fruchtbaren Bezug zueinander zu bringen ${ }^{192}$. Erst diese Stu-

188 Rosanvallon, Der Staat in Frankreich, S. 184.

189 Michael Bess, Ecology and Artifice: Shifting Perceptions of Nature and High Technology in Postwar France, in: Technology and Culture 36 (1995), S. 830-862.

190 Eine interessante Perspektive bietet der Filmhistoriker Pierre Sorlin in dem Aufsatz "Stop the Rural Exodus «: Images of the Country in French Films of the 1950s, in: Historical Journal of Film, Radio and Television 18 (1998) 2, S. 183-197, sowie Marie-Françoise LÉvy, Television, Family and Society in France 1949-1968, in: ibid. S. 199-212.

191 Siehe beispielsweise Susan Carol Rogers, Shaping Modem Times in Rural France: The Transformation and Reproduction of an Aveyronnais Community, Princeton 1991; Rosemary Wakeman, Modernizing the Provincial City: Toulouse 1945-1975, Cambridge 1997; Robert L. Frost, The Flood of »Progress«: Technocrats and Peasants at Tignes (Savoy), 1946-1952, in: French Historical Studies 14 (1985) 1, S. 117-140; Hubert Bonin, Sylvie GuIllaume, Bernard LaCHAise (Hg.), Bordeaux et la Gironde pendant la Réconstruction (1945-1954), Bordeaux 1997.

192 Siehe Anne-Marie SoHn, Âge tendre et tête de bois. Histoire des jeunes des années 1960, Paris 2001; Jean-François Sirinellı, Les baby-boomers: une génération (1945-1969), Paris 
dien werden es erlauben, die »feinen Unterschiede« in der lokalen oder regionalen Wahrnehmung und individuellen oder kollektiven Deutung der französischen Modernisierungsanstrengungen herauszuarbeiten. Vielleicht werden diese Arbeiten dazu führen, die heute unter den Schlagworten »Amerikanisierung «, "Westernization" oder "Anti-Amerikanismus « kursierenden kulturhistorischen Untersuchungen stärker an die erlebnishafte Realität der historischen Akteure zu binden ${ }^{193}$. Wie die Arbeit von Rosemary Wakeman über Toulouse zeigt, müssen jene eher abstrakt argumentierenden Studien, die die französische Nachkriegsgesellschaft generell als »amerikafeindlich" und "chauvinistisch « charakterisieren, einer nuancierteren Bewertung weichen: "For most people in Toulouse, the issue was not so much Americanization as the danger that the venerable old capital of the southwest would come to resemble Paris and its suburbs ${ }^{194}$ !

Bevor nun das französische SECAM-Farbfernsehsystem als Beispiel der staatlich instrumentalisierten Modernisierungskampagne und Medium der auBenpolitischen Neuorientierung Frankreichs unter de Gaulle analysiert wird, $\mathrm{muB}$ - wie für die Bundesrepublik ebenfalls geschehen - der engere rundfunkindustrielle Rahmen abgesteckt werden, innerhalb dessen die zentralen SECAM-Akteure agiert haben. $\mathrm{Zu}$ diesem Zweck wird in einem ersten Schritt der gröbere Kontext der französischen Modernisierungsbestrebungen im Bereich der Elektroindustrie vorgestellt, um dann auf die an der Entwicklung und Vermarktung des SECAM-Systems unmittelbar beteiligten Unternehmen und Institutionen eingehen zu können.

\subsubsection{Die französische Elektroindustrie zwischen Staat und Markt ${ }^{195}$}

Quelle que soit l'orientation politique des pouvoirs publics, l'électronique a toujours fait le consensus: elle est considérée comme une branche industrielle noble, de >pointe $<$, susceptible de permettre à la France d'affronter la compétition internationale ${ }^{196}$.

2003; Dietmar HüsER, RAPublikanische Synthese. Eine französische Zeitgeschichte populärer Musik und politischer Kultur, Köln u.a. 2004.

193 Siehe hierzu den anregenden Aufsatz von Michèle LAMONT, National Identity and National Boundary Patterns in France and the United States, in: French Historical Studies, 19 (1995) 2 S. 349-365.

194 Chapman, Modernity and National Identity in Postwar France, S. 307. Chapmans Kritik richtet sich gegen die manchmal zu oberflächlich argumentierende Studie von KuISEL, Seducing the French.

195 Diese Kapitalüberschrift ist als Referenz auf das Werk von John ZYSMAN: L'industrie française entre l'État et le marché, Paris 1972, zu verstehen.

196 Jocelyne BARREAU, Abdelaziz Mouline, L'industrie électronique française: 29 ans de relations État-groupes industriels (1958-1986), Paris 1987. 
Mit diesem Statement beginnen die beiden französischen Wirtschaftswissenschaftler Jocelyne Barreau und Abdelaziz Mouline ihre 1986 publizierte Darstellung der Beziehungen des französischen Staates zur elektrotechnischen Industrie in Frankreich zwischen 1958 und 1986. Obschon einige wenige Arbeiten im Bereich der Geschichte der französischen Elektroindustrie, spezieller im elektronischen Konsumgüterbereich vorliegen ${ }^{197}$, konzentrieren sich die folgenden Ausführungen über die engen Beziehungen zwischen dem französischen Staat und der elektrotechnischen Industrie im wesentlichen auf die Arbeit von Barreau und Mouline, da sie in prägnanter Weise die strukturelle Verflechtung beider Wirtschaftsakteure rekonstruieren und somit personelle und institutionelle Beziehungen verdeutlichen ${ }^{198}$.

Gleich zu Beginn ihrer Darstellung differenzieren die beiden Autoren die zentralen wirtschaftspolitischen Akteure auf staatlicher und privatwirtschaftlicher Ebene. Dabei unterscheiden sie auf staatlicher Ebene drei Kompetenzoder Einflußbereiche: 1. Les organismes de tutelle sectorielle; 2 . Les organismes de tutelle fonctionelle und 3. Les organismes interministériels. Die »sektoriellen Schutzorganismen« haben die Aufgabe, Beziehungen zu einem bestimmten industriellen Sektor zu unterhalten. Diese Beziehungen können die Form beobachtender Natur, begleitender Unterstützung oder direkter EinfluBnahme haben. So können etwa technische Entscheidungen der »Direction Générale des Télécommunications « unmittelbare Auswirkungen auf die Unternehmen der Telekommunikationsindustrie haben, deren Hauptkunde wiederum der französische Staat ist. Die »funktionellen Schutzorganismen« haben präzisere Aufgaben, die den industriellen Sektor weit überschreiten können. Hier geht es um Preisfestlegungen, Exportförderungen oder direkte Subventionen. Als staatliche Institutionen dieser Kategorie fungieren die unterschiedlichen Abteilungen des Finanzministeriums (Steuer, Haushalt, Schatzmeister) sowie die "satellites para-administratifs« wie der Crédit National oder die Caisse Nationale des Marchés de l'Etat. Schließlich bilden die »interministeriellen Organismen« eine dritte Kategorie von staatlichen Eingriffsmöglichkeiten in die Privatwirtschaft. Diese interministeriellen Organismen fungieren dabei eher als Koordinationsstellen der unterschiedlichen staatlichen Aktivitäten in einem industriellen Sektor. In diese Kategorie gehört auch das bereits ausführlich beschriebene Commissariat Général au Plan

197 Siehe Chantal Le Bolloc'h-Puges, La Politique industrielle française dans l'électronique, Paris 1991; Griset (Hg.): Informatique, politique industrielle.

$198 \mathrm{Zu}$ Recht weist Pierre Mounier-Kuhn in der Einleitung seiner Dissertation darauf hin, daß es sich bei der Arbeit von Barreau und Mouline nicht um eine im eigentlichen Sinne historische Arbeit handelt, da sie fast ausschließlich Sekundärliteratur für ihre Argumentation heranziehen. Wegen der strukturellen Analyse der Beziehungen zwischen französischem Staat und der Industrie ist sie für unserer Zwecke dennoch hilfreich. Siehe Pierre Mounter-Kunn, Histoire de l'informatique en France, Paris 1995. 
oder die »Délégation à l'aménagement du Territoire et à l'Action Régionale« (DATAR), eine zentrale Behörde, die den französischen Zentralismus abschwächen und die Regionalisierung fördern sollte.

Die Ernennung eines »Délégué interministériel pour la télévision en couleurs« im Frühjahr 1965 macht klar, daß wir es bei der Farbfernsehfrage vor allem mit der dritten Form staatlicher Einflußnahme zu tun haben. Da die Interventionen in allen drei Bereichen indirekter (z.B. durch Einwirkung auf das Umfeld, in dem ein Unternehmen agiert) oder direkter Natur sein können, ist es für den rekonstruierenden Historiker nicht leicht, die komplexen Entscheidungswege und Handlungsmuster genau nachzuvollziehen.

Neben den staatlichen Akteuren gestehen Barreau und Mouline auch den großen industriellen Konzernen die Rolle industriepolitischer Akteure zu. Oftmals mit Hilfe staatlicher Subventionen oder Beteiligungen entstanden, bestimmten einige wenige große Unternehmen die elektrotechnische Unternehmenslandschaft in Frankreich seit Mitte der sechziger Jahre. Zu ihnen zählen Firmen wie Thomson, CGE, MATRA, CSF oder BULL, die Anfang der achtziger Jahre 50\% der elektrotechnischen Produktion Frankreichs herstellten ${ }^{199}$. Barreau und Mouline gehen in ihrer Darstellung der französischen Elektroindustrie von der Hypothese aus, "que l'on ne peut comprendre la situation actuelle de l'industrie électronique française sans analyser les relations complexes qui s'établissent entre le système de décision étatique et le système de décision des groupes industriels. Nous sommes donc en présence de deux systèmes de décision profondément interdépendants et hétérogènes « ${ }^{200}$.

Um diese komplexe Abhängigkeit staatlicher und privatwirtschaftlicher Entscheidungsstrukturen zu visualisieren, haben die beiden Autoren ein Organigramm entwickelt, welches die Interdependenzen zwischen staatlichen und privatwirtschaftlichen Akteuren aufzeigt. Wie Barreau und Mouline betonen, funktionierten die beiden dargestellten Entscheidungsebenen bis Ende der sechziger Jahre in einem ökonomischen, politischen und sozialen Umfeld, das vornehmlich national geprägt war, während es ab Anfang der 70er Jahre zunehmend international geprägt war. Da sich der Zeitraum unseres Unter-

199 Barreau, Mouline, L'industrie électronique française, S. 11. Auch im Bereich der Rundfunkindustrie ist eine ähnliche Konzentration zu beobachten: Gab es 1948 noch ca. 3000 Firmen im Branchenverzeichnis »Hörfunk und Fernsehen«, sank diese Zahl im Laufe der 50er Jahre kontinuierlich um 1963 den Stand von 183 Unternehmen zu erreichen. Von diesen 183 Firmen realisierten 25 mehr als $83 \%$ der Produktion und $81 \%$ des Umsatzes. 1965 waren es nur noch 168 Unternehmen, von denen 4 (Thomson-Brandt, Philips, CSF und Continental Edison) 50\% Marktanteile hatten. Nach der Fusion von Thomson-Brandt und CSF 1967 machen die drei "global player « Thomson-CSF, Philips und die zu CGE gehörende Continental Edison 80\% der Produktion auf dem Radio- und Fernsehgebiet unter sich aus. Siehe Roger ANDREY, L'électronique française face à la couleur $I$, in: La Technique de l'exploitation cinématographique 289 (octobre 1967) S. 41-44.

200 Ibid. S. 13. 
suchungsgegenstandes schwerpunktmäßig in den $1960 \mathrm{er}$ Jahren befindet, haben wir es in diesem Fall mit einem überwiegend national geprägten Umfeld zu tun, in das Eingriffe anderer Staaten oder Konzerne eher selten waren. Wie sich im Laufe der Darstellung zeigen wird, können viele der Beziehungen, die Mouline und Barreau in ihrer Verflechtung der beiden Entscheidungsstrukturen aufgezeigt haben, auch im Falle der SECAM-Propagation wiedergefunden werden.

Dennoch deutete sich gerade in den Jahren von de Gaulles Präsidentschaft ein grundlegender Wandel der französischen Wirtschaftspolitik an, der von Wirtschaftshistorikern unter dem Stichwort »Öffnung zum europäischen Markt « behandelt wird. Die bewußte Wahl, die in den fünfziger Jahren stark protektionierte französische Wirtschaft verstärkt der europäischen Konkurrenz auszusetzen, bedeutete aber nicht, daß man zu einer liberalen Wirtschaftspolitik übergegangen war. Planwirtschaftliche Eingriffe waren auch für de Gaulle »une ardente obligation«. Charakteristisch für die Wirtschaftspolitik de Gaulles war vielmehr das Nebeneinander mehrerer Zielsetzungen, die sich auf den ersten Blick zu wiedersprechen scheinen: "Les grandes orientations économiques décisives pour le devenir de l'industrie française furent le choix de la compétition européenne, le recours à une planification indicative et le refus de la domination des techniques américaines ${ }^{201}$.

Das erklärte Ziel de Gaulles, die französische Industrie mit der europäischen Konkurrenz zu konfrontieren, erforderte eine entsprechende Umstrukturierung der Verwaltungsorganisation, die sich rückblickend vor allem in der sukzessiven Schwächung des Industrieministeriums zugunsten des Finanzministeriums zeigt. Dieser schleichende Kompetenzabbau des Industrieministeriums, so McArthur und Scott, ist aber nicht wirklich mit einer Neudefinition der gesamtstaatlichen Strukturen einher gegangen ${ }^{202}$.

Ein deutlicher Hinweis für die wachsende Bedeutung der Elektronik im industriepolitischen Kalkül Frankreichs ist die Gründung der »Commission Permanente de l'Électronique du Plan", die 1961 gegründet wurde. Sie war die einzige permanente Kommission des Planungsbüros und hatte die Aufgabe, die Bedeutung der Elektronik für die anderen industriellen Branchen zu beurteilen. In einem Perspektivplan der Kommission aus dem Jahre 1963, in der die Entwicklungsperspektiven, die aktuelle wirtschaftliche Bedeutung und die militärische Bedeutung einzelner Wirtschaftssektoren analysiert wurden, nahm die elektrotechnische Branche nach dem Erdöl bereits den zweiten Platz ein und war somit vorrangiger als die Branchen Chemie und Automobil$\mathrm{bau}^{203}$. Obschon die zentrale Bedeutung der elektrotechnischen Industrie -

201 Ibid. S. 25.

202 John MCARThUR, Bruce R. ScotT, L'industrie française face aux plans: Harvard ausculte la France, Industrial Planning in France, Paris 1970.

203 BarReau, Mouline, L'industrie électronique française, S. 34. 
vor allem im Bereich der elektronischen Bauteile - somit bereits Anfang der sechziger Jahre erkannt wurde, gab erst die »affaire Bull« im Jahre 1964 den Ansto $B \mathrm{zu}$ einer massiven staatlichen Intervention in den Bereich eines elektrotechnischen Konsumgütersektors: der Rechnerindustrie. Aber auch die Radio- und Fernsehindustrie war Teil des Plans. Am 22. April 1964 wurde im Zentralen Planungsbüro die Gründung der »Commission de la Radiodiffusion et de la Télévision« beschlossen, die die industrielle Bedeutung des Rundfunks für den anstehenden fünften Plan abschätzen sollte ${ }^{204}$. Aushängeschild des fünften Plans (1966-1970), der ganz den Konzentrationsbemühungen in industriellen Leitsektoren gewidmet war, wurde mit dem »Plan Calcul« jedoch ein ehrgeiziges Entwicklungsprogramm im Bereich der Informatikindustrie, dessen Resultate sehr kontrovers bewertet wurden.

Obwohl der »Plan Calcul« als Paradebeispiel der staatlichen Industriepolitik im Bereich der Elektroindustrie gilt, liegen diese Bemühungen zeitlich hinter den Ereignissen, die für die Geschichte der Farbfernsehkontroverse von Bedeutung sind. Es ist daher notwendig, sich jenen Institutionen auf staatlicher und privatwirtschaftlicher Ebene zuzuwenden, die seit Anfang der sechziger Jahre als Akteure der SECAM-Offensive aufgetreten sind.

\subsubsection{Henri de France und die »Compagnie Française de Télévision« (CFT)}

In Frankreich war die Entwicklung des SECAM-Systems mit dem Namen eines Mannes (Henri de France) und die Vermarktung des Systems mit dem einer Firma (CFT) verbunden. Im Gegensatz zur bundesdeutschen Entwicklung haben wir es bei Henri de France und der CFT jedoch nicht mit "Einzelkämpfern « zu tun, sondern mit einem ganzen SECAM-Netzwerk, in das industrielle und politische Akteure eng miteinander verwoben waren. Am Beginn der Ausbildung dieses Netzwerkes stand die SECAM-Patentanmeldung durch Henri de France im Mai 1956. Durch seine zahlreichen Kontakte gelang es Henri de France, den Generaldirektor der Compagnie de Télégrafie sans Fil (CSF), Maurice Ponte ${ }^{205}$, für sein Farbfernsehsystem zu interessieren. Da Ponte von der industriellen Zukunft des Farbfernsehens überzeugt war, kam es am 1. Dezember 1957 zur »Wiederbelebung« einer Firma namens Compagnie Française de Télévision, die seit einigen Jahren nur mehr auf dem Papier existierte. Maurice Ponte hatte den Generaldirektor des großen französischen Glaskonzerns Saint-Gobain, M. Grandgeorges, dafür gewinnen können, als Kapitalgeber für die Wiederbelebung der CFT aufzutreten. Beide Unternehmen (CSF und Saint-Gobain) waren mit 50\% an der CFT beteiligt, die Prä-

204 Siehe »Commission de la radiodiffusion et de la télévision au Commissariat Général du Plan d'Équipement et de la Productivité«, in: Bulletin de la FNIE 25 (juin/juillet/aoat 1964) S. (25)-5-130.

${ }^{205}$ Zur Person von Maurice Ponte siehe den Beitrag von L. Neel, wie Ponte Mitglied der Acedémie Française, in: http://www.radar-france.net/eloge_Ponte.htm (15. September 2005) 
sidentschaft sollte alternierend von Ponte und Grandgeorges wahrgenommen werden $^{206}$. Als Direktor der CFT wurde der Sohn des berühmten Generals Weygand, Edouard Weygand, eingesetz ${ }^{207}$. Ziel der CFT-Aktivitäten war es, das SECAM-System international bekannt zu machen und es - wenn möglich - als europäische Alternative zum NTSC durchzusetzen. Zu diesem Zweck wurde 1959 in Levallois ein Entwicklungszentrum eingerichtet, in dem Henri de France nach dem Konkurs seiner Firma Radio Industries mit einigen Mitarbeitern an der Weiterentwicklung des SECAM-Systems sowie der Entwicklung einer neuartigen Farbfernsehröhre forschen sollte ${ }^{208}$.

Obwohl der »Durchbruch « für das SECAM-System wie bereits geschildert erst mit den Demonstrationen auf der CCIR-Zwischentagung in Bad-Kreuznach im Juni 1962 gelang, setzten die Werbeaktivitäten bereits wesentlich früher ein. Schon auf der CCIR-Tagung in Moskau im Juni 1958 hatte Henri de France als Mitglied der französischen Delegation und CFT-Angestellter bei den sowjetischen Behörden für das SECAM-System geworben. Im Oktober 1959 wurde an den sowjetischen Minister für Telekommunikation, M. Krivocheiev, ein offizielles Schreiben adressiert, das diesem einen Besuch von CFT-Ingenieuren zwecks Demonstration des SECAM-Systems vorschlug ${ }^{209}$. Bereits im April des darauffolgenden Jahres machte sich eine CFT-Delegation auf den Weg nach Moskau, um dort vom 15. März bis 6. April 1960 mit sämtlichen fernsehtechnischen Experten der Sowjetunion zusammenzutreffen. Der Reisebericht des CFT-Ingenieurs François Dognin klang aber wenig enthusiastisch: "Découvertes successives des points faibles du système Henri de France par les techniciens russes. [...] Notre moral est très bas ce soir. Un Russe, dont je ne connais pas le nom, a trouvé très drôle (presque absurde) de se servir deux fois de la même information ${ }^{210}$.

Auch wenn die Vorführungen demnach nicht so positiv verlaufen waren wie erhofft, wurde mit diesem ersten Besuch der CFT-Techniker in Moskau

206 Siehe "La Compagnie Française de Télévision (CFT) de 1958 à 1968«, Privatunterlagen von Jacques Fagot (Paris), 6 maschinegeschriebene Seiten.

207 Jacques Fagot bezeichnet Weygand als »trop gentil«, was darauf hindeutet, daB Weygand als Generaldirektor wohl eher eine Fehlbesetzung war. Siehe Entretien avec Jacques Fagot, ingenieur Thomson, Paris, 25.05. 1984, in: Archives du CHTV/NA, Bry-sur-Mame.

${ }^{208} \mathrm{Zu}$ den Mitarbeitern Henri de Frances zählten am Anfang Pierre Cassagne, Roland Fessard und Bernard Dognin, die an der Optimierung des SECAM-Systems arbeiteten, sowie Roger Cahen und François Dognin, die an der Röhrenentwicklung arbeiteten.

209 In einer Mitteilung von M. Chaste von der Direction Générale Technique de la C.S.F. an Eduard Weygand (CFT) vom 23. Dezember 1959 heißt es: »Dans cette lettre dont nous joignons copie à la présente note, nous proposions une visite en URSS dans le but (exposé en termes diplomatiques) d'y défendre le système de la France«. In: Archives du CHTV/INA, Nachlaß Michel Dubail.

210 Reisebericht von François Dognin, "Déplacement de Moscou, 15 mars - 6 avril 1960« vom 21. April 1960, in: Archives du CHTV/INA, NachlaB Michel Dubail. 


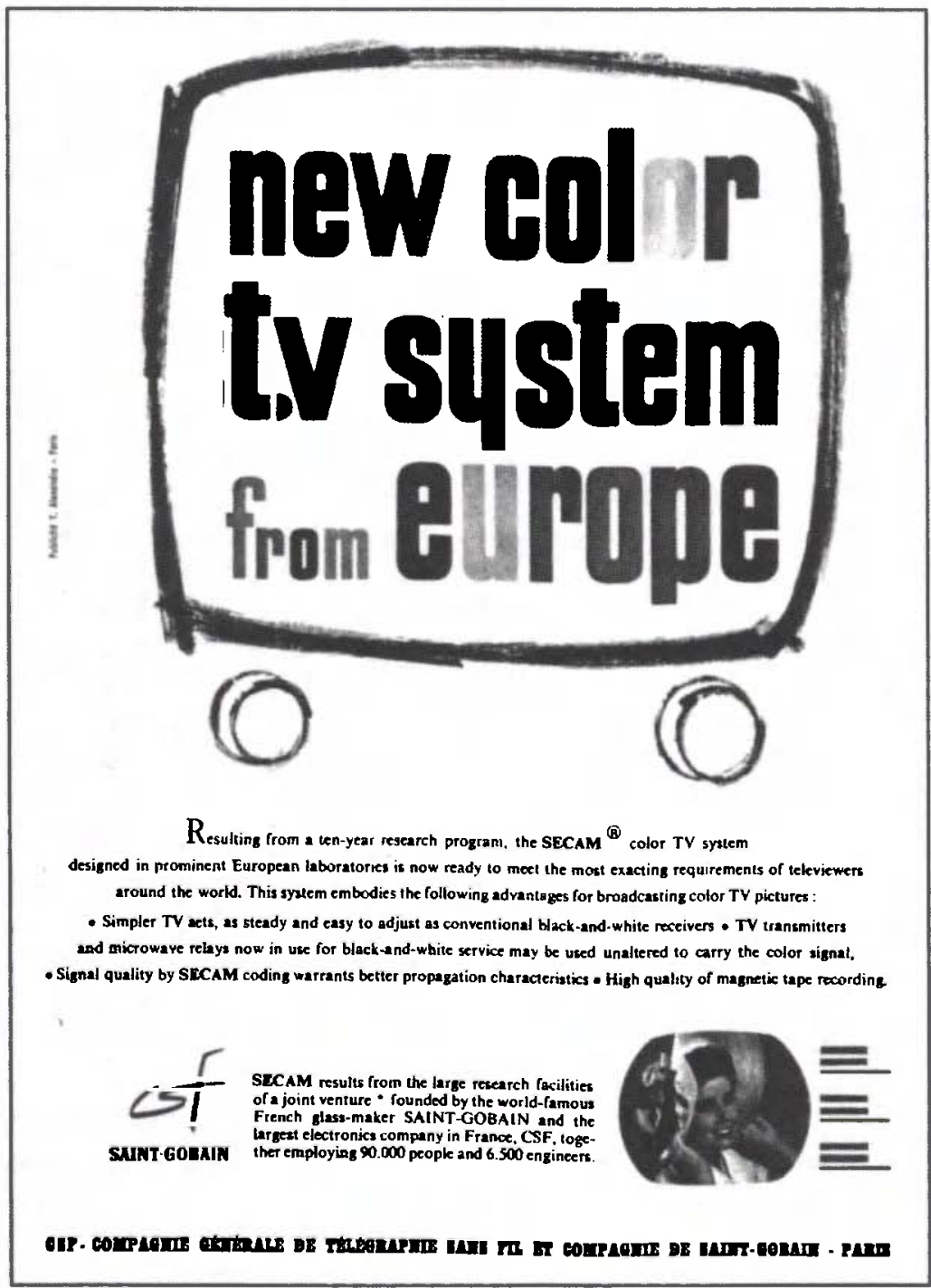

Abb. 14: "new colour tv system from Europe*. 1962 werben the world-famous French glass maker" Saint-Gobain und "the largest electronics company in France CSF in einer Anzeige des "Time Magazine" vom 28. Dezember für das SECAM-System. Gerichtet an eine amerikanische Leserschaft, wird SECAM als europäische Alternative zum NTSC präsentiert! Aus: Archives du CHTVINA, Nachlaß Michel Dubail.

der Grundstein für eine intensive Beziehüng zwišchen der CFT und entsprechenden sowjetischen Behörden gelegt. Bereits im September 1961 wurde den sowjetischen Fernsehspezialisten vom Telekommunikationsministerium eine komplette SECAM-Experimentieranlage für sechs Monate überlassen, 
welche die CFT auf der Moskauer Wirtschaftsmesse ausgestellt hatte ${ }^{211}$. Die eigentliche "propagation du SECAM «, die Werbetour für das SECAM-System, begann aber erst nach der Aufnahme des SECAM-Systems als zu untersuchende Systemvariante im Rahmen der EBU ad-hoc-Kommission Ende 1962. Um die verschiedenen Aktivitäten (F\&E, Werbung, Zusammenarbeit mit RTF und staatlichen Stellen) der CFT zu koordinieren, wurde ein »Comité de Direction « gegründet, das die Entscheidungen der Generaldirektion der CFT sowie der beiden Kapitalgeber CSF und Saint-Gobain unterstützen soll$\mathrm{te}^{212}$. Im Zuge der zunehmenden politischen Bedeutung der SECAM-Technologie wuchs die CFT-Mannschaft von anfänglich sechs Ingenieuren auf über hundert Personen im Jahre 1966 an. Entsprechend aufwendig wurde auch die Ausstattung, die aus mobilen Demonstrationsanlagen, Studios, Empfängerparks, Codier- und Decodieranlagen etc. bestand. Zudem muBten zahlreiche SECAM-Versuchsanlagen an entsprechend interessierte Stellen geliefert und mit dem nötigen Informationsmaterial versorgt werden ${ }^{213}$. Bevor jedoch näher auf diese internationalen Bemühungen der SECAM-Promotion eingegangen wird, die eng mit der Politisierung des SECAM-Systems verbunden waren, muB ein Blick auf das Verhältnis der CFT zur übrigen Rundfunkindustrie Frankreichs und deren Einstellung gegenüber dem SECAM-System geworfen werden.

Wie in der Bundesrepublik war auch die elektrotechnische Industrie in Frankreich in einem Zentralverband organisiert, der Fédération Nationale des Industries Électroniques (FNIE), heute Fédération des Industries Électriques, Electroniques et de Communications (FIEEC). Dieser Verband, der im Sinne des Beziehungsgeflechts von Barreau und Mouline ebenfalls als zentraler industrie- und wirtschaftspolitischer Akteur verstanden werden kann, war nicht nur Sprachrohr der französischen Elektroindustrie, sondern trug in Form von Studiengruppen oder Vertretungen bei internationalen Standardisierungsbehörden ebenfalls zu technischen Entwicklungen bei. So wurden beispielsweise Studiengruppen der FNIE zur Besichtigung der Farbfernsehaktivitäten in die USA oder nach Japan gesandt. Ähnlich wie in der Bundesrepublik wurden auch in Frankreich eigene Entwicklungsarbeiten im Bereich der Farbfernsehtechnik vor allem mit dem höheren Qualitätsanspruch der Europäer begründet:

211 Brief von Weygand an M. Fedorovitch, Direction Générale Technique du Ministère des Télécommunications, Moskau, 13. September 1961, in: Archives du CHTV/INA, NachlaB Michel Dubail.

212 Diesem Komitee gehörten zeitweilig die Herren Aubert, Polonsky, Peycher, Charles und Fagot an. Nach dem Einstieg der Groupe Floirat in das SECAM-Untemehmen im Jahre 1965 dann auch Sylvain Floirat selber sowie M. Lagardère.

${ }^{213}$ Bereits 1959 wurden die Techniker des Schweizer Post- und Telekommunikationsministeriums sowie das IRT in München mit Versuchseinrichtungen versorgt. Es folgten die Techniker der PTT in Italien und Moskau, sowie Telefunken und die BBC in London 1960. 
Nous devions en outre tenir compte du fait que les publics européens sont beaucoup plus sensibles à la notion de qualité et sont de ce fait très exigeants et difficiles à convaincre. Cet esprit critique que nous avons appris à mesurer par les réactions du public français est finalement constructif quand il s'oppose à des innovations qui ne se justifieraient pas par un avantage induscutable aisément perceptible ${ }^{214}$.

Um diesem selbst gesetzten Qualitätsanspruch gerecht zu werden, wurde bereits im September 1962 eine entsprechende Studienkommission eingesetzt, um die neuartigen Entwicklungen im Farbfernsehsektor detailliert zu untersuchen und zu bewerten. Leitlinien der Untersuchungen waren folgende vier Gesichtspunkte: 1. Die Funktionssicherheit des Systems; 2. Die Bildqualität im Empfänger; 3. Die Kompatibilität mit dem s/w-Bild (819-Zeilen); 4. Die Bedienungsfreundlichkeit für den Zuschauer ${ }^{215}$. Während der erste Punkt in Absprache mit den verantwortlichen Ingenieuren der FNIE im wesentlichen von den technischen Experten der RTF/ORTF untersucht wurde, wurden die anderen drei Punkte meist in enger Kooperation mit diesen realisiert. Ähnlich wie in der Bundesrepublik muBten die zuständigen Stellen des staatlichen Fernsehrundfunks entsprechende Studio- und Sendeanlagen bereitstellen, damit die Rundfunkindustrie die Testprogramme zur Empfängerentwicklung nutzen konnten. Ab 1962 wurden von einem neu eingerichteten Sender der RTF in Paris (Buttes Chaumont) sowie von dem ebenfalls farbtauglich gemachten Sender auf dem Eiffelturm wöchentlich 47 Stunden farbige Testprogramme ausgestrahlt.

Das Arbeitsprogramm der Studienkommission der FNIE wurde sehr eng an die Untersuchungen im Rahmen der EBU ad-hoc-Kommission gekoppelt, an der ebenfalls sechs französische Rundfunkfirmen beteiligt waren:

C'est ce même programme d'essais qui fût repris et adopté par la Commission des experts de la Fédération qui, après une longue et minutieuse étude et de nombreuses expérimentations en vraie grandeur fut en mesure de donner un avis solidement motivé aux organismes Directeurs de notre Fédération. Après une étude attentive de ce rapport, le Conseil de la Direction de la Fédération a pris la décision de donner préférence au système SECAM en raison notamment de son incontestable supériorité dans le domaine de la facilité d'utilisation qui constitue un élément fondamental dont dépend le développement rationnel et rapide du nouveau marché de la télévision en couleurs $^{216}$.

214 »'Industrie électronique française devant le problème de la télévision en couleurs«, in: Bulletin de la FNIE 27 (1965) S. 173.

215 Ibid.

216 Ibid. S. 174 f. Michel Dubail, ehemaliger Generaldirektor der CFT, gab im Interview zu erkennen, daB Philips Frankreich eine entscheidende Rolle im EntscheidungsprozeB der FNIE gespielt habe. Erst als Philips Frankreich seine Unterstützung für das SECAM-System zugesagt habe, seien auch die anderen Firmen auf den SECAM-Kurs eingeschwenkt. Laut Dubail wollte sich Philips Frankreich mit dieser Entscheidung mehr Autonomie gegenüber dem niederländischen Mutterhaus erkämpfen. 
Obschon somit bereits Ende des Jahres 1964 die Entscheidung der französischen Rundfunkindustrie zugunsten des SECAM-Systems gefallen war, beschloss die FNIE, weitere Versuche mit dem SECAM-Empfänger zu unternehmen, vor allem um praktische Erfahrung bei der industriellen Produktion $\mathrm{zu}$ gewinnen. $\mathrm{Zu}$ diesem Zweck wurde ein »100-Empfänger-Programm« beschlossen, an dem zehn führende Rundfunkunternehmen beteiligt waren "malgré la rivalité commerciale qui les opposait couramment ${ }^{217}$. Der wahre Grund für die Initiierung des $» 100$-Empfänger-Programms « war jedoch, daß den Franzosen auf diversen Sitzungen der EBU ad-hoc-Kommission immer wieder vorgehalten wurde, daß das SECAM-System zwar eine interessante technische Alternative darstelle, man aber über das Experimentierstadium bislang nicht hinaus gelangt sei, das heißt, daß man keinerlei praktische Erfahrungen im Bereich der industriellen Fertigung des komplizierten SECAM-Empfängers vorweisen könne. So berichtete der technische Berater des Informationsministers Alain Peyrefitte, Jean Cerez, diesem nach seiner Rückkehr von der CCIR-Tagung in London im November 1964, daß man den Franzosen vorgeworfen habe, daß sie einen schwierig zu realisierenden Empfänger hätten und keinerlei praktische Erfahrung im Bereich der Produktion. Daraufhin, so Cerez, habe die ORTF das SCART (Syndicat des Constructeurs d'Appareils Récepteurs de Télévision) gebeten, augenblicklich einige »dizaines de récepteurs « zu bauen, damit man diese praktische Erfahrung vorweisen könne ${ }^{218}$. Wenn diese Hürde genommen sei, so der Senator Edouard Bonnefous in einer Senatsdebatte, sei Frankreich bereit für die Verteidigung des SECAM-Systems auf der anstehenden CCIR-Konferenz in Wien 1965: »Cette expérience permettra de dissiper les incertitudes qui pouvaient encore subsister dans certains esprits et donnera à l'administration française, lors de la prochaine confrontation prévue pour avril 1965, les moyens de réfuter de façon pertinente les objections avancées à la rencontre du système français $\aleph^{219}$.

Das Problem der mangelnden Fertigungserfahrung spielte jedoch schon viel früher eine Rolle in der internen Diskussion des SECAM-Verfahrens. Bereits im Januar 1964 hatte Alain Peyrefitte dieses Problem in einem Brief an den Premierminister Georges Pompidou angeschnitten. In der dem Brief beigefügten »Note concernant la télévision en couleurs« heißt es:

217 Ibid. S. 175.

218 Note de Jean Cerez à Alain Peyrefitte, Paris, 13.11.1964, in: Archives du MAE, Affaires Économiques et Financières, Affaires Générales, Nr. $219 \mathrm{a}$.

219 Edouard Bonnefous (1907-1992) hatte von 1952 bis 1959 diverse Ministerämter inne und war ab 1959 französischer Senator. Seit 1958 war er Mitglied, ab 1968 Präsident der einflußreichen »Académie des sciences politiques et morales«. Zitat in: Archives nationales, Signatur F-41 bis/1910. 
Le procédé français n'est pas au stade de l'exploitation industrielle alors que le procédé américain a derrière lui une expérience déjà longue et bénéfice d'une organisation industrielle très solide. C'est là où notre défense est la plus faible. Beaucoup de nos interlocuteurs considèrent que le procédé SECAM est un bricolage très ingénieux, même supérieur en technique pure au procédé américain, mais qui n'a pas subi l'épreuve de l'exploitation à grande échelle. Il est bien vrai que la CSF, malgré l'aide très utile de la RTF, n'a qu'à peine dépassé le stade expérimental et dispose à l'heure actuelle de quelques récepteurs seulement de télévision couleur ${ }^{220}$.

Um diesem negativen Image zu begegnen, wurde, wie bereits erwähnt, das sogenannte »100-Empfänger-Programm« auf die Beine gestellt, das die Leistungsfähigkeit der französischen Rundfunkindustrie unter Beweis stellen sollte. Zusätzlich $\mathrm{zu}$ der gewonnenen Produktionserfahrung sollten diese 100 Empfangsgeräte aber auch eine propagandistische Funktion erfüllen, indem 72 dieser Empfänger sogenannten »observateurs« zur Verfügung gestellt wurden. Von diesen 72 Beobachtern sollten 40\% aus dem Kader der ORTF stammen, $40 \%$ aus dem Bereich der Privatindustrie. Die restlichen $20 \%$ der Empfänger wurden an »personnalités sans qualification technique particulière« verteilt. In die letzte Kategorie fielen unter anderem der französische Staatspräsident (2 Empfänger standen im Elysée-Palast) sowie der Premierminister, der Informationsminister und der Industrieminister, die jeweils mit einem Empfänger bedacht wurden ${ }^{221}$. Die Ergebnisse dieser Beobachtungen, die, wie es in dem Bericht der FNIE heißt, mit »äußerster Gewissenhaftigkeit und Unparteilichkeit« durchgeführt worden seien, hätten schließlich zur einmütigen Bevorzugung des SECAM-Systems geführt: »Les énormes risques commerciaux encourus, l'importance des investissements qu'éxigera la fabrication en grande série des téléviseurs couleur et l'engagement pour un très long terme qui résultera du choix du système ont obligé l'industrie française à n'être pas influencée par l'origine du procédé. Bien qu'elle ne peut se féliciter de son origine française, il ne pouvait s'agir d'une raison déterminante en faveur de son adoption $\aleph^{222}$.

Es bedarf kaum des Hinweises darauf, daß diese Worte schon der Ausdruck eines politisierten Diskurses sind, in dem der französischen Rundfunkindustrie - ähnlich wie im Falle der 819-Zeilendiskussion - die Rolle eines patriotischen Akteurs zugedacht wurde. Doch so einmütig, wie dieser Abschlußbericht der FNIE glauben machen möchte, war die Reaktion der französischen Rundfunkindustrie auf das SECAM-System keineswegs. Dies lag weniger an der technischen Bewertung des SECAM-Systems als an der Art

${ }^{220}$ Brief von Alain Peyrefitte an Georges Pompidou, Paris, 27 Januar 1964, Annexe »Note concernant la situation de la télévision en couleurs, 6 maschinegeschriebene Seiten, hier S. 2, in: Archives nationales, Signatur F-41/2310.

${ }^{221}$ Siehe Note de Jean Cerez à Alain Peyrefitte, Paris, 13.11.1964, in: Archives du MAE, Affaires Économiques et Financières,Affaires Générales, Nr. 219a.

222 "L'Industrie électronique française devant le problème de la télévision en couleurs«, in: Bulletin de la FNIE 27 (1965) S. 175. 
und Weise, in der die CFT versuchte, politische Unterstützung für die SECAM-Propagation zu erlangen und sich somit zur Schnittstelle privatwirtschaftlicher und industriepolitischer Interessen zu machen. In einer ausführlichen Note über die Frage des Farbfernsehens von Philippe Olivier, einem Technischer Berater im Kabinett von Alain Peyrefitte, vom 2. September 1965 heißt es diesbezüglich:

Lorsqu'il [le gouvemement, A.d.V.] prit la décision d'engager une action en faveur du SECAM, dont la CFT détient le brevet, le gouvernement français connaissait cet état de choses, mais il escomptait que le manque de moyens de la CFT-CSF la conduirait à associer à l'oeuvre de promotion industrielle du SECAM l'ensemble de l'industrie électronique française. Ce calcul devait se révéler faux, en raison de la position de la CFT-CSF désireuse avant tout d'agir seule, fut-ce en renonçant à conquérir des positions à l'extérieur. Pour leur part, les autres industriels de l'électronique, prenant acte de ce refus de coopérer de la CFT-CSF, n'étaient pas disposées à soutenir financièrement cette dernière, à laquelle en définitive profiterait surtout ce soutien. C'est donc en orde dispersé que l'industrie électronique française abordait et mène encore à ce jour la bataille du SECAM ${ }^{223}$.

Im Prinzip handelte es sich also um eine gegenseitige Schuldzuweisung: Während die Mehrzahl der Rundfunkunternehmen beklagte, nicht in das Kalkül und die Planungen der CFT-CSF eingebunden gewesen zu sein, beanstandete der Generaldirektor der CSF, Maurice Ponte, die lediglich "platonische" Unterstützung, welche die CSF von den anderen Firmen erhalten habe: »La ssolidarité des autres industriels de l'électronique à l'égard de la CFT-CSF est demeurée platonique et ils ont refusé de s'engager financièrement à ses côtés, n'hésitant pas à affirmer qu'ils n'avaient, en fin de compte, pas plus d'intérêt sur le plan matériel à l'adoption du SECAM qu'à cette du procédé américain ou du procédé allemand $\aleph^{224}$.

Diese Zitate geben deutlich die ambivalente Situation wieder, in der sich die Mehrheit der französischen Rundfunkunternehmen Ende 1964 befand: Zum einen war den meisten Firmen klar, daß sie im Falle der Wahl eines einheitlichen europäischen Systems dem Druck der bundesdeutschen und englischen Rundfunkindustrie kaum gewachsen waren, zum anderen existierte die Angst vor der erneuten Isolation (Stichwort 819 Zeilen), die auf lange Sicht jedwede Exportmöglichkeiten zunichte machen würde. Philippe Olivier brachte diese Sorge in seinem Bericht für den Informationsminister deutlich zum Ausdruck:

223 »Note a.s. de la Télévision en couleurs«, von Philippe Olivier, Paris, 2.09. 1965, 21 maschinegeschriebene Seiten, hier S. 6, in: Archives du M.A.E., Affaires Économiques et Financières, Affaires Générales, Nr. 220c.

224 Brief von Jean-Jacques de Bresson, Kabinettschef von Alain Peyrefitte, an Burin de Roziers, Secrétaire Général de la Présidence de la République, Paris, 8. 10.1965, in: Archives du MAE, Affaires Économiques et Financières, Affaires Générales, Nr. 220c. Bresson gibt hier die Meinung Ponte's wieder, mit dem er zuvor über diese Frage gesprochen hatte. 
La capacité de production de la R.F.A. en matière de récepteurs de télévision est supérieure aux besoins de l'Allemagne. Les prix de production en R.F.A. sont inférieurs de 25 à $30 \%$ aux prix de production des mêmes matériels en France. Dans ces conditions, le fait que la R.F.A. et la France auraient adopté le méme système aurait pour conséquence de mettre l'industrie française en concurrence directe, sans protection contingentaire ni douanière, avec l'industrie allemande, alors que pour le moment ou plusieures années encore l'industrie française n'est compétitive. Il en résulte chez nombre d'industriels français, consciemment ou non, un réflexe protectionniste ${ }^{225}$.

$\mathrm{Da}$ sich die französische Rundfunkindustrie letztlich dennoch für das SECAM-System entschieden hat, ist mehreren Faktoren zuzuschreiben. Während sich die Patentinhaber des SECAM-Systems (CFT bzw. CSF/Saint-Gobain) im Falle der Einführung von SECAM satte Lizenzeinnahmen erhofften, herrschte bei den meisten mittelständischen Betrieben Angst vor der mächtigen bundesdeutschen und englischen Konkurrenz. Diese Sorge war berechtigt, vor allem wegen der Bestimmungen der Römischen Verträge, die ab 1. Januar 1968 den Wegfall der Binnenzölle innerhalb der EWG und die Aufhebung der Gesetze zur mengenmäßigen Beschränkung der Einfuhr von Gütern aus EWG-Ländern vorsah.

Die Tatsache, daß der "réflexe protectionniste« im Falle der 819-Zeilennorm zu einer Isolation und einem verzögerten Wachstum der französischen Rundfunkindustrie im europäischen Vergleich geführt hatte, wurde in der politisierten Debatte nur von wenigen Personen in Erinnerung gerufen ${ }^{226}$. Mit ähnlichen Problemen sollte die französische Rundfunkindustrie auch nach der Einführung des Farbfernsehens im Jahre 1967 zu kämpfen haben, was jedoch vor allem mit der ungesättigten Lage des $\mathrm{s} / \mathrm{w}$-Marktes zu tun hatte. Hinzu kamen die hohen Preise für Farbfernsehempfänger, die mit 4000 bis 5000 Francs so viel wie ein Kleinwagen kosteten ${ }^{227}$ ! Die eigentlichen Verlierer dieser Situation waren also die französischen Fernsehzuschauer, die für die komplizierteren Mehrnormenempfänger deutlich tiefer in die Tasche greifen muBten als ihre deutschen Nachbarn.

225 "Note pour le Ministre« (Alain Peyrefitte), Paris, 26.02. 1965, 6 maschinegeschriebene Seiten, hier S. $4 \mathrm{f}$, in: Archives du MAE, Affaires Économiques et Financières, Affaires Générales, Nr. 219a.

226 Über diese kritischen Stimmen, die vor allem von Seiten der ORTF-Ingenieure sowie aus der Finanzabteilung des Außenministeriums geäußert wurden, wird später ausfihrlich berichtet werden.

227 „Zum zweiten muß gesagt werden, daß die Geräte für den Durchschnittsbürger praktisch unerschwinglich teuer sind. Fü den gleichen Preis kann man einen Kleinwagen kaufen, und damit ist diese Frage für den Durchschnittsfranzosen ubberhaupt keine Frage: Das Auto geht vor.« N.N., Farbfernsehen in Frankreich, in: Funk-Technik 23 (1968) 5 S. 154. 


\subsection{Zusammenfassender Vergleich}

Wenige Monate vor der CCIR-Konferenz im Frühjahr 1965 in Wien, auf der über ein einheitliches europäisches Farbfernsehsystem verhandelt werden sollte, hatten sich sowohl die deutsche als auch die französische Rundfunkindustrie hinter die jeweiligen Systemalternativen PAL und SECAM gestellt. Wie gesehen war dieser Entscheidungsprozeß in beiden Ländern von durchaus unterschiedlichen Motivationslagen geprägt. In der Bundesrepublik war die Entscheidung für das PAL-System das Resultat eines Verhandlungsprozesses zwischen den »drei Säulen« des Fernsehrundfunks: den Landesrundfunkanstalten, der Bundespost und der Rundfunkindustrie. Zentraler Akteur in diesem Netzwerk war der Telefunken-Ingenieur und PAL-Entwickler Walter Bruch, der alle entscheidenden Schnittstellen des Netzwerkes besetzte. Bruch gelang so die schrittweise Gewinnung seines Arbeitgebers, der deutschen Rundfunkindustrie sowie der technischen Experten der Bundespost und der Landesrundfunkanstalten für "sein « PAL-System. Nachdem technische Untersuchungen die Gleichwertigkeit des PAL-Systems mit dem amerikanischen NTSC-System gezeigt hatten, überließen Bundespost und Landesrundfunkanstalten die Entscheidung zugunsten einer dieser Systemvarianten der Rundfunkindustrie. Für die Rundfunkindustrie waren letztlich zwei Kriterien entscheidend: die Höhe der Lizenzgebühren sowie die Exportchancen. Vor allem das von dem Telefunken-Vorstandsvorsitzenden Dr. Felix Herriger ausgehandelte Abkommen mit Fritz Philips in Eindhoven über die Kooperation im Bereich der Farbfernsehröhre kann als entscheidender Schritt zur Gewinnung des ZVEI für PAL interpretiert werden.

War die Entscheidung der deutschen Rundfunkindustrie für das PAL-System somit aus rein wirtschaftsstrategischen Überlegungen gefält worden, standen auf französischer Seite industriepolitische Interessen im Vordergrund. Auch wenn die enge Verzahnung politischer und privatwirtschaftlicher Interessen im Fall der SECAM-Promotion erst im folgenden Kapitel detailliert rekonstruiert wird, ist es wichtig darauf hinzuweisen, daß das SECAM-System vom Beginn der strategischen CFT-Wiederbelebung bis zur offiziellen Rückendeckung durch die FNIE in das industriepolitische Klima der de Gaulleschen "politique de la grandeur« eingebunden war. Das SECAM-System wurde sukzessive zum "champion national " aufgebaut und kann in diesem Sinne als ein Ergebnis der »modernisation à la française« gedeutet werden.

In beiden Entscheidungswegen sind typische Muster der unterschiedlichen Modemisierungskonzepte beider Länder nach 1945 erkennbar. Während die bundesdeutsche Rundfunkindustrie lange Zeit das amerikanische NTSC-System bevorzugte, sah man in Frankreich im SECAM-System sehr früh eine Chance, sich von der amerikanischen Marktherrschaft zu emanzipieren. 


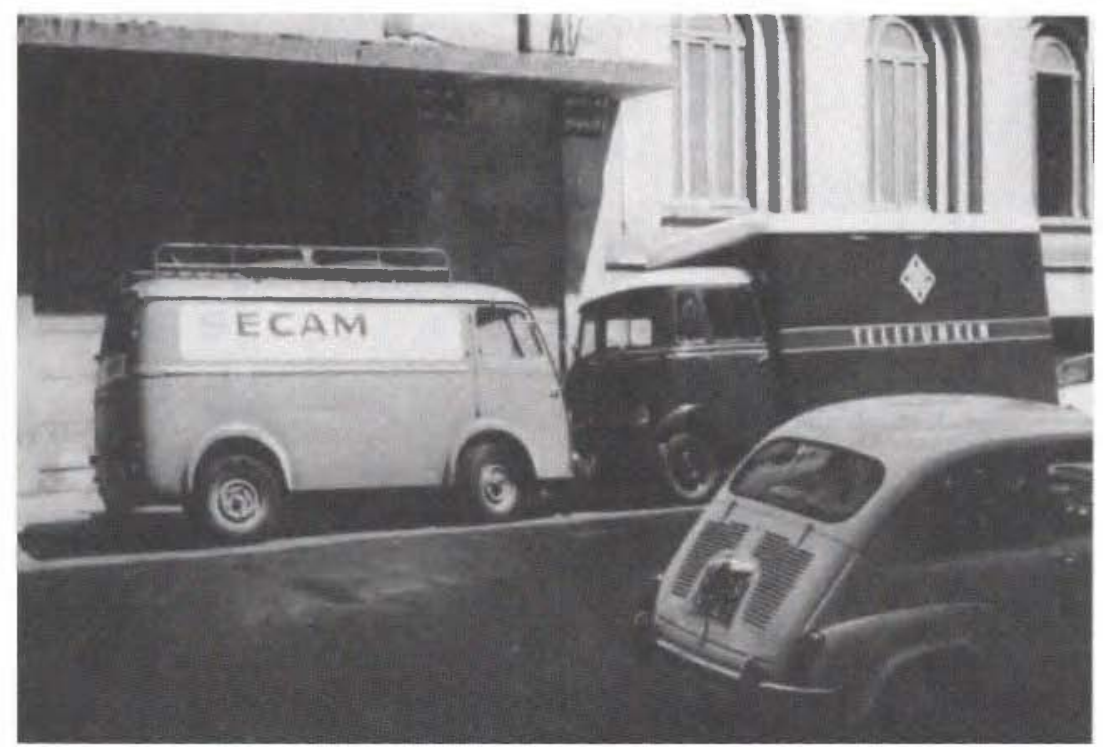

Abb. 15: Symbolhafte Konfrontation: Kleintransporter der CFT, und von Telefunken vor dem Studio der RAI in Rom 1963, aus: Archiv des Deutschen Museums München, Nachlaß Walter Bruch, Signatur NL 101, Nr. 123.

Auch wenn sich die französische Rundfunkindustrie vor einer erneuten Isolation fürchtete, überwogen in der Entscheidungsfindung letztlich industriepolitische Argumente. Vor dem Erfahrungshintergrund staatlich regulierter Wirtschaftslenkung und in Erwartung entsprechender protektionistischer Schutzmaßnahmen versammelte sich die französische Rundfunkindustrie trotz Meinungsverschiedenheiten mit der CFT hinter SECAM.

Mit dem Selbstvertrauen wirtschaftlicher Potenz auf deutscher und dem Vertrauen auf politische Einflußnahme auf französischer Seite traten so beide Seiten als wirtschaftliche Akteure in die Endphase der Systemauseinandersetzung ein, die im folgenden Kapitel geschildert wird. 
